\title{
Physical Properties of Snow
}

\author{
J.W. POMEROY AND E. BRUN
}

\section{Introduction: Snow Physics and Ecology}

As demonstrated in the previous chapter, snow interacts strongly with the global climate system, both influencing and forming as a result of this system. The following chapters discuss the interaction of snow with the chemical and biological systems. This chapter discusses the physical properties of snow as the habitat and regulator of the snow ecosystem. In this sense, the physical snow cover may be perceived not only as the medium but also as the mediator of the snow ecosystem that transmits and modifies interactions between microorganisms, plants, animals, nutrients, atmosphere, and soil. The role of snow as a habitat for life is discussed by Hoham and Duval (Chapter 4) and Aitchison (Chapter 5). Snow cover mediates the snow ecosystem because it functions as an:

1. Energy bank: snow stores and releases energy. It stores latent heat of fusion and sublimation and crystal bonding forces (Langham, 1981; Gubler, 1985). The bonding forces are applied by atmospheric shear stress, diffusion along, vapour pressure gradients, drifting snow impact, and the impact of animals' walking over the snow (Schmidt, 1980; Pruitt, 1990; Kotlyakov, 1961; Sommerfeld and LaChapelle, 1970). The intake and release of energy throughout the year makes snow a variable habitat.

2. Radiation shield: cold snow reflects most shortwave radiation and absorbs and reemits most long-wave radiation (Male, 1980). Its reflectance of shortwave radiation is a critical characteristic of the global climate system. As snowmelt progresses, the snow cover reflects less shortwave radiation because of a change in its physical properties (O'Neill and Gray, 1973). This reflectance can be additionally reduced about 50 percent by in situ life forms such as populations of snow algae (Kohshima et al., 1994).

3. Insulator: as a porous medium with a large air content, snow has a high insulation capacity and plays an important role protecting microorganisms, 
plants, and animals from wind and severe winter temperatures (Palm and Tveitereid, 1979). Its insulation can result in strong temperature gradients that fundamentally restructure the snow composition and provide opportunities and constraints for organisms that live in the snow cover (Colbeck, 1983).

4. Reservoir: snow is a reservoir of water that provides habitat and food sources for various life stages of microbes, invertebrates, and small mammals. The physical properties of snow - especially radiation penetration, density, gas content, temperature, wetness, and porosity - control intranivean biological activity and in turn may be influenced by the behaviour of supranivean organisms.

5. Transport medium: snow moves as a particulate flux as it is relocated by the wind in open environments or intercepted by vegetation in forests (Budd, Dingle, and Radock, 1966; Schmidt and Gluns, 1991). This flux is influenced to a great degree by macrophyte vegetation. Snow is transformed to a vapour because of sublimation, resulting in transport to colder surfaces or to the atmosphere (Schmidt, 1991; Santeford, 1979). During melt, snow moves as meltwater in preferential pathways within the snowpack to the soil or directly to streams and lakes (Marsh and Woo, 1984a).

\subsubsection{Unique Physical Properties of Snow}

Snow covers are the milieu or habitat of unique ecosystems partly because of the distinctive physical properties of snow compared with other environments on the Earth's surface. These properties are intrinsic to the snow ecosystem, and all organisms living in the snow ecosystem must contend with or take advantage of them in order to survive and prosper. The unique physical properties of snow are as follows:

1. At $0^{\circ} \mathrm{C}$ water may exist as a solid, liquid, or vapour on the Earth's surface; below this temperature water exists as primarily as ice (snow) and vapour supplemented by thin liquid-like layers on the edge of snow crystals. Above $0^{\circ} \mathrm{C}$, water exists as liquid or vapour. Because of diurnal and annual temperature variations, most of the Earth's snow is seasonal in that it melts (to liquid) or sublimates (to vapour) on an annual basis and interacts with vapour and liquid-like phases of water at temperatures below zero. The liquid water content of a snowpack declines rapidly as the snow temperature drops below $0^{\circ} \mathrm{C}$. However, other factors are also important, such as the 
rate of melt within the snow cover, rate of rainfall to the snow-covered surface, liquid retention capacity of snow, and rate of drainage of water from the pack. The combination of these factors can cause rapid variations in the liquid water content of snowpacks.

2. The latent heat of vaporisation is extremely large, approximately $2.83 \mathrm{MJ}$ $\mathrm{kg}^{-1}$ of snow. The energy required to sublimate $1 \mathrm{~kg}$ of snow therefore is equivalent to that required to raise the temperature of $10 \mathrm{~kg}$ of liquid water $67^{\circ} \mathrm{C}$. Vaporisation is reversible, as this energy is released to the environment upon recrystallisation of vapour to ice.

3. The latent heat of fusion is large, approximately $333 \mathrm{~kJ} \mathrm{~kg}^{-1}$ of snow. The energy required to melt $1 \mathrm{~kg}$ of snow (already at $0^{\circ} \mathrm{C}$ ) therefore is equivalent to that required to raise the temperature of $1 \mathrm{~kg}$ of water $79^{\circ} \mathrm{C}$. Latent heat is released to the environment during freezing, when liquid water crystallises.

4. The thermal conductivity of a snow cover is low compared with soil surfaces and varies with the density and liquid water content of the snow cover. A typical thermal conductivity for dry snow with a density of $100 \mathrm{~kg} \mathrm{~m}^{-3}$ is $0.045 \mathrm{~W} \mathrm{~m}^{-1} \mathrm{~K}^{-1}$, over six times less than that for soil. This means that snow can insulate over six times more effectively than soil for equivalent depths. The total insulation provided by snow strongly depends on its depth.

5. The proportion of shortwave (solar) radiation incident upon a snow cover and then reflected (albedo) is high compared with soil and vegetation and varies over the winter. A fresh, continuous snow cover has an albedo of $0.8-0.9$; as a snow cover ages and becomes patchy and wet the snow albedo can drop to 0.5 with areal albedo dropping even further as vegetation and soil become partly exposed. Bare soil and vegetation therefore will absorb as much as eight times the shortwave radiation as a fresh, continuous snow cover. The shortwave radiation that is not reflected by a snow cover is absorbed largely in the top $30 \mathrm{~cm}$ of the snowpack. The degree to which this radiation penetrates varies with wavelength - in general, the shorter wavelengths penetrate further than longer wavelengths.

6. Snow cover behaves almost as a blackbody; hence, the long-wave (thermal infrared) radiation incident on a snow cover is absorbed and reradiated as thermal radiation. The wavelength of emission depends on the surface temperature of the snow cover. 
7. Snow covers are aerodynamically smooth compared with most land surfaces. Snow surfaces have aerodynamic roughness heights $\left(z_{0}\right)$ of 0.01 to $0.7 \mathrm{~mm}$, except during drifting snow when $z_{0}$ increases substantially. Land surfaces typically have aerodynamic roughness heights several orders of magnitude greater than this. The result is that, for a constant geostrophic wind speed, the wind speed is usually greater over snow cover than over vegetated surfaces, and turbulent transfer of sensible and latent heat between the atmosphere and the surface is smaller for a snow surface than for adjacent vegetated surfaces.

\section{$2.2 \quad$ Accumulation}

Snow accumulation is the first part of any snow ecology study, as the snow cover is the abiotic core of any snow ecosystem. Accumulation is traced from snow formation in the atmosphere and precipitation as snowfall, to wind transport, interception, and deposition and from large scales to small scales with reference to the important role of overwinter sublimation in reducing the final accumulation of snow in many snow environments.

\subsubsection{Snowfall}

An understanding of snowfall formation helps the snow ecologist to better understand the structure of snow crystals and snow covers and to interpret the spatial distribution of the snow environment. Snowfall formation is also important to snow chemistry, as the incorporation of chemical species in the forming snow crystals leads to wet deposition of chemical species (see Tranter and Jones, Chapter 3). Snow crystals derive from clouds, which form when the atmosphere is supersaturated in that the water vapour pressure exceeds the saturation level. Snow forms in clouds when the temperature is less than $0^{\circ} \mathrm{C}$ and supercooled water and suitable aerosols (cloud condensation nuclei; $\mathrm{CCN}$ ) are present. Growth of ice crystals from vapour results in snow crystals, and growth from collision of supercooled water droplets produces hail and graupel particles. Ice crystals form around $\mathrm{CCN}$ and rapidly grow through aggregation of small ice crystals and riming from water droplets into the familiar snowflake form. The most effective CCN are large aerosol particles with high water solubility. As marine air masses contain higher concentrations of large CCN than do continental air masses, precipitation is more likely from marine air masses with other factors constant (Wallace and Hobbs, 1977). For snowfall to occur there must be sufficient 
depth of cloud to permit the growth of snow crystals and sufficient moisture and aerosol nuclei to replace those removed from the cloud in falling snowflakes (Schemenauer, Berry, and Maxwell, 1981).

Snowfall in meteorological records is the depth of fresh snow that falls to the ground during a given period (see Groisman and Davies, Chapter 1). In many countries this is measured with a snowfall gauge, which is an open-top cylinder that is exposed to snowfall with resulting accumulations measured periodically and expressed as millimetres of snow water equivalent (SWE) or the equivalent depth of water on the ground if all fresh snowfall melted. Snowfall gauges should be shielded from wind exposure to reduce undercatch due to wind, but even better shields such as the Nipher or Tretyakov shields are subject to undercatch of about 25 percent at wind speeds of $7 \mathrm{~m} \mathrm{~s}^{-1}$. Pomeroy and Goodison (1997) report upward revision of published annual snowfall quantities of 31 percent in the Canadian Prairies and from 64 to 161 percent in the Canadian Arctic when snowfall records are corrected for gauge undercatch and other losses. Snowfall in some countries is expressed as a depth (centimetres) of new snow on the ground, assuming a density of $100 \mathrm{~kg} \mathrm{~m}^{-3}$, or as a depth of equivalent water on the ground in millimetres as SWE. If these measurements are reported from areas with open exposure to strong winds (farmland, prairies, tundra) it is almost impossible to relate them to the original snowfall quantity because of redistribution by wind. Even the density of fresh snow $\left(\rho_{\mathrm{s}}, \mathrm{kg} \mathrm{m}^{-3}\right)$ that is deposited without strong wind speeds varies considerably from the $100 \mathrm{~kg} \mathrm{~m}^{-3}$ assumption; for instance, Goodison, Ferguson, and McKay (1981) found that fresh snow density in Canada varied from 70 to $165 \mathrm{~kg} \mathrm{~m}^{-3}$. The variation of fresh, dry snow density, $\rho_{\mathrm{s}}$, with air temperature $\left(T_{\mathrm{a}},{ }^{\circ} \mathrm{C}\right)$ can be estimated with an equation developed by Hedstrom and Pomeroy (1998) from measurements reported by the U.S. Army Corps of Engineers (1956) in the Central Sierra Mountains of California and by Schmidt and Gluns (1991) in British Columbia and Colorado, where

$$
\rho_{\mathrm{s}}=67.9+51.25 e^{\frac{T_{\mathrm{a}}}{2.59}}
$$

The relationship suggests fresh snow densities of $143 \mathrm{~kg} \mathrm{~m}^{-3}$ at air temperatures of $1^{\circ} \mathrm{C}$ declining to $68 \mathrm{~kg} \mathrm{~m}^{-3}$ for temperatures below about $-10^{\circ} \mathrm{C}$.

\subsubsection{Distribution of Snowfall and Snow Cover}

The distribution of snowfall may be distinguished into two scales, macroand mesoscale, with local-scale effects more strongly associated with redistribution after snowfall. Macroscale snowfall distribution includes distances of 100 to $1,000 \mathrm{~km}$ and varies with latitude, physiographic province, and proximity to large bodies of water. 
At this scale, dynamic meteorological effects such as flow deviations due to the Coriolis effect, standing waves in the atmosphere, flow around mountain ranges, latitudinal temperature changes, and regional moisture sources such as oceans are important. Mesoscale snowfall distribution includes distances of 1 to $100 \mathrm{~km}$, over which changes in orographic cooling or warming, deviation of flow due to sharp topographic change, or convective precipitation in response to addition of heat and water vapour from lakes occur. Groisman and Davies (Chapter 1) discuss snow climatology and the large-scale factors that influence snowfall and distributions of snow cover on a global scale.

Figure 2.1 provides an example of the mesoscale distribution of snowfall in the Great Lakes region of North America (Norton, 1991). Most of the Great Lakes remain open throughout much of the winter, providing a water vapour source to the atmosphere. As topographic influences alone are small in this area, the major influences on snowfall are the dominant paths of winter storms over the Great Lakes and the decrease in temperature with latitude and from water to land. Intensive local convection occurs over relatively warm lake water, producing cloud and snowfall, which move inland with the prevailing wind. As the air mass rises upon reaching the lakeshore, it cools, saturates, and precipitates, producing large amounts of snowfall. These influences cause an increase in annual snowfall from $100 \mathrm{~cm}$ deep in southwestern Ontario, where relatively few storms arrive from the Great Lakes, to $320 \mathrm{~cm}$ just east of Lake Huron, where a northwesterly flow over the lake dominates after passage of a cold front. Intensive areas of snow accumulation also occur in the fabled snowbelt southeast of Lake Erie and Lake Ontario, where heavy snowfalls occur from Cleveland to Buffalo.

Where vegetation and micro-relief do not vary with elevation, the depth of seasonal snow cover usually increases with elevation because of the increasing number of snowfall events and the decrease in melt as elevation increases. Thus, at a specific location in a mountainous region, a strong linear association is often found between seasonal SWE and elevation within a selected elevation band (U.S. Army Corps of Engineers, 1956). As demonstrated by Meiman (1970), however, even along specific transects the rate of increase in SWE with elevation may vary widely from year to year. In northern latitudes, relatively small differences in evaporation and melt over an elevation transect suppress the observed increase in snow depth with elevation. In western Canadian mountains, the influence of elevation on snow accumulation is most apparent at elevations above $600 \mathrm{~m}$. The increase in accumulation with elevation is more dramatic where wind flows ascend mountains rather than where a descending flow occurs, as shown in Figure 2.2 for the lee side of the Monashee Mountains and the windward side of the Selkirk Mountains of British Columbia (Auld, 1995). 


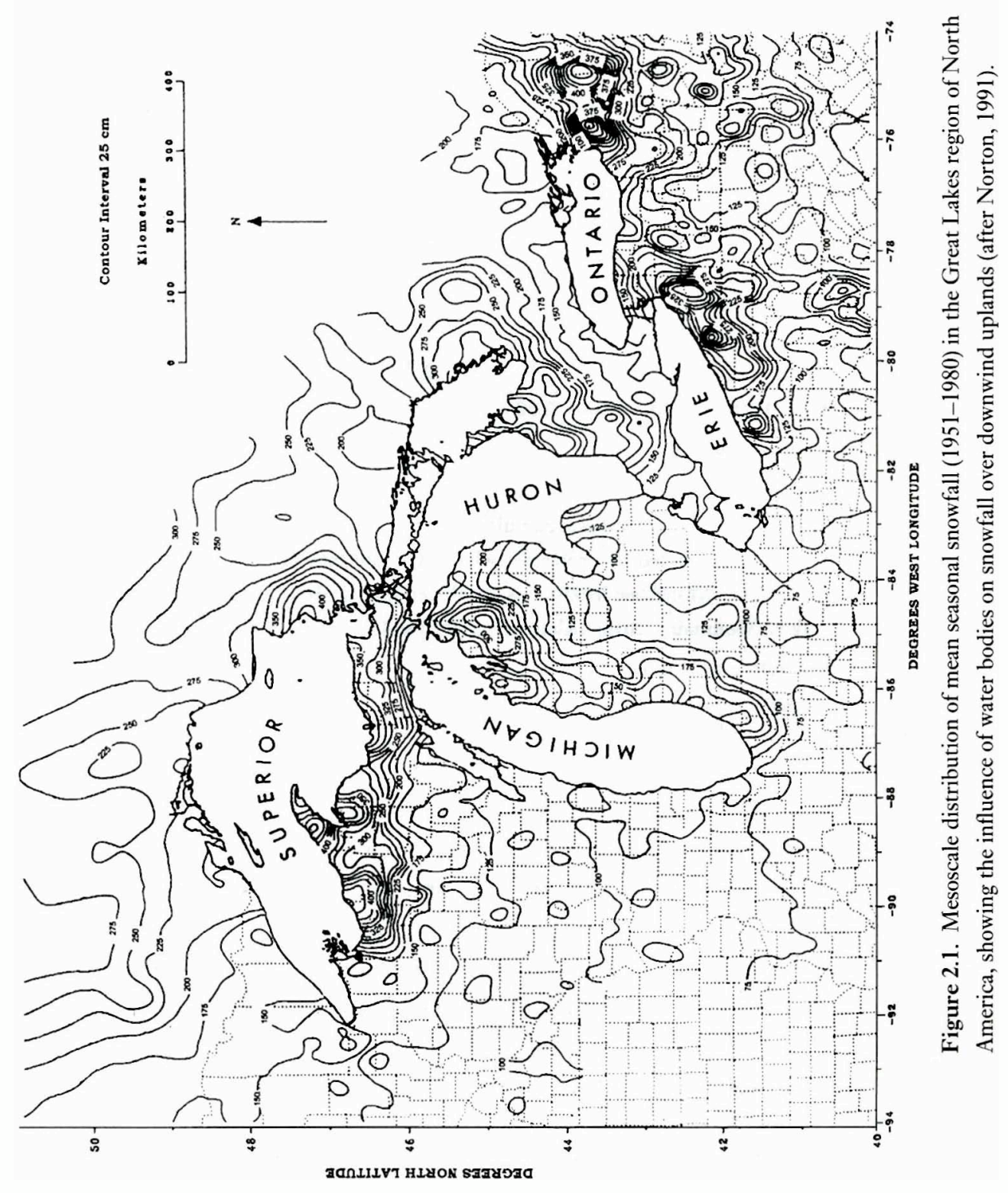




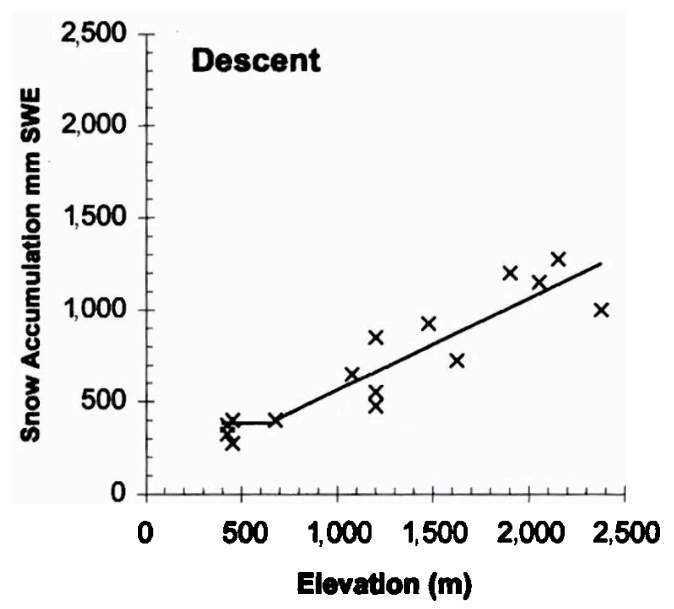

(a)

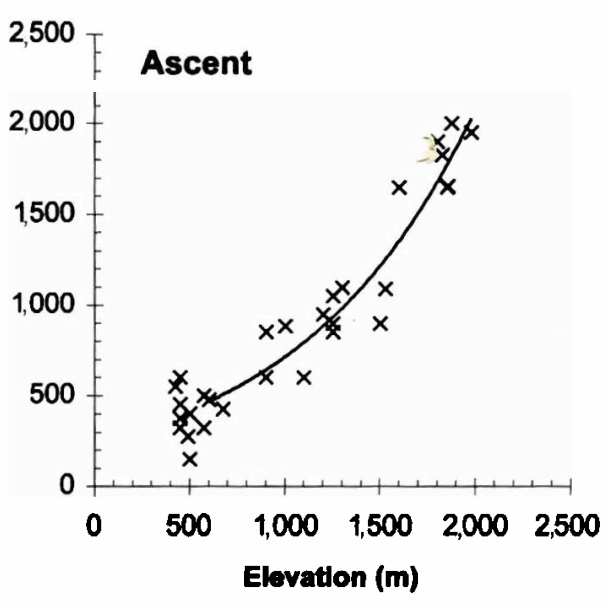

(b)

Figure 2.2. Variation in snow accumulation with elevation as mountain ranges are ascended and descended by air masses, which generate snowfall. (a) Descending air mass is shown for the Monashee Mountains. (b) Ascending air mass is shown on the right for the Selkirk Mountains, British Columbia (after Auld, 1995).

Elevation alone is not a causative factor in snow cover distribution; a host of other variables such as slope, aspect, vegetation, wind, temperature, and weather systems must be considered to interpret distribution patterns accurately. Orographic precipitation can be more related to terrain slope and wind flow than to elevation in mountain environments with complex topography. Rhea and Grant (1974) studied the effects of large-scale vertical air mass movement, convective activity, and orographic cooling on Rocky Mountain snowfall. From an analysis of Colorado winter precipitation they found that the long-term average snowfall at a point was strongly correlated with the topographic slope located $20 \mathrm{~km}$ upwind. They also found that long-term average precipitation is not well correlated with station elevation except for points along the same ridge.

\subsubsection{Wind Redistribution}

The effects of wind on the evolution of a snow cover are most evident in open environments. Wind redistribution of snow involves erosion of snow cover by the shear force of the wind, transport of blowing snow from exposed sites with low aerodynamic roughness, sublimation of blowing snow in transit, and deposition of snow to sites with higher aerodynamic roughness or less exposure to wind. Dyunin et al. (1991) noted that wind redistribution of snow is the primary process of desertification in steppe 
environments, and they associate the phenomenon of "northern desertification" with suppression of vegetation in the Russian steppes and forests and the resulting increase in frequency of blowing snow. Dyunin recalls that the Soviet administration attempted to manage snow ecology in the Russian steppes through "Stalin's Nature Transforma" tion Plan," which involved increasing vegetation on the steppes to improve regional water supplies in the 1930s. Walker, Billings, and de Molenaar (Chapter 6) discuss the implications of snow redistribution on vegetation and soils of alpine ecosystems. Estimates of maximum snow cover erosion due to blowing snow are similar in continental steppe or prairie environments; Komarov (1957) estimates that up to 70 percent of annual snowfall is eroded by blowing snow from open terrain in Siberia. In North America the estimate for highland plains in Wyoming is up to 75 percent (Tabler and Schmidt, 1986) and for fallow fields in the southern Canadian prairies it is up to 77 percent (Pomeroy and Gray, 1995). Tabler et al. (1990a) found that about $86 \mathrm{Mg}$ of snow per metre width was transported by wind on the arctic coast of Alaska. Estimates of sublimation increase with downwind fetch but can be up to five times larger than the amount of snow transported off a fetch for long fetches. Tabler (1975) found that 25 percent of eroded snow sublimated in transport over fetches of $1 \mathrm{~km}$, increasing to 75 percent for a $6-\mathrm{km}$ fetch. Snow accumulation in wind-swept environments in the absence of concurrent melt therefore cannot be determined directly from snowfall but from the following mass balance:

$$
Q_{\text {surface }}=Q_{\text {snowfall }}-\frac{d Q_{\mathrm{T}}}{d x}(x)-Q_{\mathrm{E}}
$$

where $Q_{\text {surface }}$ is snow accumulation $\left(\mathrm{kg} \mathrm{m}^{-2} \mathrm{~s}^{-1}=\mathrm{mm}\right.$ of SWE $\left.\mathrm{s}^{-1}\right), Q_{\text {snowfall }}$ is the snowfall rate $\left(\mathrm{kg} \mathrm{m}^{-2} \mathrm{~s}^{-1}=\mathrm{mm}\right.$ of $\left.S W E \mathrm{~s}^{-1}\right), Q_{\mathrm{T}}$ is the blowing snow horizontal transport flux $\left(\mathrm{kg} \mathrm{m}^{-1} \mathrm{~s}^{-1}\right), x$ is some distance along a fetch $(\mathrm{m})$, and $Q_{\mathrm{E}}$ is the sublimation flux $\left(\mathrm{kg} \mathrm{m}^{-2} \mathrm{~s}^{-1}\right)$. Erosion of snow cover is caused by the downwind increases in transport rate and the sublimation flux. Deposition of snow cover is caused by snowfall and downwind decreases in transport rate. Pomeroy, Marsh, and Gray (1997a) found that, in the Low Arctic of northwestern Canada, snow accumulation varied from 54 to 419 percent of snowfall, depending on vegetation and exposure. Similar degrees of variation in snow accumulation are found in prairie environments (Gray and others, 1979).

Blowing snow transport involves three modes of movement:

1. Creep: the rolling movement of those particles that are too heavy to be lifted by the wind. 


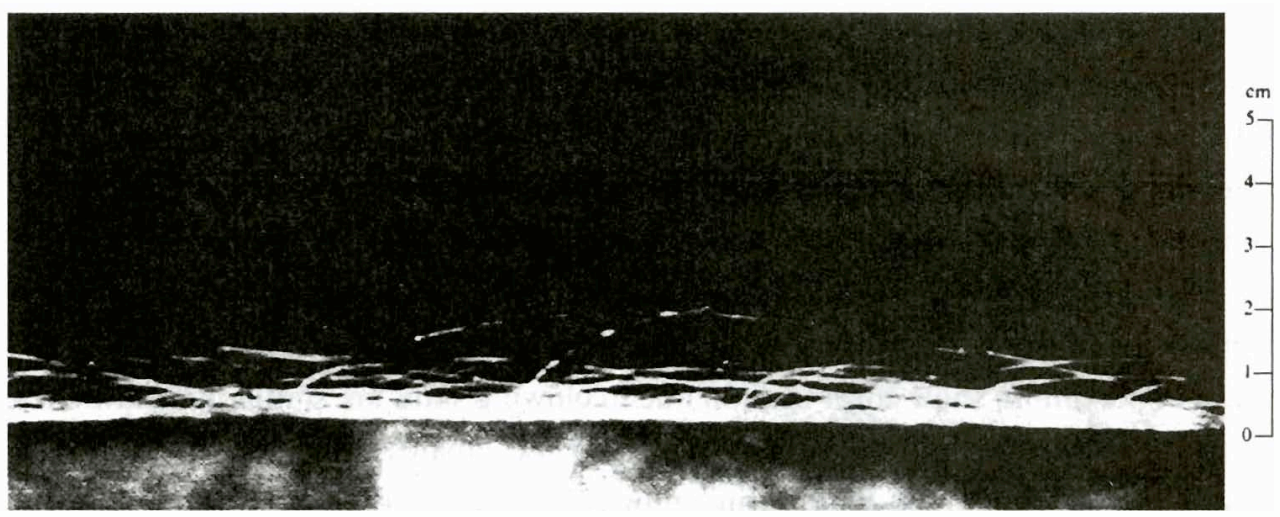

Figure 2.3. Photograph of trajectories of saltating snow particles, with flow direction from left to right (Kobayashi, 1972).

2. Saltation: the movement of snow particles by a "skipping" or "jumping" action along the snow surface.

3. Turbulent diffusion (suspension): the movement of snow particles in suspended flow at a mean horizontal velocity close to that of the moving air.

In the first few centimetres above the snow surface, particles move primarily in saltation (Figure 2.3). Saltation is the source of all other snow particle movement and is itself derived from eroded snow. Erosion of snow particles occurs when the shear stress exerted on the snow surface by the wind exceeds the sum of snow surface strength and any shear force exerted on vegetation and rocks. The partitioning of atmospheric shear stress by moving snow, surface snow, and vegetation is critical to understanding the control exerted on blowing snow by vegetation and wind exposure. The shear stress itself is approximately proportional to the square of the wind speed; the proportionality is controlled by the aerodynamic surface roughness.

The atmospheric shear stress directly applied to the snow surface does not contribute to supporting the weight of the saltating snow, but it breaks snow crystal bonds and overcomes cohesive forces due to wetness in the snow cover. By breaking bonds and overcoming cohesion, this stress makes wind erosion of snow possible. The shear stress is related to the threshold wind speed, which is the wind speed at the termination or initiation of snow transport. Higher threshold wind speeds are associated with stronger particle bonds and cohesion. Kotlyakov (1961) shows a correlation between threshold wind speed and surface snow hardness in Antarctica. Kind (1981) reports data from several authors who note snow surface hardness of $100 \mathrm{~N} \mathrm{~m}^{-2}$ for a threshold wind speed of $4.3 \mathrm{~m} \mathrm{~s}^{-1}$ rising to $100 \mathrm{kN} \mathrm{m}^{-2}$ for a threshold wind speed of $9 \mathrm{~m} \mathrm{~s}^{-1}$ and 
$250 \mathrm{kN} \mathrm{m}^{-2}$ for $18 \mathrm{~m} \mathrm{~s}^{-1}$. By describing the resistance of the snow surface to shattering, the threshold wind speed defines the relationship between saltation transport rate and wind speed (Pomeroy and Gray, 1990). Li and Pomeroy (1997) found that for northern prairie environments wet or icy snow has a higher threshold wind speed $\left(9.9 \mathrm{~m} \mathrm{~s}^{-1}\right.$ at 10 -m height) than does dry snow $\left(7.5 \mathrm{~m} \mathrm{~s}^{-1}\right.$ for fresh dry snow, $8.0 \mathrm{~m} \mathrm{~s}^{-1}$ for aged dry snow). Threshold wind speeds of dry snow are lowest at temperatures near $-25^{\circ} \mathrm{C}$ $\left(7 \mathrm{~m} \mathrm{~s}^{-1}\right)$, increase slightly at colder temperatures, and increase more dramatically as the temperature approaches $0^{\circ} \mathrm{C}\left(9.4 \mathrm{~m} \mathrm{~s}^{-1}\right)$.

Pomeroy and Gray (1990) have modeled saltation transport as a function of the threshold wind speed, exposure of vegetation, and wind speed. The implications of their model are that although saltation transport starts at lower wind speeds over fresh, loose snow, it is relatively inefficient over these snow surfaces. At high wind speeds, greater transport rates may be achieved over the high threshold windhardened snow. Exposed vegetation rapidly diminishes the wind energy available to transport snow; as a result, little or no snow erosion can occur from within stands of dense vegetation until the snow depth is within a few centimetres of the vegetation height.

Suspended snow is supported by turbulent diffusion and carried along by moving air at a velocity approximately equal to that of the mean horizontal wind. The source of all suspended snow (in the absence of concurrent snowfall) is saltating snow, so suspended transport can proceed only when saltation transport is occurring. Instead of bouncing along the snow surface, suspended snow is lifted from the top of the saltation layer by turbulent eddies in the atmosphere. Suspended snow exists in a layer from a few centimetres above the snow surface to hundreds of metres above the ground; its maximum height is determined by the duration of the blowing snow storm, intensity of turbulence, and upwind distance of open, snow-covered terrain. As shown in Figure 2.4, the concentration of suspended snow above continuous snow covers reaches a maximum just above the saltation layer and decreases with height at a rate that depends on the wind speed. The peak mass flux of suspended blowing snow may be responsible for abrasion of stems from exposed plants (Bégin and Boivin, Chapter 7) and occurs $10-25 \mathrm{~cm}$ above the snow surface, being higher with stronger wind speeds. Pomeroy and Male (1992) show that 77 percent and 40 percent of this total transport would occur below a height of $1 \mathrm{~m}$ at $10-\mathrm{m}$ wind speeds of $10 \mathrm{~m} \mathrm{~s}^{-1}$ and $30 \mathrm{~m} \mathrm{~s}^{-1}$, respectively. Although mass concentration of suspended snow is usually smaller than that of saltating snow, the total mass flux of snow moving in suspension may be large because of the great vertical thickness of the layer and higher wind speeds away from the snow surface. 


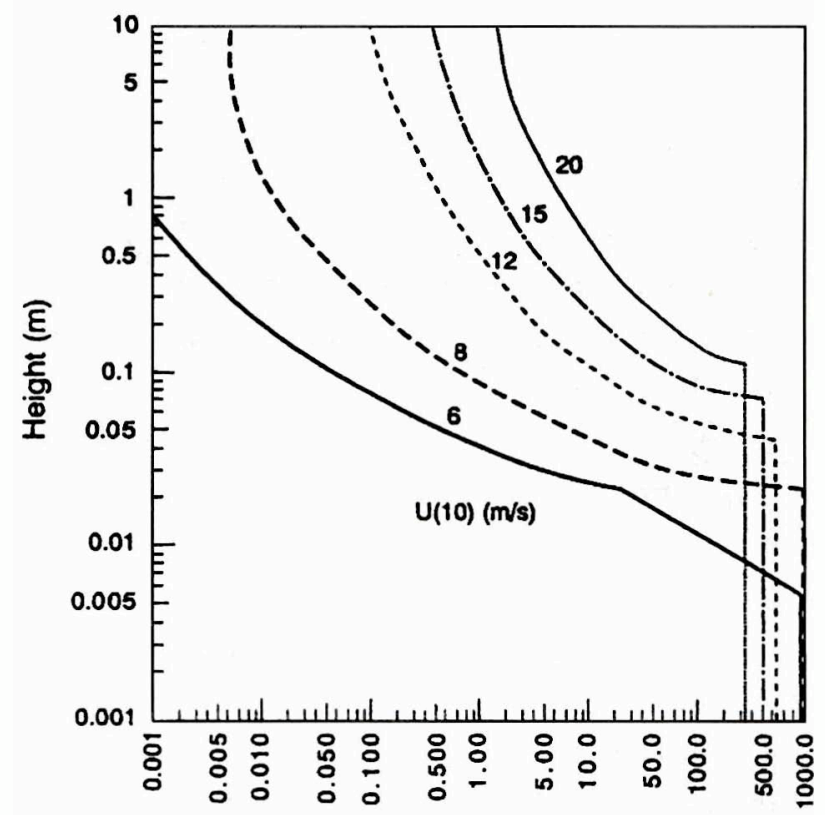

Blowing Snow Mass Concentration ( $\mathrm{g} / \mathrm{m}^{3}$ )

Figure 2.4. Vertical profiles of blowing snow mass concentration as a function of wind speed (after Pomeroy and Male, 1992).

The total snow transport rate $q_{\mathrm{T}}$ can be estimated by summing the saltation and suspension components. Figure 2.5 shows the relative contribution of saltation and suspension transport for a threshold wind speed corresponding to the $10-\mathrm{m}$ wind speed, $u_{10}=5.5 \mathrm{~m} \mathrm{~s}^{-1}$ (dry snow of moderate hardness), over an unvegetated, level, and extensive snow field. Suspension dominates over saltation transport, especially at high wind speeds. Alternatively, empirical expressions are available that may be used to estimate $q_{\mathrm{T}}$ directly from wind speed. Pomeroy, Gray, and Landine (1991) recommend

$$
q_{\mathrm{T}}=0.0000022 u_{10}^{4.04}
$$

where $q_{\mathrm{T}}$ is blowing snow horizontal transport $\left(\mathrm{kg} \mathrm{s}^{-1}\right)$ through a $1-\mathrm{m}$-wide column extending over a range of height from 0 to $5 \mathrm{~m}$ and $u_{10}\left(\mathrm{~m} \mathrm{~s}^{-1}\right)$ is the wind speed measured at a $10-\mathrm{m}$ height.

Sublimation from blowing snow is a significant loss to the surface snow pack during dry winter weather. The theory of sublimation of blowing snow has been described (Schmidt, 1972; Male, 1980; Pomeroy, Gray, and Landine, 1993). The high rates of sublimation of blowing snow particles with respect to the surface of a snow cover are 


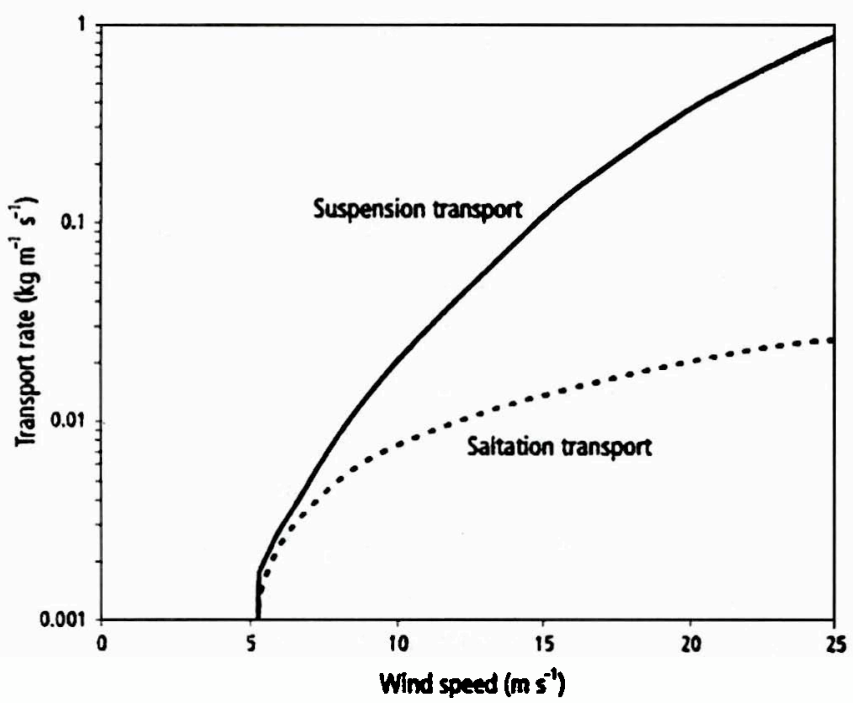

Figure 2.5. Transport rate of blowing snow by saltation and suspension as a function of wind speed (after Pomeroy and Male, 1992).

due to much higher turbulent exchange for suspended snow and a much higher ratio of surface area to mass for a snow particle removed from the pack. For instance, a unit mass of blowing snow has about 3,000 times more surface area exposed to the atmosphere than does an equivalent mass of snow on the ground. The sublimation rate can be calculated with a heat and mass transfer equation developed by Schmidt (1972) and implemented for standard meteorological measurements by Pomeroy (1989). The magnitude of sublimation loss depends on blowing snow mass concentration, wind speed, air temperature, relative humidity, and, less importantly, solar radiation.

Daily variations in temperature or humidity through typical ranges cause at least an order of magnitude change in the sublimation rate, whereas variations in daily radiation input cause only a small change in this rate. For example, the sublimation rate increases 25 -fold when air temperature increases from $-35^{\circ} \mathrm{C}$ to $-1^{\circ} \mathrm{C}$. For a blowing snow storm with wind speed at $10-\mathrm{m}$ height equal to $20 \mathrm{~m} \mathrm{~s}^{-1}$, temperature of $-15^{\circ} \mathrm{C}$, and relative humidity of 70 percent, the sublimation loss from blowing snow particles is equivalent to about $1 \mathrm{~mm}$ of SWE per hour and will produce an erosion rate of this magnitude where fetches are sufficiently long. Pomeroy and Gray (1995) have calculated the annual losses of snow to wind transport (to field edges, hedgerows, gullies, etc.) and to sublimation during blowing snow on the Canadian Prairies. The average annual blowing snow losses on 1-km fetches of grain stubble (stalk height $=25 \mathrm{~cm}$ ) 
and fallow (surface roughness equivalent to grain stalk height $=1 \mathrm{~cm}$ ) at four locations in the province of Saskatchewan show:

1. On average at least 8 to 11 percent of annual snowfall is removed from a $1-\mathrm{km}$ fetch of $25-\mathrm{cm}$ stubble by wind transport and redeposited. On the southern prairies this percentage doubles (19 percent).

2. Blowing snow fluxes are greater on fallow than stubble. The largest increases with a change in land use from stubble to fallow occur on the southern prairies where the annual transport at least doubles and the annual sublimation losses increase by 7 percent.

3. The percentage of annual snowfall lost to sublimation from a $1-\mathrm{km}$ fetch ranges from 23 to 41 percent of annual snowfall, an amount equal to or greater than (ranging up to 2.6 times) the amount of snow transported and redeposited. The results from 16 locations in the Canadian Prairies show that the average annual amount of snow water lost to sublimation from a $1-\mathrm{km}$ fetch may be up to five times the amount of snow transported to the field edge.

In the prairies of North America, blowing snow erosion generally tends to decrease with increasing latitude from the grassland to boreal forest because of climatic differences and changes in vegetation. Lower wind speeds, air temperatures, and higher humidities prevail at the northerly stations and the vegetation changes from open grassland to mixed grassland, deciduous, and boreal forest. In Arctic regions, blowing snow fluxes are also large, despite low temperatures, because of open exposure and high winds. Pomeroy and Marsh (1997) estimated that 27 percent of annual snowfall sublimated as blowing snow in tundra locations along the subarctic/arctic transition with 31 percent sublimating from tundra surfaces well north of the treeline in northwestern Canada.

Pomeroy and Gray (1994) compared monthly snow losses to transport (to the field edge where redeposition occurs) and sublimation with mean monthly climate variables in order to describe the climatology of blowing snow over the prairie provinces; the results are briefly discussed below.

1. Wind speed: mean monthly blowing snow transport and sublimation tend to increase linearly with increasing monthly mean of wind speed.

2. Temperature: mean monthly blowing snow transport and sublimation increase with decreasing monthly minimum or maximum temperature (below $0^{\circ} \mathrm{C}$ ). The trend for sublimation is opposite the effect of temperature on 
the sublimation rate for an ice sphere. However, low air temperatures result in snow covers with low cohesion and low transport thresholds and hence more frequent transport. The increased frequency of blowing snow events more than compensates for lowering of the sublimation rate due to a decrease in temperature. The effect of decreasing air temperature on snow transport is most important at low wind speeds. For a mean monthly wind speed of $5 \mathrm{~m} \mathrm{~s}^{-1}$, transport quadruples as the monthly mean of daily maximum air temperature drops from $-2^{\circ} \mathrm{C}$ to $-25^{\circ} \mathrm{C}$. Mean monthly snow transport on stubble displays a strong temperature dependence because of the effect of midseason melts in reexposing buried vegetation. The frequency of these melts increases as temperature increases; hence, transport increases dramatically as monthly mean daily maximum temperature drops below $-10^{\circ} \mathrm{C}$.

3. Relative humidity: there is a slight increase in snow transport on fallow and stubble land with increasing relative humidity. This trend is presumed to be due to higher humidities that suppress sublimation, leaving more snow available for transport.

4. Snowfall and snow depth: on fallow land, the transport and sublimation fluxes increase with increasing mean monthly snowfall. Sublimation rate exhibits the greatest increase per unit increase in snowfall. On stubble land mean monthly snow transport and sublimation increase exponentially with increasing depth of snow on the ground. The largest increase occurs when the snow cover water equivalent is less than $30 \mathrm{~mm}$ because stalks of vegetation are exposed to the wind. At greater depths of snow cover the vegetation is inundated and snow transport will be similar to that on a field of fallow.

In open environments vegetation and terrain features can produce dramatic variations in snow accumulation by trapping wind-transported snow. The effect of a hedgerow in the centre of a field and varying crop vegetation heights is shown in Figure 2.6. Snow accumulation near the hedge is over 10 times greater than that in adjacent fields, and snow accumulation in the fields depends on wheat stubble height. The effect of a sharp topographic change is presented in Figure 2.7, which shows a SWE transect at Trail Valley Creek, $60 \mathrm{~km}$ north of Inuvik, Northwest Territories, Canada. The upper tundra plateau drops sharply to the valley bottom, inducing formation of a major side drift. Slightly higher lowland vegetation on the valley bottom holds more snow than the short vegetation on the upland plateau. Mountain ridges are a special case, as data of Föhn and Meister (1983) from near Davos, Switzerland, 


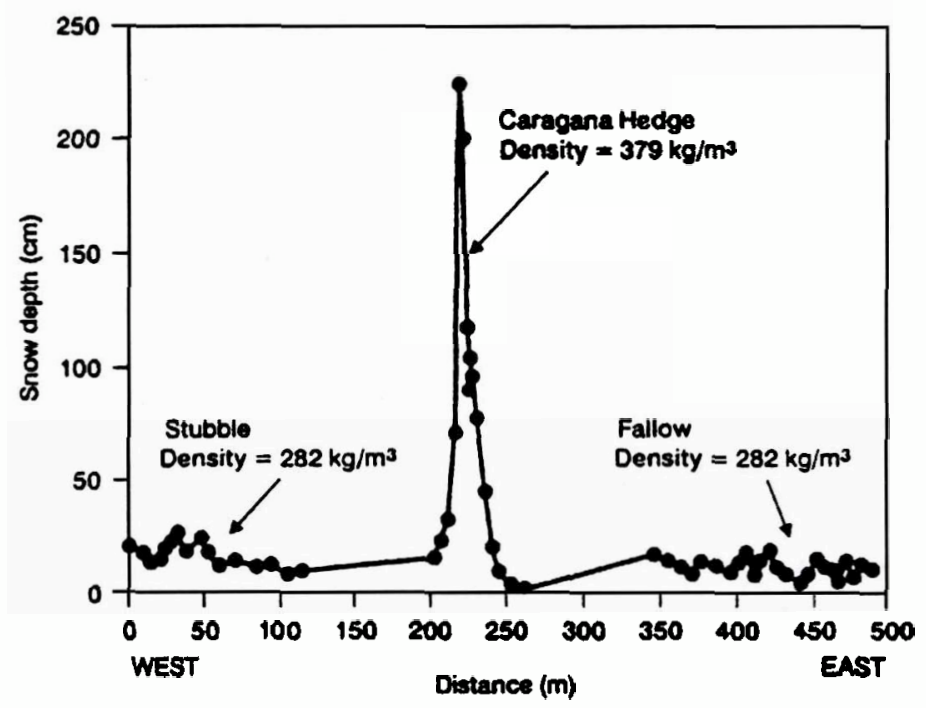

Figure 2.6. Transects of snow depth and density along a fallow field and stubble field divided by a Caragana hedge, measured east of Saskatoon, Canada, in late winter (after Pomeroy et al., 1993).

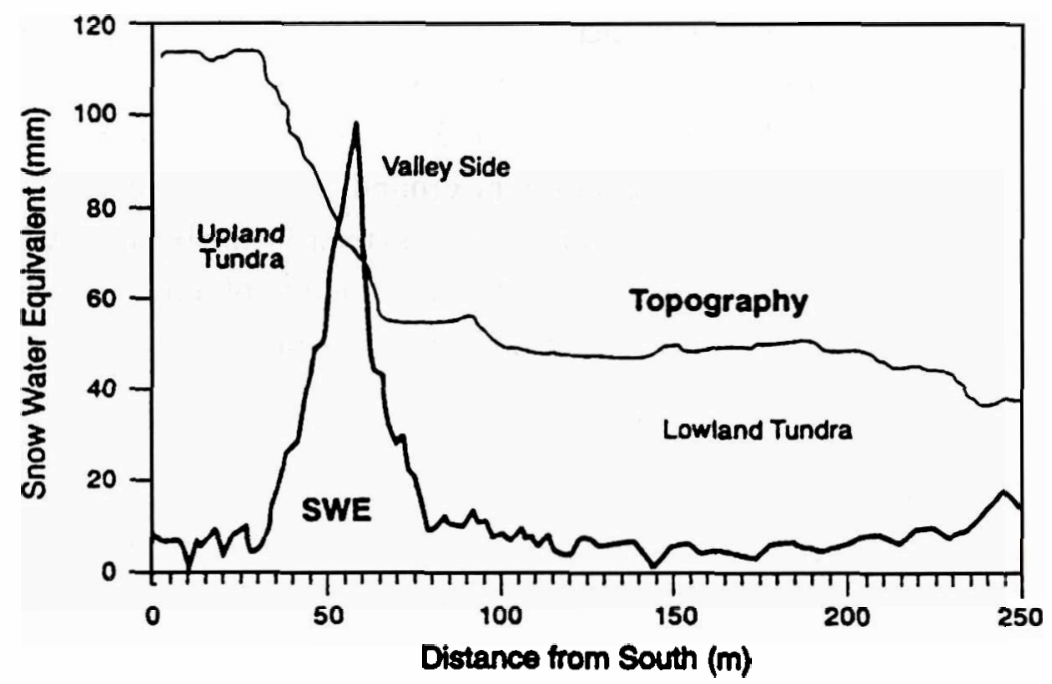

Figure 2.7. Transects of SWE and topography from an upland tundra plateau down a valley side to a lowland tundra valley bottom, north of Inuvik, Canada, measured in late winter (after Pomeroy and Gray, 1995). 


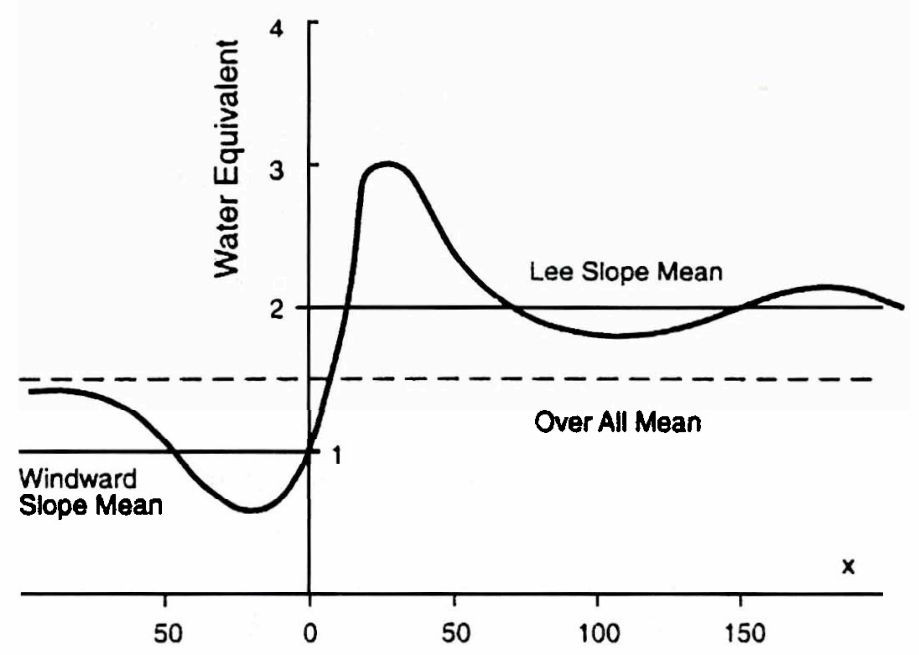

Figure 2.8. SWE deposition patterns on alpine ridges as related to windward and lee slope accumulation, near Davos, Switzerland (after Föhn and Meister, 1983).

show in Figure 2.8. For a snowdrift formed from a prevailing wind direction perpendicular to a sharp crest, the windward and lee slopes have distinctive patterns. The mean snow accumulation on the lee slope is about twice that formed on the windward slope, with a maximum accumulation in the lee slope cornice about six times that of the minimum accumulation on the windward slope just below the crest. The drifts formed near hedges, mountain crests, and valley sides persist much later than adjacent snow covers during melt and provide an important source of late spring meltwater.

The landscape-wide effects of the small-scale snow cover response to vegetation and terrain are particularly evident in prairie and arctic landscapes where a long and windy winter season with a mix of open short vegetation terrain, brushland, pockets of trees, plateaux, and gullies produces distinctive snow accumulations in various landscape types. Snow accumulations in a prairie environment are shown in Table 2.1, which lists the relative amounts of snow water retained by various landscapes at a time near maximum accumulation. It is evident that the combination of terrain and vegetation types provide landscape classes with distinctive influences on snow accumulation.

In Arctic environments similar types of snow accumulation patterns occur with snow relocated to sites of high vegetation and sharp topography. Pomeroy et al. (1997a) divided a forest-tundra transitional landscape north of Inuvik, Northwest Territories, Canada into sources (frozen water, tundra, sparse shrub tundra, exposed soil) and sinks (open and closed shrub tundra, sparse forest, drifts) of blowing snow based on 
Table 2.1. Relative snow water retention on various landscape types in an open grassland environment (Gray et al., 1979).

\begin{tabular}{lc}
\hline \hline Landscape type & Relative accumulationa \\
\hline Level plains & 1.00 \\
fallow & 1.15 \\
stubble & 0.60 \\
pasture (grazed) & \\
Gradual hill and valley slopes & $1.0-1.10$ \\
fallow, stubble, hayland & 1.25 \\
pasture (ungrazed) & \\
Steep hill and valley slopes & 2.85 \\
pasture (ungrazed) & 4.20 \\
brush & \\
Ridge and hilltops & $0.40-0.50$ \\
fallow, ungrazed pasture & 0.75 \\
stubble & \\
Small shallow drainageways & $2.0-2.15$ \\
fallow, stubble, pasture (ungrazed) & \\
Wide valley bottoms & 1.30 \\
pasture (grazed) & 2.40 \\
Farm yards (mixed trees) & \\
\hline \hline
\end{tabular}

${ }^{2}$ Snow water equivalent normalized to snow water equivalent monitored on level plains under fallow.

vegetation and topographic slope criteria. Drifts were indicated for incised stream channels or slopes exceeding $9^{\circ}$ adjacent to source areas. They then simulated snow cover development with a blowing snow model for each of the landscape types. The results are shown for one seasonal simulation in Figure 2.9, and indicate drastically different accumulation regimes for drift and tundra sites. The tundra reached its maximum snow accumulation after five months, where as the drift continued to accumulate snow to the eighth month of winter with a maximum measured accumulation about nine times greater than that on the tundra. The shrub-tundra accumulation regime more closely followed snowfall inputs because exposed vegetation restrained blowing snow.

Snow management is practised to increase snow accumulation in windswept areas, to provide water for crops and livestock in many agricultural environments, and to control snow drifting onto highways and buildings. The primary principle used is to increase the roughness of the landscape to trap blowing snow. Commonly used 


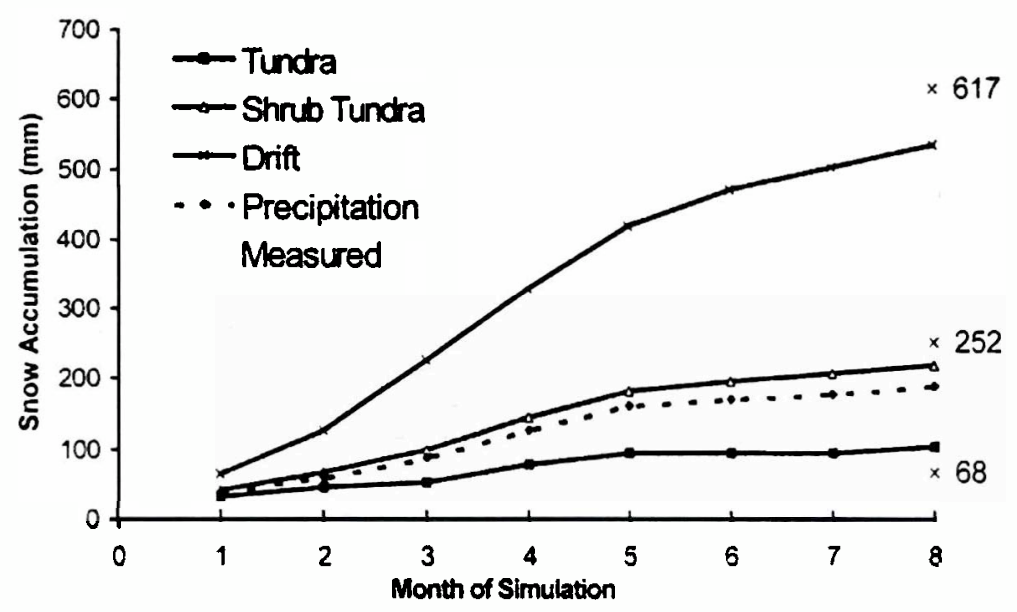

Figure 2.9. Monthly SWE accumulation for different landscape types in a lowland tundra environment, calculated by using a distributed blowing snow model. Modeled period is from October 1992 through May, 1993. Measured SWE is based on long snow surveys of depth and density conducted in early spring (Pomeroy et al., 1997a).

practises are windbreaks of snow fences, woody vegetation (caragana, ash, maple, or other hedgerows), or nonwoody vegetation (strips of sudan grass, tall wheatgrass, uncut strips of grain); crop stubble management (tall and alternate height stubble, trap strips); and snow ridges (Pomeroy and Gray, 1995). Tall stubble will generally induce snow accumulation to near the height of the stubble. An example of snow accumulation in alternative height stubble is shown in Figure 2.10, where snow depth and stubble height are plotted along a transect; this technique is quite effective and still provides straw for farmers. Pomeroy and Gray recommend the following equation to predict the maximum mean depth of snow, $d_{\mathrm{s}}(\mathrm{m})$,

$$
d_{\mathrm{s}}=H-v \frac{A_{\mathrm{s}}}{S_{\mathrm{d}}}
$$

where $H$ is the average plant height (m), $A_{\mathrm{s}}$ is the average ground surface area occupied by each plant $\left(\mathrm{m}^{2}\right)$, and $S_{\mathrm{d}}$ is the stalk diameter or width of plant $(\mathrm{m})$. For dense vegetation (wheat stalks, grass) the dimensionless snow trapping coefficient $v=0.03$, whereas Tabler and Schmidt (1986) recommend $v=0.01$ for sparse vegetation (sagebrush). Spacing of hedgerows and grass barriers of from $10 H$ to $20 H$ where $H$ is the windbreak vegetation height have proven useful in a variety of steppe and prairie environments. Properly designed porous (50 percent) snow fences will trap snow up to $15 \mathrm{H}$ upwind and $35 \mathrm{H}$ downwind and capture a volume of snow that increases with the 


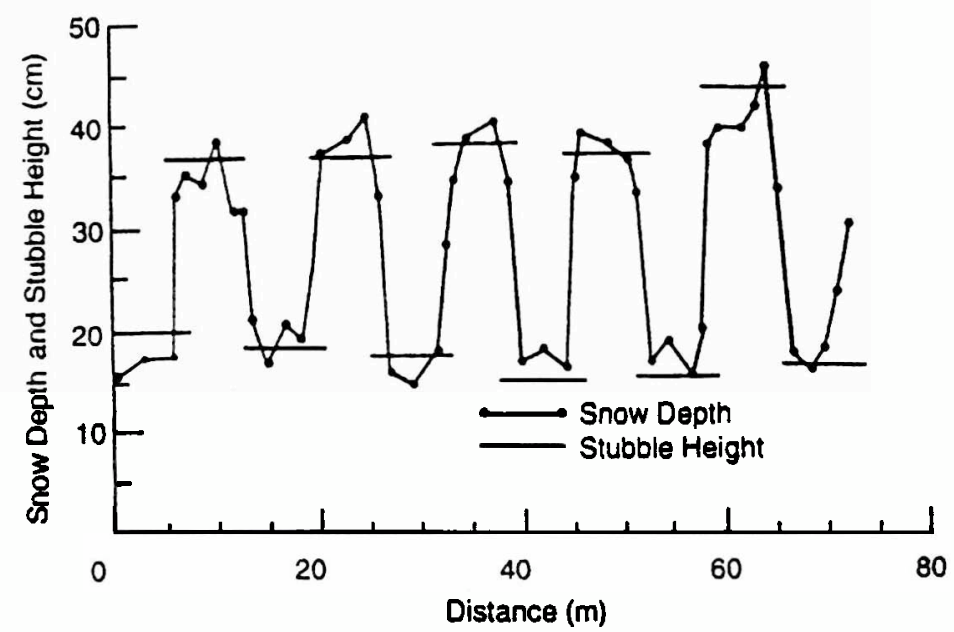

Figure 2.10. Snow depth patterns and stubble height on a wheat field harvested with alternate-height stubble management practice, southern Saskatchewan, Canada (after Pomeroy and Gray, 1995).

square of fence height (Tabler, Pomeroy, and Santana, 1990b). The ecological implications of deep snowdrifts formed by snow fences on tundra vegetation are discussed by Walker et al. (Chapter 6 ).

\subsubsection{Interception by Vegetation}

Interception of snowfall by vegetation plays a major role in the snow ecology of coniferous forests, as it results in characteristic snow distributions and winter microclimate. Snow interception is controlled by accumulation of falling snow in the canopy. This snow is subsequently affected by sublimation, melt, and unloading of snow by canopy branches and wind redistribution. Intercepted snow receives snow from snowfall and snow unloaded from upper branches and, of less importance, drip from melting snow on upper branches and vapour deposition during supersaturated atmospheric conditions. Intercepted snow can sublimate to water vapour or become suspended by atmospheric turbulence, followed by further sublimation or deposition to surface snow. Deposition to the surface also may occur by melt and drip to the surface or by directly unloading from branches. Hence, intercepted snow may reach the ground as a solid, liquid, or vapour, but not all intercepted snow eventually reaches the ground (Figure 2.11). The importance of these specific processes in governing snow cover development varies with climatic region, local weather pattern, tree species, and canopy density. 


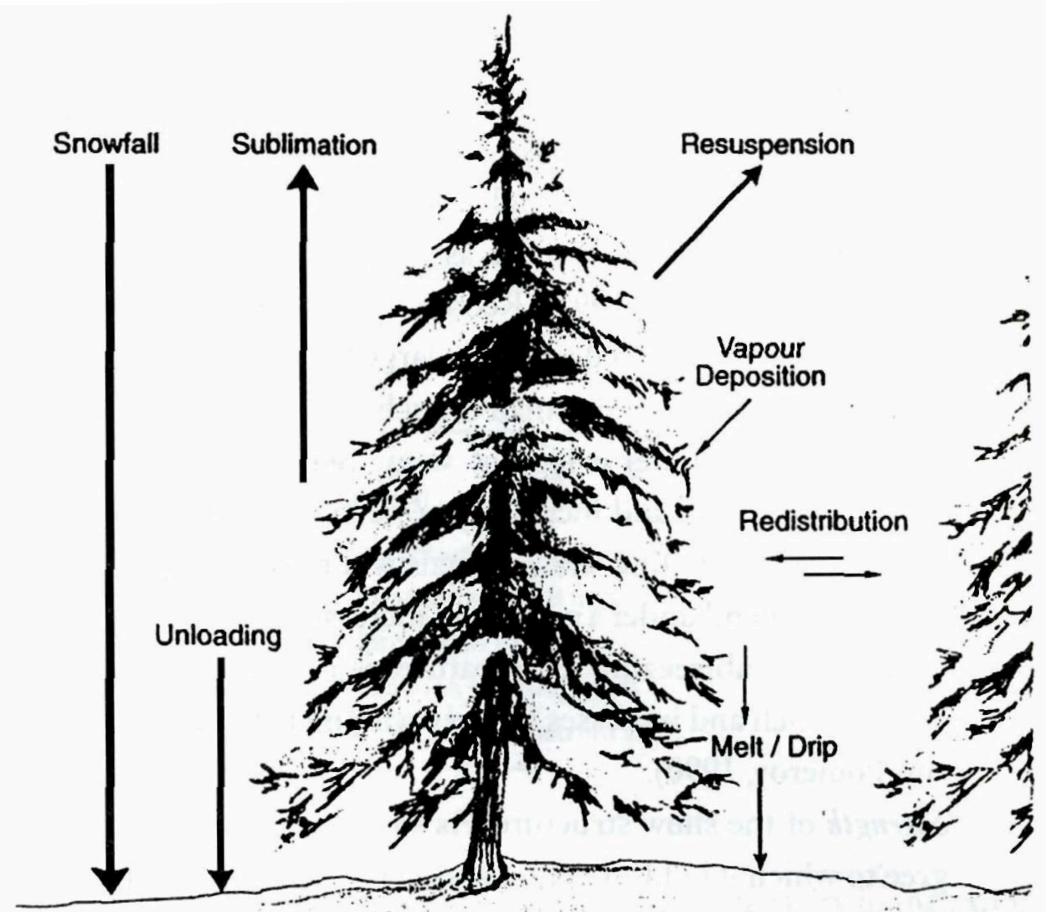

\section{Surface Snow}

Figure 2.11. Mass fluxes associated with the disposition of winter snowfall in a boreal forest (after Pomeroy and Schmidt, 1993).

The interception efficiency of a canopy is the ratio of snowfall intercepted to the total snowfall; this efficiency is an integration of the collection efficiencies for individual branches that compose the canopy. At the branch scale, the collection efficiency is the ratio of snow retained by a branch to that incident on the horizontal area of the branch. In early stages of snowfall, snowflakes fall through the spaces between branches and needles, lodging in the smallest spaces until small bridges form at narrow openings. These snow bridges increase the collection area and hence the efficiency with which a branch accumulates snow; further snow is retained on the bridges by cohesion. Cohesion of snow results from the formation of microscale ice bonds between snow crystals shortly after contact because of the movement of a thin, liquid-like layer surrounding the crystals or because of the small-scale vaporisation and condensation of water vapour (Langham, 1981). Shortly after initial contact, cohesion increases rapidly; the rate of cohesion accelerates as temperatures approach the melting point. Hence, other factors being equal, the collection efficiency of a branch due to the cohesion of snow increases with increasing temperature. 
The collection efficiency of a branch is limited by three primary factors (Pomeroy and Gray, 1995):

1. Elastic rebound of snow crystals falling onto branch elements and onto snow held by the branch. Rebound is most pronounced below temperatures of $-3^{\circ} \mathrm{C}$ and declines rapidly as temperature rises from $-3^{\circ} \mathrm{C}$ to $0^{\circ} \mathrm{C}$ (Schmidt and Gluns, 1991). Rebound from the branch occurs most effectively near the branch edge; hence large branches lose proportionately less snow to rebound than do small branches.

2. Branch bending under a load of snow. Bending decreases the horizontal area of the branch and increases the vertical slope, thereby increasing the probability that falling snow crystals will rebound. The degree to which a branch will bend under a given load increases with branch elasticity. Branch elasticity at subfreezing temperatures is related to the ice crystal content of the branch and increases linearly with increasing temperature (Schmidt and Pomeroy, 1990).

3. Strength of the snow structure. As snow accumulates on a branch the degree to which it holds together and to the branch is related to the degree of bonding or strength of the interlocking snow crystals. As temperature increases, the rate at which the snow structure "simplifies" (reduced number of bonds) due to metamorphism increases. Hence, snow strength will decrease with increasing temperature and, when accumulations are large, this may lead to decreased interception efficiency (Gubler and Rychetnik, 1991).

High winds may induce snow redistribution from conifer branches during snowfall, reducing the collection efficiency during a storm. The lowest branch collection efficiencies in the measurements of Schmidt and Gluns (1991) occurred during the highest wind speeds. More effective snow particle rebound during high winds may be the reason for reduced interception efficiency in these cases, though release of accumulating snow, triggered by branch vibrations in the wind may play a role as well.

There are differences in the relationships between canopy-scale interception efficiency and branch-scale collection efficiency with snowfall. Working at small scales, Satterlund and Haupt (1970) and Schmidt and Gluns (1991) found collection efficiencies low for low snowfall, high for medium snowfall, and low for high snowfall amounts. At the canopy scale, Strobel (1978) and Calder (1990) found that interception efficiency declined with snowfall amount. Hedstrom and Pomeroy (1998) developed a physically based model of snow interception from the assumption that the incremental 


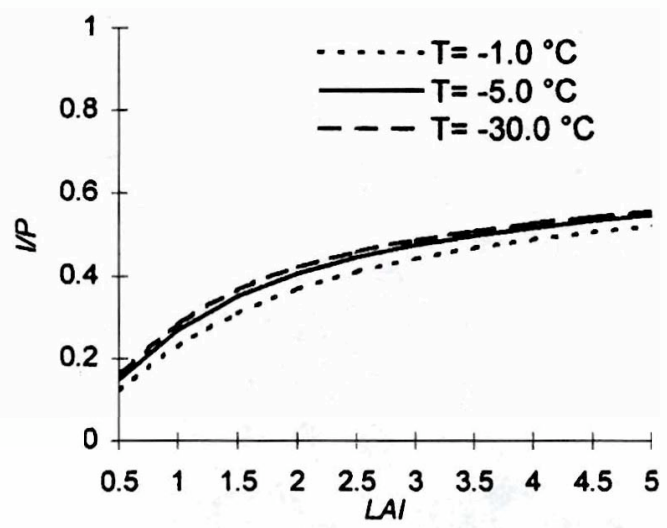

Figure 2.12. Modeled interception efficiency (interception/snowfall) for a snowfall of $10 \mathrm{~mm}$ SWE, closed canopy pine forest with initial snow-free conditions, as a function of canopy leaf area index and air temperature (after Hedstrom and Pomeroy, 1998).

interception efficiency is proportional to the snow storage capacity in the canopy (e.g., as the canopy fills with snow the interception efficiency diminishes). The snow storage capacity increases with canopy leaf area and diminishes with existing canopy snow load. Snowfall amount, temperature, canopy closure, wind speed, and time since snowfall also influence interception in this model. The modeled interception efficiency as a function of leaf area index (LAI) and air temperature is shown in Figure 2.12. A doubling of LAI from 2 to 4 causes the interception efficiency to increase from approximately 0.4 to 0.5 . Interception is slightly more efficient at low temperatures because of lower fresh snow density in cold conditions and hence better retention in the canopy.

Sublimation of snow can consume considerable amounts of energy from a forest environment in winter. However, the vertical distribution of intercepted snow through the lower 10 to $20 \mathrm{~m}$ of the atmosphere results in a large volume of air exposed to snow. This, in addition to the large surface area to mass ratio of intercepted snow and low canopy reflectance of shortwave radiation, results in the potential for notable rates of turbulent transfer of atmospheric heat to the intercepted snow and concomitant removal of water vapour produced at the intercepted snow surface (Harding and Pomeroy, 1996). Figure 2.13 shows snow intercepted in an evergreen canopy at both large and microscale, illustrating the distribution and exposure of snow in the canopy. Pomeroy and Schmidt (1993) provide data suggesting that, for a unit mass of snow, 


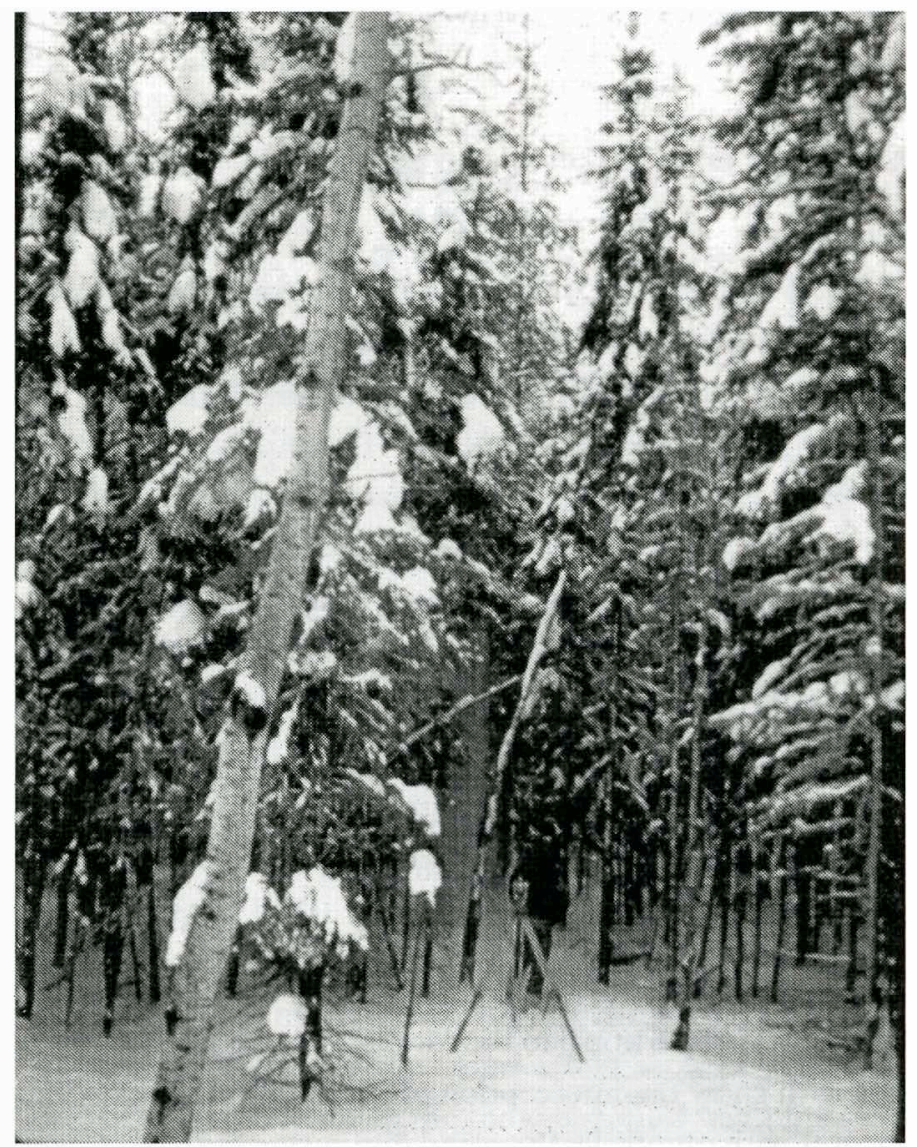

(a)

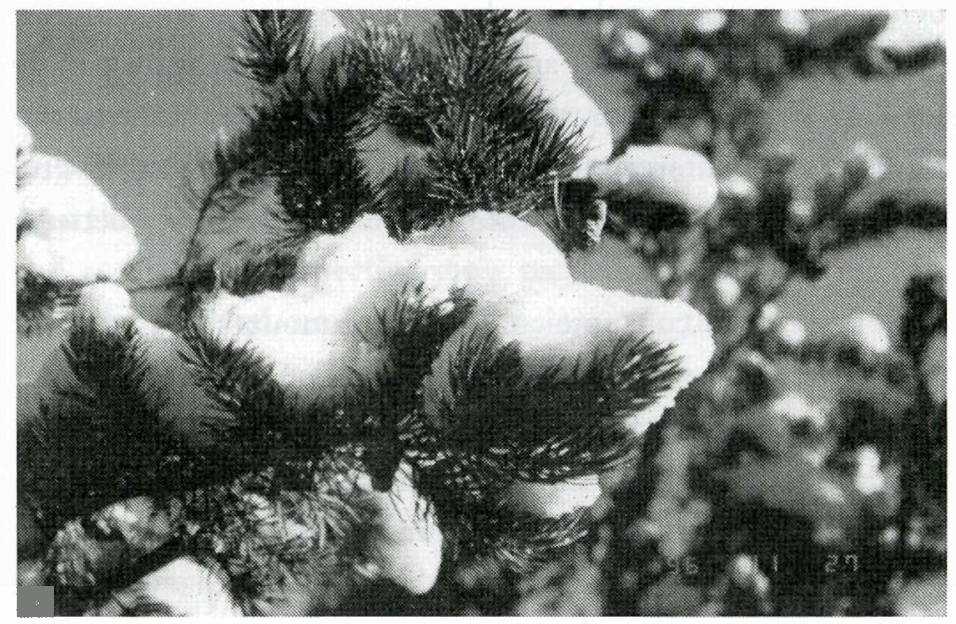

(b)

Figure 2.13. Photographs of snow-covered spruce canopy (a) and a snow-covered branch (b), Prince Albert National Park, Saskatchewan, Canada. 
the surface area of intercepted snow exposed to the atmosphere is 60 to 1,800 times greater than that of snow on the ground. This high surface area and the long period of exposure of snow-covered canopies during northern winters thus provide ample opportunity for sublimation to occur, even when cold temperatures suppress the rate.

Measurements in Prince Albert National Park, Saskatchewan, during December 1992 and January 1993 show that $9 \mathrm{~kg}$ of snow accumulated on a single black spruce tree in a cold period $\left(-25^{\circ} \mathrm{C}\right.$ to $\left.-45^{\circ} \mathrm{C}\right)$. In late January $\left(-20^{\circ} \mathrm{C}\right.$ to $\left.-2^{\circ} \mathrm{C}\right)$ about $3 \mathrm{~kg}$ of this snow sublimated, whilst the rest fell to the ground; the evolution of mass of tree and snow during this period is shown in Figure 2.14. Landscape-based snow surveys over the winter showed that 31 percent of the annual snowfall sublimated from intercepted snow in black spruce and jack pine canopies. A review of the loss of intercepted snow by sublimation (Schmidt and Troendle, 1992) suggests that approximately one-third of annual snowfall is lost to sublimation from intercepted snow in dense coniferous canopies in the region. Extrapolating this figure to the boreal forest of western Canada (Northwestern Ontario to Great Slave Lake) and correcting for spatial distributions of coniferous canopy density leads to an average loss of $46 \mathrm{~mm} \mathrm{SWE}$ in a region that receives from 100 - to $200-\mathrm{mm}$ water equivalent of annual snowfall. Hence

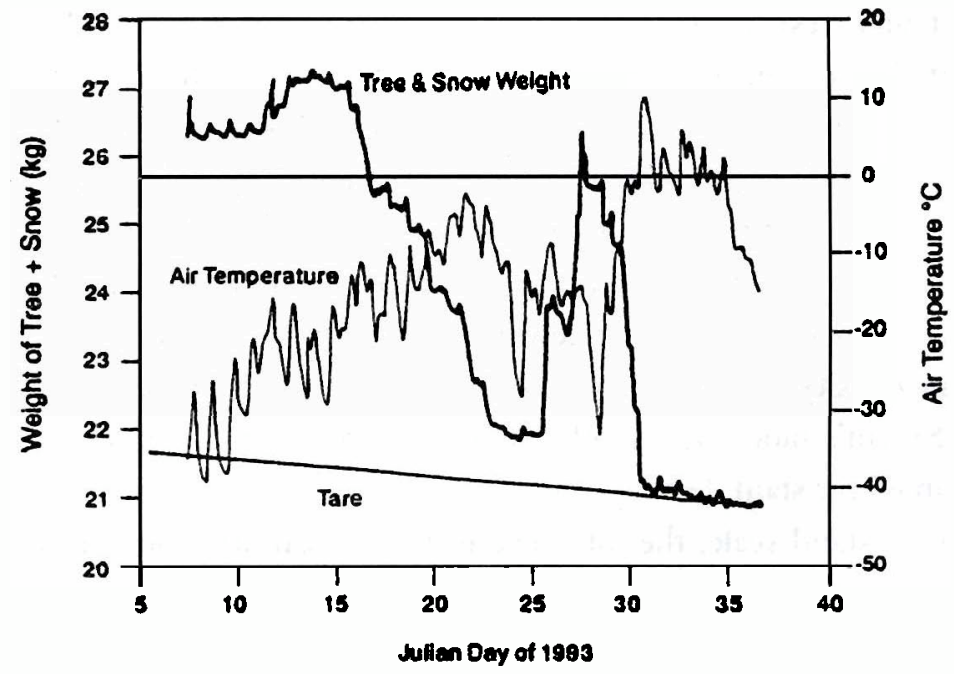

Figure 2.14. Combined weight of a $12-\mathrm{m}$ black spruce tree and its intercepted snow load along with air temperature during a sequence of sublimation, snowfall, and sublimation, Prince Albert National Park, Saskatchewan (after Pomeroy and Gray, 1995). 
sublimation of intercepted snow has important effects on the amount of snow that accumulates on the ground and subsequently water supply to the terrestrial and aquatic ecosystems. At local scales sublimation losses vary with canopy cover and provide a mechanism for forest structure to influence water supply through the medium of snow.

The result of interception processes is that, under a forest canopy, both snow depth and water equivalent vary:

1. In relation to the distance to trees, decreasing with decreasing distance to a coniferous tree trunk and slightly increasing with decreasing distance to a deciduous tree trunk; and

2. Between stands of different tree species, with higher accumulations under deciduous trees and smallest accumulations under coniferous trees.

Sturm (1992) developed the following model for snow depth $d_{\mathrm{s}}(\mathrm{cm})$ as a function of distance $x(\mathrm{~m})$ from a coniferous tree trunk in a boreal forest, using data from Alaska, USA, and northern Ontario, Canada:

$$
d_{\mathrm{s}}(x)=d_{\mathrm{s}}(3)+\left[d_{\mathrm{s}}(0)-d_{\mathrm{s}}(3)\right] e^{-\left(\frac{x}{k}\right)^{2}}
$$

where $d_{s}(x), d_{s}(0)$, and $d_{s}(3)$ are the snow depths at distances of $x, 0$, and $3 \mathrm{~m}$ from the central trunk, respectively, and $k(\mathrm{~m})$ is a tree size parameter that varies from 0.2 for stunted black spruce in northern boreal forests to 5 for larger white spruce or fir trees in montane or southern boreal forests. Woo and Steer (1986) present measurements showing $d_{\mathrm{s}}(0)$ is approximately one-half of $d_{\mathrm{s}}(3)$. Figure 2.15 shows the change in SWE and snow depth with distance from a single 10-m tall white spruce in a predominantly aspen forest near Waskesiu Lake, Saskatchewan, Canada. Note that SWE undergoes a greater change with distance from the trunk than does depth, because snow density is lower under the spruce branches than beyond the branches. Therefore, Sturm's model for depth cannot be directly modified to calculate SWE with an assumed constant density.

At the forest stand scale, the influence of winter leaf area index (horizontal area of needles and stems over a unit area of ground) on snow accumulation is shown in Figure 2.16, as measured in midwinter in the southern boreal forest of Saskatchewan, Canada. Wind relocation and midwinter melts are not important factors in these relatively calm, cold forests. Leaf + stem area index was measured for the canopy above each snow measurement point. There is a roughly linear decrease in SWE with increasing leaf area, although individual tree species have distinctive effects and there 


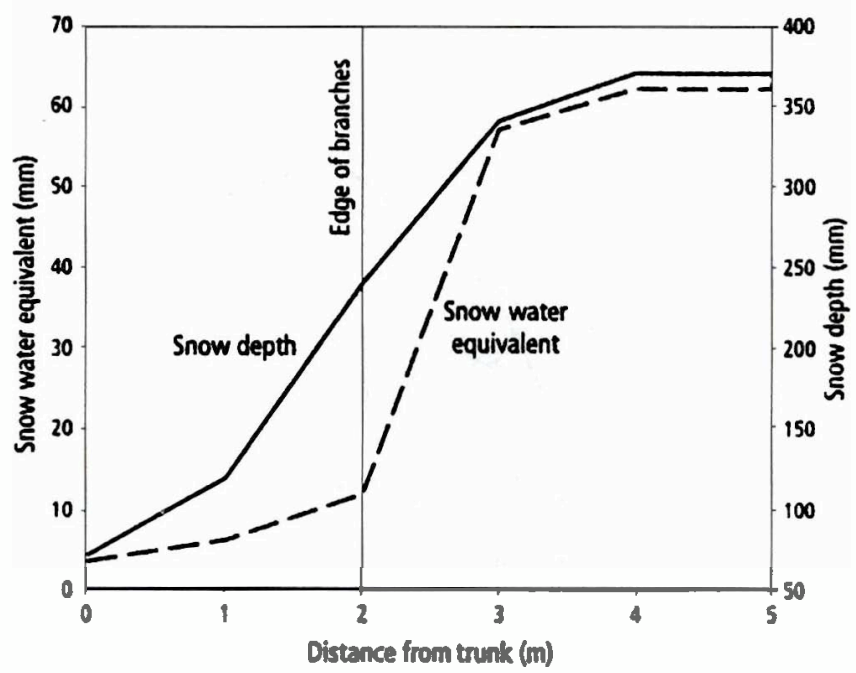

Figure 2.15. Change in midwinter snow depth and SWE with distance from a white spruce in a stand of trembling aspen, Prince Albert National Park, Saskatchewan, Canada (after Pomeroy and Goodison, 1997).

is a variation of SWE and leaf area within a species type for conifers that departs from the larger trend somewhat.

The winter evolution of average SWE by stand species type over time in the same boreal forest is examined in Figure 2.17. It is evident that throughout the winter the aspen stand and small clearing accumulated more snow than did the jack pine or black

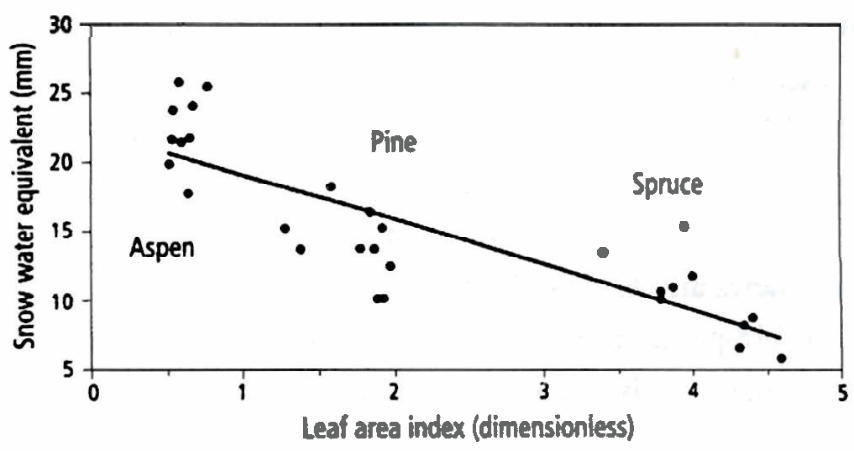

Figure 2.16. Relationship between $\mathrm{LAI}$ and SWE in midwinter, southern boreal forest, Prince Albert National Park, Saskatchewan, Canada (after Pomeroy and Goodison, 1997). 


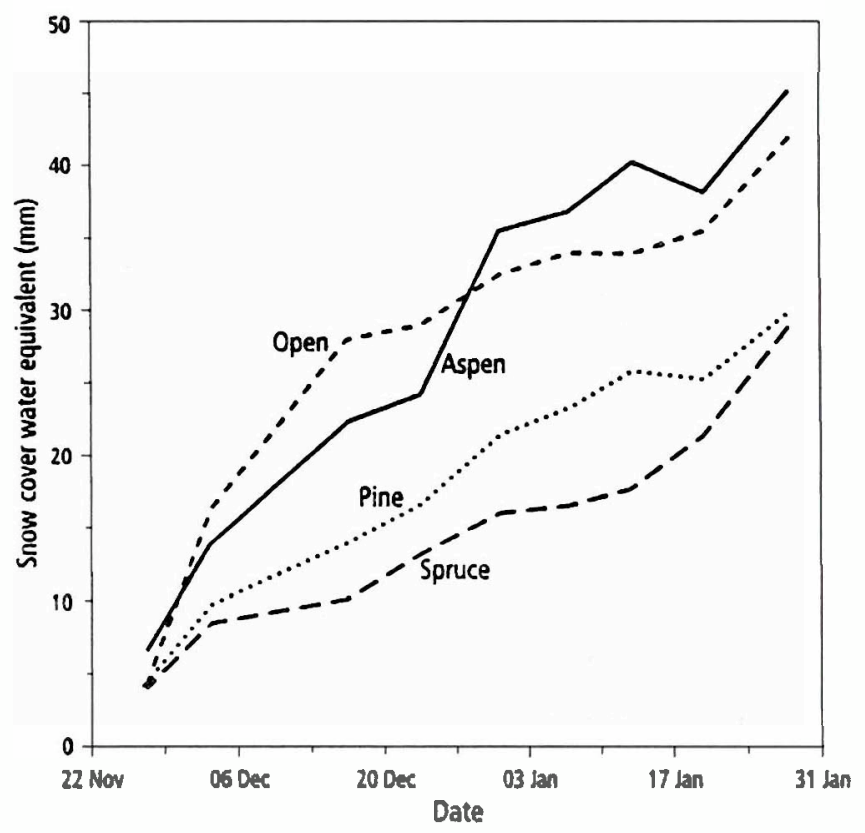

Figure 2.17. Winter evolution of SWE under various forest stands and in a small clearing, southern boreal forest, Prince Albert National Park, Saskatchewan (after Pomeroy and Gray, 1995).

spruce stands. A warming trend at the end of January removed all intercepted snow from the canopy so the differences in SWE at the end of that month represent differential losses due to sublimation of intercepted snow and amount to about 35 percent of the snowfall to that date. Sublimation directly from the snow cover on the ground is negligible in this environment (Harding and Pomeroy, 1996).

Logging operations are changing the vegetation of many forests throughout the world, and some research on snow cover distribution in forested environments has concentrated on the differences between the amounts of snow collected in forests and in openings. The results demonstrate larger amounts of snow in clearings, although the degree of difference is related to the size of the clear-cut. In southeastern British Columbia, Canada, Toews and Gluns (1986) report that snow accumulation in clearcuts ranged from 4 to 118 percent more than that in adjacent coniferous forests, with a mean difference of 37 percent. In the foothills of southern Alberta, Canada, Golding and Swanson (1986) report snow accumulation increased from 20 to 45 percent from forest to clearing.

Kuz'min (1960) suggests that the SWE in a forest $\left(S W E_{\mathrm{f}}\right)$ and in a clearing $\left(S W E_{\mathrm{c}}\right)$ can be empirically related to forest canopy cover density $p$ (expressed as a decimal 
fraction) as:

$$
S W E_{\mathrm{f}}=S W E_{\mathrm{c}}\left(1-b_{\mathrm{f}} p\right)
$$

where for a Russian fir forest $b_{\mathrm{f}}=0.37$. Harestead and Bunnell (1981) develop a similar form of equation and find $b_{\mathrm{f}}$ varies from 0.24 to 1.4 for coniferous forests in California and Montana in the United States. This expression compares forest to open area accumulation without reference to the size of the clearing. The average depth of snow in a clearing, however, can vary with the size of the opening; increasing the size decreases the average depth in windy, cold snow environments. Troendle and Leaf (1981) and others note that an opening of diameter $5 H$ ( $H=$ height of the surrounding forest canopy) accumulates the maximum amount of snow in the high mountains of Colorado. Beyond diameters of $12 \mathrm{H}$, the clearing retains less snow than the adjacent coniferous forest. The reduction in snow cover in large clearings is caused by the increasing likelihood that wind transport erodes snow from the clearing as clearing size increases. This feature of snow accumulation in forest clearings has important implications for the effects of clear-cut blocks on snow accumulation in formerly forested regions. In more humid and temperate regions such as southern British Columbia, blowing snow is suppressed by warm temperatures and SWE does not vary substantially with clear-cut size (Toews and Gluns, 1986).

\subsection{Energetics of Snowpacks}

\subsubsection{Atmospheric Boundary}

The energy and mass exchanges between the snow cover and the atmosphere involve various interacting processes, primarily sensible and latent turbulent heat transfer, radiative energy transfer, and phase changes. The energy flow associated with these processes is often expressed as a flux of energy $\left(\mathrm{W} \mathrm{m}^{-2}\right)$ or daily energy flux $\left(\mathrm{kJ} \mathrm{m}^{-2}\right)$ with respect to a unit area of the snow surface. Hence sensible heat flux involves a convective (turbulent) flow of heat, latent heat flux is an equivalent heat exchange due to phase change (evaporation, sublimation, refreezing), and radiative flux is due to absorption of shortwave or long-wave radiation and emission of long-wave radiation. By convention, most snow scientists classify the energy used in melting snow as a separate flux from latent (evaporative) heat. Shook and Gray (1997) found for continuous snowpacks in open environments that more than 90 percent of total phase change energy went to melt rather than evaporation. Complete reviews of energy exchanges during winter and snowmelt seasons are provided by Male (1980), Male and 


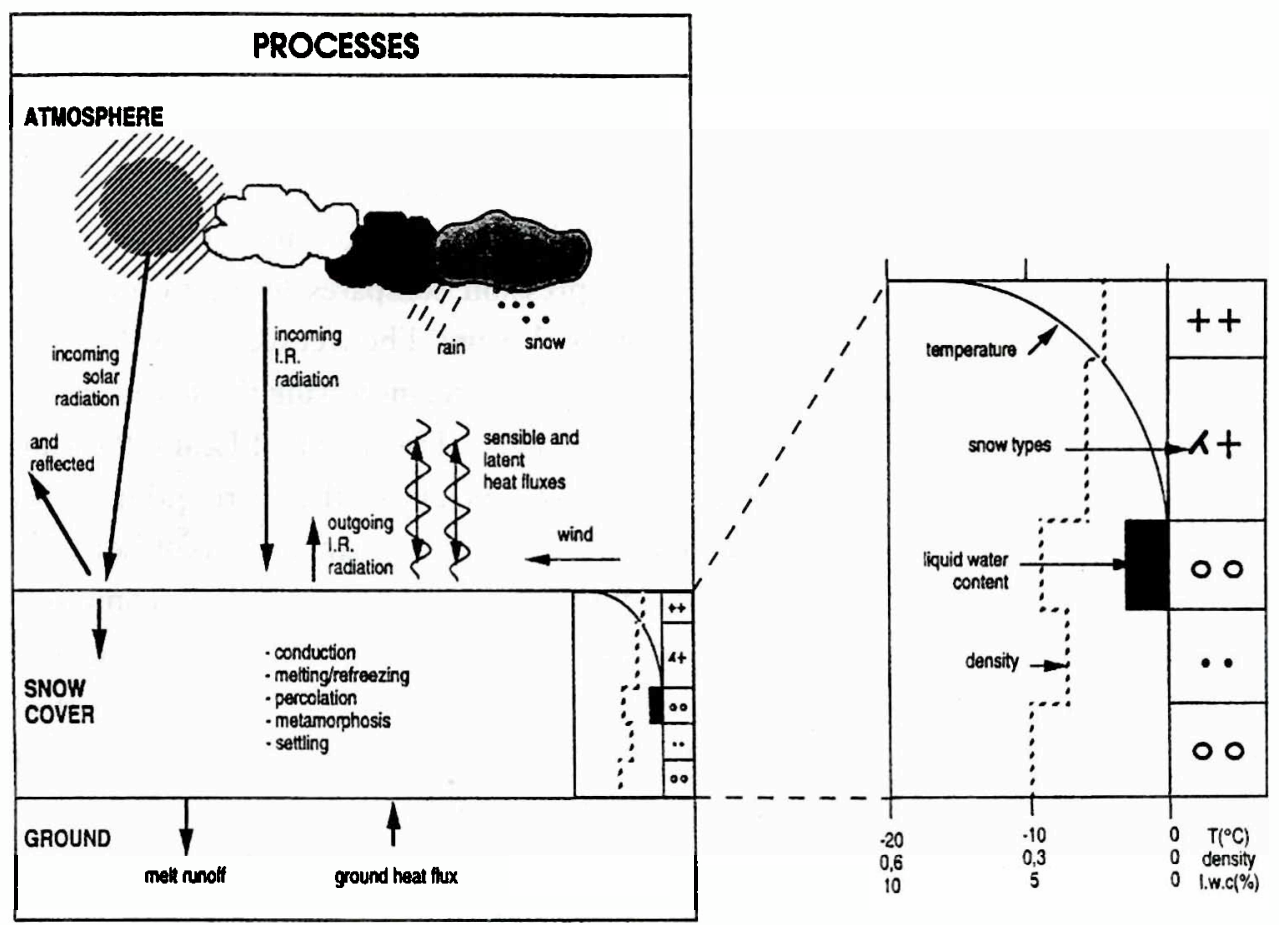

Figure 2.18. Conceptual schematic of mass and energy fluxes controlling the energetics of a snow cover and their relation to snowpack structure, properties and processes, the atmosphere, and the ground. I.R., infrared; l.w.c, liquid water content.

Gray (1981), and Pomeroy and Goodison (1997). These exchanges and other important snowpack energetic processes are shown in Figure 2.18. Their relative importance depends on:

1. Weather conditions: air temperature, humidity, wind speed, incoming shortwave and long-wave radiation and precipitation; and

2. State of the snow cover: albedo, snow surface temperature, surface roughness.

Specific weather and snow cover conditions may favour one or more of these processes in supplying energy to the snow cover for a period of time, while at another time the same processes may remove energy. In most places, incoming shortwave (solar) radiation is the principal source of energy, but other processes can involve energy exchanges of similar orders of magnitude (i.e., between 100 and $500 \mathrm{~W} \mathrm{~m}^{-2}$ ). Processes such as photosynthesis, snowmelt, and evaporation driven by solar energy follow a marked diurnal cycle, and the daily average of the resulting fluxes or transformations may be much smaller than peak values. 


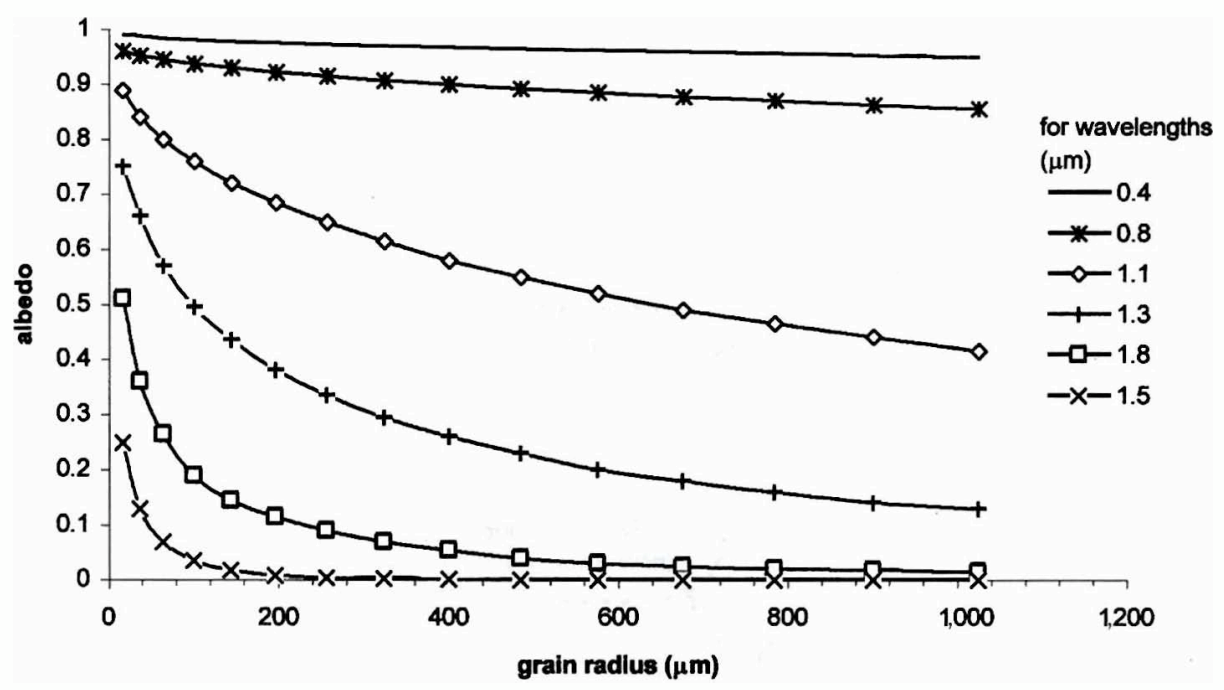

Figure 2.19. Diffuse albedo versus snow crystal radius for six wavelengths (after Warren, 1982).

As solar radiation is a major component of the energy flux to snow, the time of the year and latitude have strong effects on the snow energy balance. Much of the shortwave radiation incident on a snow surface is reflected, with albedos as high as 0.9 for compact, dry, clean snow, dropping to $0.5-0.6$ for wet snow and to $0.3-0.4$ for porous, dirty snow. A comprehensive review of measurements and mathematical models of snow reflectance and transmission of radiation is given by Warren (1982). Figure 2.19 shows the model results of Warren and Wiscombe (1980) for diffuse light albedo of pure, dry, deep, level snow as a function of wavelength and snow grain radius. Although the albedo is a bulk shortwave reflectance, the spectral reflectance of snow differs substantially over the range of wavelengths from 200 to $2,800 \mathrm{~nm}$. From 200 to $800 \mathrm{~nm}$, reflectance is very high and relatively independent of grain size. Above $1,900 \mathrm{~nm}$, reflectance is very low. Between 800 and $1,900 \mathrm{~nm}$, reflectance declines sharply and is very sensitive to snow grain size. The larger and more rounded the grains, the lower the reflectance in this range. Variation of albedo from 0.9 to 0.5 is an important factor for the surface energy balance for plants and animals.

Male (1980) notes that in field conditions the albedo is primarily a function of snow grain size, whether the surface is illuminated by diffuse radiation or direct sunlight, contamination, and the roughness of the surface. In general the spectral reflectance of fresh snow is high, and once snow has thawed reflectance decreases. Refreezing of snow cover causes no notable change in albedo although contaminants such as soil dust can lower albedo (Conway, Gades, and Raymond, 1996). Warren (1982) calculated that 


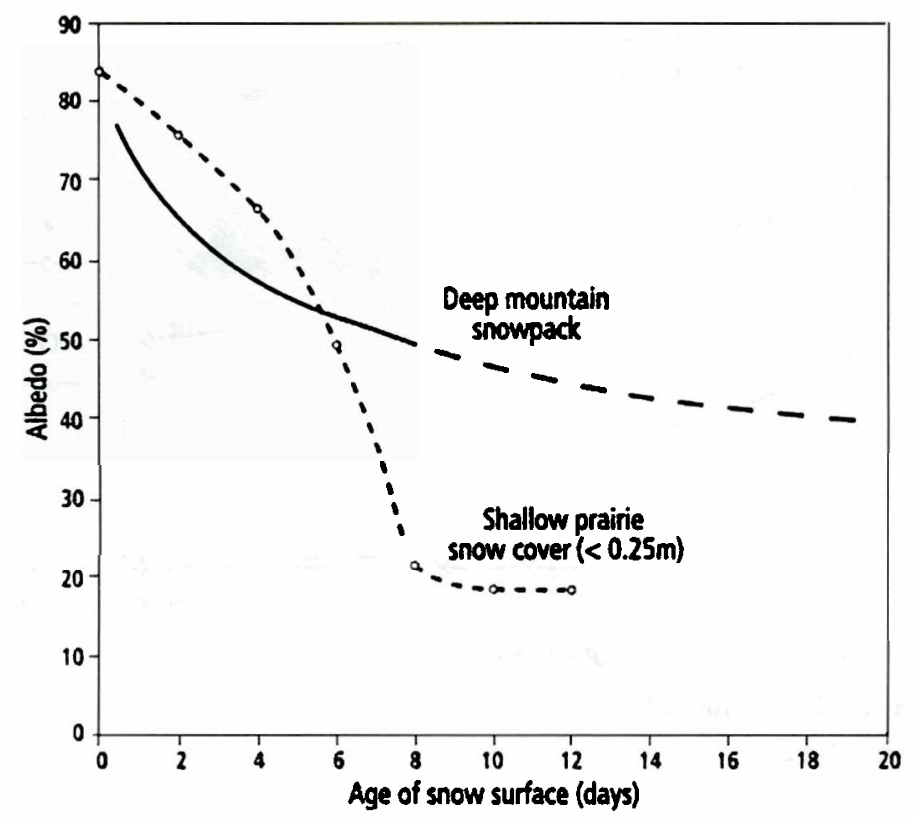

Figure 2.20. Variation in albedo, expressed as percent, over time for melting snowpacks in the mountains (deep) and prairies (shallow) (O’Neill and Gray; 1973).

0.1 percent of volcanic ash in snow will decrease peak albedo in the visible wavelengths from 0.95 to 0.4 for $1-\mathrm{mm}$-radius snow grains. Albedo in polar climates can increase with time as blowing snow shatters snow crystals and reduces grain size on the surface (Liljequest, 1956). However, albedo in subpolar climates decays with time since the last snowfall, with very different decay rates for shallow and deep snowpacks as shown in Figure 2.20. As snow covers less than $30 \mathrm{~cm}$ deep melt, the underlying ground begins to influence the areal albedo, as shown in the data of O'Neill and Gray (1973) for Canadian Prairie snowpacks; the decrease in the actual snow albedo, however, is much less than that of the areal value as wet, bare ground has an albedo of about 0.1. For shallow snow covers in continental environments, a seasonal decrease in albedo of 0.0061 per day has been observed during the premelt period ( 1 February to melt) and 0.071 per day during melt, dropping to an average value of 0.17 when the surface is free of snow (Granger and Gray, 1990). Snow intercepted in coniferous canopies has no effect on the areal albedo of forests despite the high reflectance of individual intercepted snow clumps (Pomeroy and Dion, 1996) because these canopies act as light traps, retaining most incoming solar radiation and therefore warming above ambient air temperatures when the incoming solar radiation flux is notable. Under coniferous 
forest canopies albedo is strongly controlled by accumulation of leaf litter on the snow surface and on reduction in snow-covered area during melt.

Over snow surfaces exposed to the atmosphere, outgoing long-wave radiation is generally larger than incoming radiation, leading to a net loss of long-wave radiative energy from the snow cover (Male and Granger, 1979). However, under forest canopies, or when warm air masses enter a previously cold area, a downward net long-wave flux can develop. Incoming long-wave radiation depends on the temperature of the emitting surface (upper atmosphere, cloud layer, or plant canopy) and generally is greater on cloudy days and in forested environments where conifers absorb shortwave radiation and radiate long-wave radiation (Male, 1980). The downward long-wave flux from canopies increases with increasing solar angle because shortwave radiation penetrates further into the canopy and therefore warms the lower branches, which then emit longwave radiation toward the underlying snowpack (Pomeroy and Dion, 1996). Emitted long-wave radiation is proportional to the fourth power of surface temperature and may be calculated from the Stefan-Boltzmann law

$$
L \uparrow=\varepsilon_{\mathrm{s}} \sigma T_{\mathrm{s}}^{4}
$$

where $\varepsilon_{\mathrm{s}}$ is the surface emissivity, $\sigma$ is the Stefan-Boltzmann constant $(5.67 \times$ $\left.10^{-8} \mathrm{~W} \mathrm{~m}^{-2} \mathrm{~K}^{-4}\right)$, and $T_{\mathrm{s}}$ is the absolute temperature of the surface (K). The emissivity of snow is generally taken as 0.98 , although Warren (1982) shows that it varies from 0.975 to 0.995 with radiation wavelength over the range 3 to $15 \mu \mathrm{m}$ and varies from 0.96 to 0.99 with snow grain size at wavelengths above $15 \mu \mathrm{m}$.

The radiation balance over snow shows wide variations because of cloud cover, forest canopy, and topography. The simple situation of melting snow over an open area of low relief is shown in Figure 2.21 (Granger and Male, 1978). The first two days are clear, followed by continuous cloud on the third day. Fog occurs for a period on the first day. The high snow albedo causes the reflected shortwave flux to be the same magnitude as incoming shortwave radiation. Incoming and outgoing long-wave radiation are also of similar magnitude. Outgoing long-wave radiation remains nearly constant because of the limited range of surface temperatures during melt.

The example shown in Figure 2.21 contrasts with nonmelting snow where longwave cooling at night and the low thermal conductivity of the snowpack cause the snow surface temperature and hence outgoing long-wave radiation to drop dramatically. Under coniferous forests, the net shortwave flux to snow decreases sharply with increasing canopy density and can be an order of magnitude less than incoming radiation to the canopy top under mature coniferous canopies. The daily mean net radiation flux decreases with increasing canopy density up to canopy densities of about 


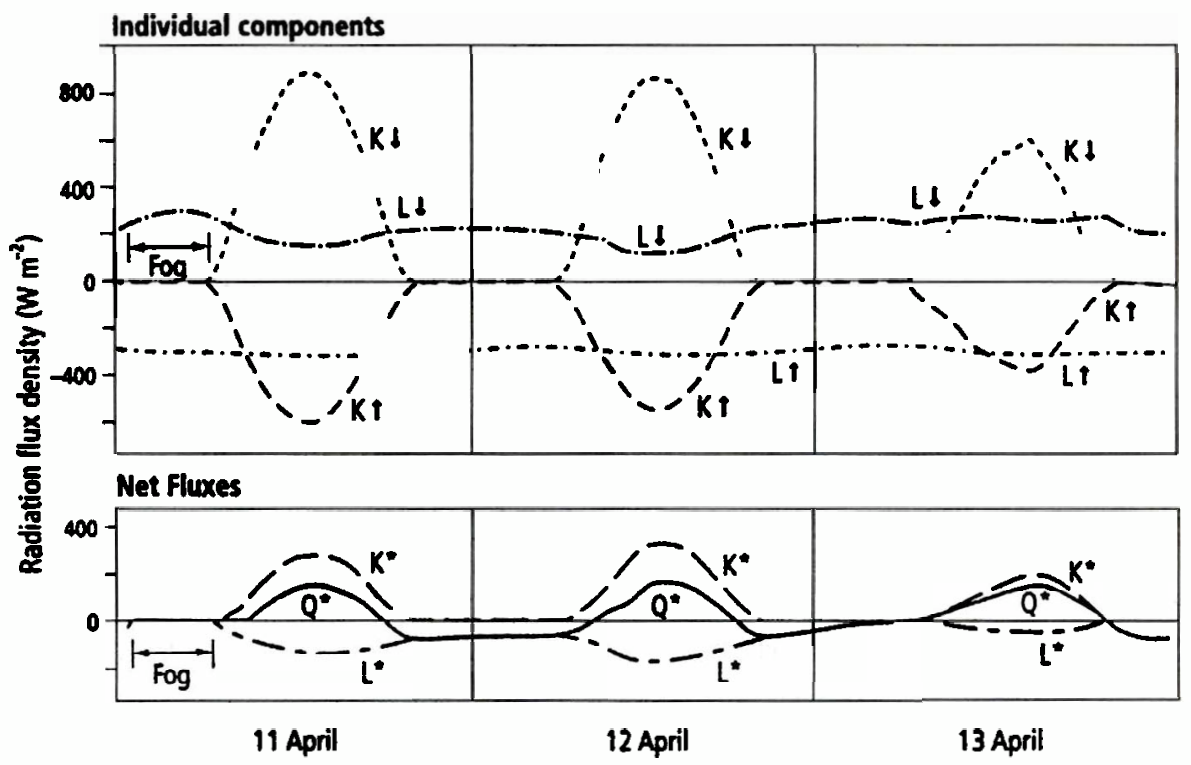

Figure 2.21. The component fluxes of incoming $(K \downarrow, L \downarrow)$ and outgoing $(K \uparrow, L \uparrow)$ shortwave and long-wave radiation, respectively, and the radiation balance (net) of all-wave $\left(Q^{*}\right)$, shortwave $\left(K^{*}\right)$, and long-wave $\left(L^{*}\right)$ radiation during 3 days over a melting prairie snow cover. Day 1, fog then clear; day 2, clear; day 3, cloud cover (from Granger and Male, 1978).

60 percent, whence the flux rises. Net radiation at the snow surface can be significantly greater in a deciduous forest than in an open area because of emission of long-wave radiation from the canopy.

The turbulent fluxes of sensible $\left(Q_{\mathrm{H}}\right)$ and latent $\left(Q_{\mathrm{E}}\right)$ heat are also important to the energy balance of a snow cover. Sensible heat is derived from atmospheric heat energy, and its flux is the rate at which heat is carried to or from the snow surface by atmospheric turbulence. Latent heat is that released by sublimation or evaporation at the snow surface, and its flux is the rate at which water vapour is carried to or from the snow surface by atmospheric turbulence. The fluxes of sensible and latent heat depend on the respective vertical gradients of temperature and humidity in the atmosphere and turbulent transfer of heat and water vapour at the snow surface. Wind, temperature, and humidity gradients above snow covers are normally not available, requiring the use of bulk transfer calculations to estimate $Q_{H}$ and $Q_{\mathrm{E}}$. Male (1980) reports that bulk transfer formulae are generally poor estimators of the latent heat flux over snow, as the atmospheric water vapour pressure at one level above the snow surface provides insufficient information to accurately define a gradient and therefore 
the water vapour flux. Male and Granger (1979) do report correlations between daily totals of sensible heat estimated by profile and bulk transfer approaches; however, significant differences can exist on any single day.

Bulk transfer equations for estimating turbulent fluxes take the form

$$
Q_{\mathrm{H}}=D_{\mathrm{H}} u_{\mathrm{z}}\left(T_{\mathrm{a}}-T_{\mathrm{s}}\right), \quad Q_{\mathrm{E}}=D_{\mathrm{E}} u_{\mathrm{z}}\left(e_{\mathrm{a}}-e_{\mathrm{s}}\right)
$$

where $T$ is air temperature $\left({ }^{\circ} \mathrm{C}\right) ; u_{\mathrm{z}}$ is wind speed at height $z ; e$ is water vapour pressure $(\mathrm{mb})$, subscripts a and $\mathrm{s}$ denote air and snow surface, respectively; $D_{\mathrm{H}}$ is the convective heat bulk transfer coefficient $\left(\mathrm{kJ} \mathrm{m}^{-3}{ }^{\circ} \mathrm{C}^{-1}\right)$; and $D_{\mathrm{E}}$ is the latent heat bulk transfer coefficient $\left(\mathrm{kJ} \mathrm{m}^{-3} \mathrm{~Pa}^{-1}\right)$. In eastern Canada, Gold and Williams (1961) found $D_{\mathrm{H}}$ to be 0.015 and $D_{\mathrm{E}}$ to be 0.025 for $u_{\mathrm{z}}$ at $2 \mathrm{~m}, T_{\mathrm{a}}$ at $1.2 \mathrm{~m}$, and $e_{\mathrm{a}}$ measured independently. For melting snow in western Canada, $D_{\mathrm{H}}$ is approximately 0.007 and $D_{\mathrm{W}}$ is approximately 0.0052 for $1-\mathrm{m}$ measurement heights ( $\mathrm{z}$ and $\mathrm{a}$ ); notable variation from these values may be expected depending on stability, fetch distance, and uniformity of terrain.

For continuous snow covers in open environments, the direction of latent heat flux is controlled by the direction of net radiation with cycles of condensation at night and evaporation during the day. Male and Granger (1979) report daily net evaporation rates (less condensation) in central Saskatchewan ranging from 0.02 to $0.3 \mathrm{~mm}$ of SWE/day with a mean of $0.1 \mathrm{~mm}$ of SWE/day. These fluxes removed for 14 to 22 percent of the incoming energy to the snow cover.

For discontinuous snow covers in open environments, local advection of sensible energy from bare ground to snowpatches becomes an important component of snowpack energy balance. Gray and O'Neill (1974) report that sensible heat transfer supplied 44 percent of the incoming energy to an isolated snowpatch; when surrounded by continuous snow cover this value drops to 7 percent. The model developed by Liston (1995) shows a 30 percent increase in energy inputs to melting snow as the area of exposed ground increases. The energy inputs also increased with increasing patchiness of snow. Shook and Gray (1996) show that the patchiness of snow during melt can be described mathematically by the mean and coefficient of variation of snow depth before melt begins. Areas of deciduous vegetation (grain stubble, tall grasses, shrubs) collect deep, even snow covers with low coefficient of variation of SWE. Snow in such taller vegetation will remain less patchy during melt than snow over short vegetation, prolonging the melt period compared with poorly vegetated sites with similar snow depth. Local advection of energy driven by turbulent transfer from very tall $(2-3 \mathrm{~m})$, brushy vegetation stalks to underlying snowpacks caused snowpacks in clear-cuts to melt five times faster than that in adjacent mature forest canopies in the southern 
boreal forest of western Canada and resulted in a 2-week shorter snow season in cleared lands compared with natural forest (Pomeroy and Granger, 1997).

\subsubsection{Soil Boundary}

The ground heat flux to snow on a daily basis is typically considered to be a small component of the energy balance. However, because it is persistent, it can have an important cumulative effect early in the melt season in retarding or accelerating the time of melt and in affecting the intranivean environment. Incorrect calculation of ground heat flux can therefore significantly change the estimated timing and magnitude of snowmelt. In locations with incompletely frozen soils, the ground heat flux is positive; Gold (1957) measured up to $860 \mathrm{~kJ} \mathrm{~m}^{-2}$ per day moving from warm soils to melting snow near Ottawa. However, in the Arctic the flux is negative in late winter; recent measurements showed a peak of $-900 \mathrm{~kJ} \mathrm{~m}^{-2}$ per day during snowmelt over frozen permafrost soils near Inuvik, Northwest Territories. Marsh and Woo (1987) report similarly elevated levels from permafrost near Resolute, Northwest Territories. The large negative ground heat flux plays a major role in delaying the snowmelt season in northern Canada despite high sensible and radiant heat fluxes.

The ground heat flux is not completely due to the temperature gradient and thermal conductivity of soils; infiltration of meltwater into soils can involve a significant energy flow, especially if the meltwater refreezes in frozen soils, releasing latent heat. Infiltration may result in a warming of upper soil layers, an increase in apparent thermal conductivity, and further melting of frozen soil water or refreezing of meltwater in the frozen soil (Zhao, Gray, and Male, 1997). The refreezing of meltwater at the soil-snow interface, forming a basal ice layer, releases a significant quantity of latent heat and is a distinctive characteristic of melting Arctic snow covers (Woo, Heron, and Marsh, 1982). These phenomena change the ground heat flux by transferring sensible heat to the soil and absorbing or releasing latent heat. Hence, in an unsaturated frozen soil, infiltration and refreezing of meltwater in soils may reduce the ground heat flux from large negative to very small values (smaller than $-10 \mathrm{~W} \mathrm{~m}^{-2}$ ). Rouse (1990) divides the ground heat flux for frozen soil into that due to the change in storage of sensible heat and the change in storage of the latent heat of fusion in ground ice; however, relatively few values for these individual components are available. Male and Granger (1979) measured net daily ground heat flux from 454 to $-378 \mathrm{~kJ} \mathrm{~m}^{-2}$ per day over 3 years in central Saskatchewan during melt over frozen soils, with strong variation from year to year. Granger and Male (1978) note that the soil heat flux on the prairies shows a diurnal cycle that lags the radiation cycle and is of opposite sign. As shown in Figure 2.22, when snowmelt begins, this 


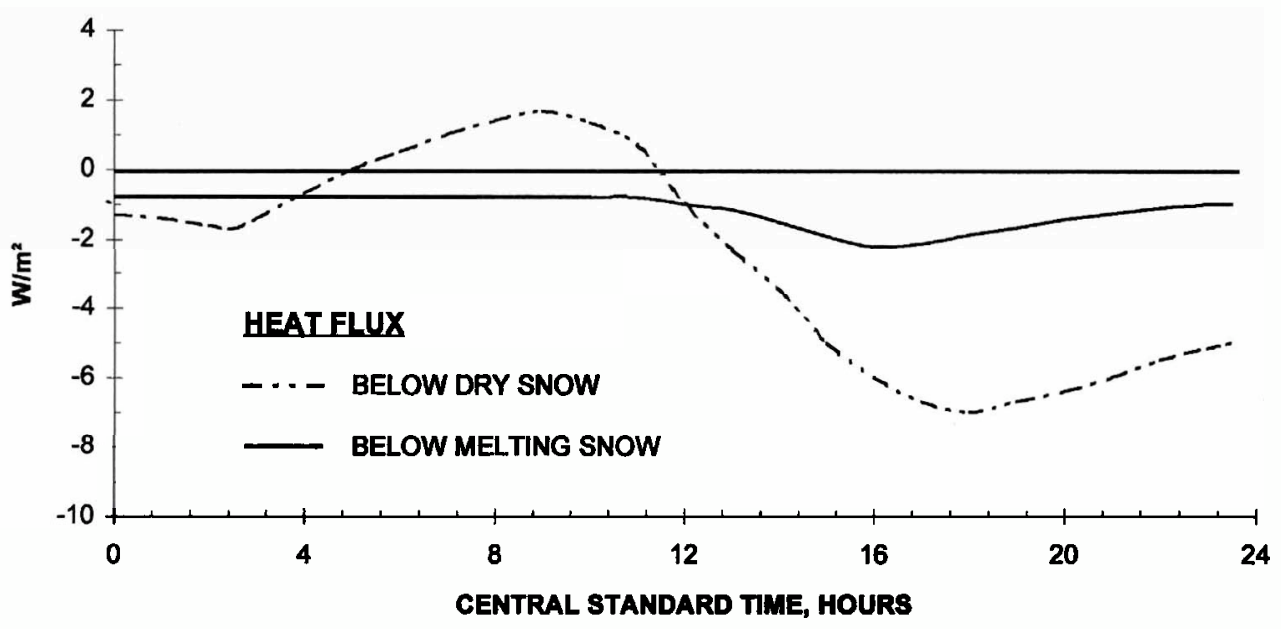

Figure 2.22. Soil heat flux below a shallow prairie snowpack for dry snow and for melting (wet) conditions. Note that, after the meltwater reaches the soil and is refrozen, the soil heat flux is dramatically dampened (after Granger and Male, 1978).

diurnal cycle is almost completely eliminated because of meltwater's refreezing in frozen soils.

\subsubsection{Internal Energetics}

Most of the energy exchanges between snow and its environment occur at the atmosphere or ground interfaces; however, because snow is porous, some radiation and convective fluxes occur within the top few centimetres of the snowpack. The important fluxes that can directly penetrate the snowpack are radiation, conduction, convection, and meltwater or rainwater percolation. Phase change within the snowpack complicates the discussion of internal energetics but can be extremely important for life forms requiring liquid water (see Hoham and Duval, Chapter 4) or as media for chemical reactions (see Tranter and Jones, Chapter 3).

Whilst most shortwave radiation is reflected by snow, part of the solar radiation flux penetrates the snowpack and is absorbed a few centimetres beneath the surface. The penetration and extinction of incoming shortwave radiation is of prime importance to the development of life within the snowpack. Sergent et al. (1987) measured the spectral extinction of radiation as a function of snow grain size and density; the results permit the theoretical description of radiation penetration through snow. Figure 2.23 shows irradiance penetration of natural light as a function of wavelength for various depths in a snowpack with $100-\mu$ m-radius spherical grains and a density of $200 \mathrm{~kg} \mathrm{~m}^{-3}$. 


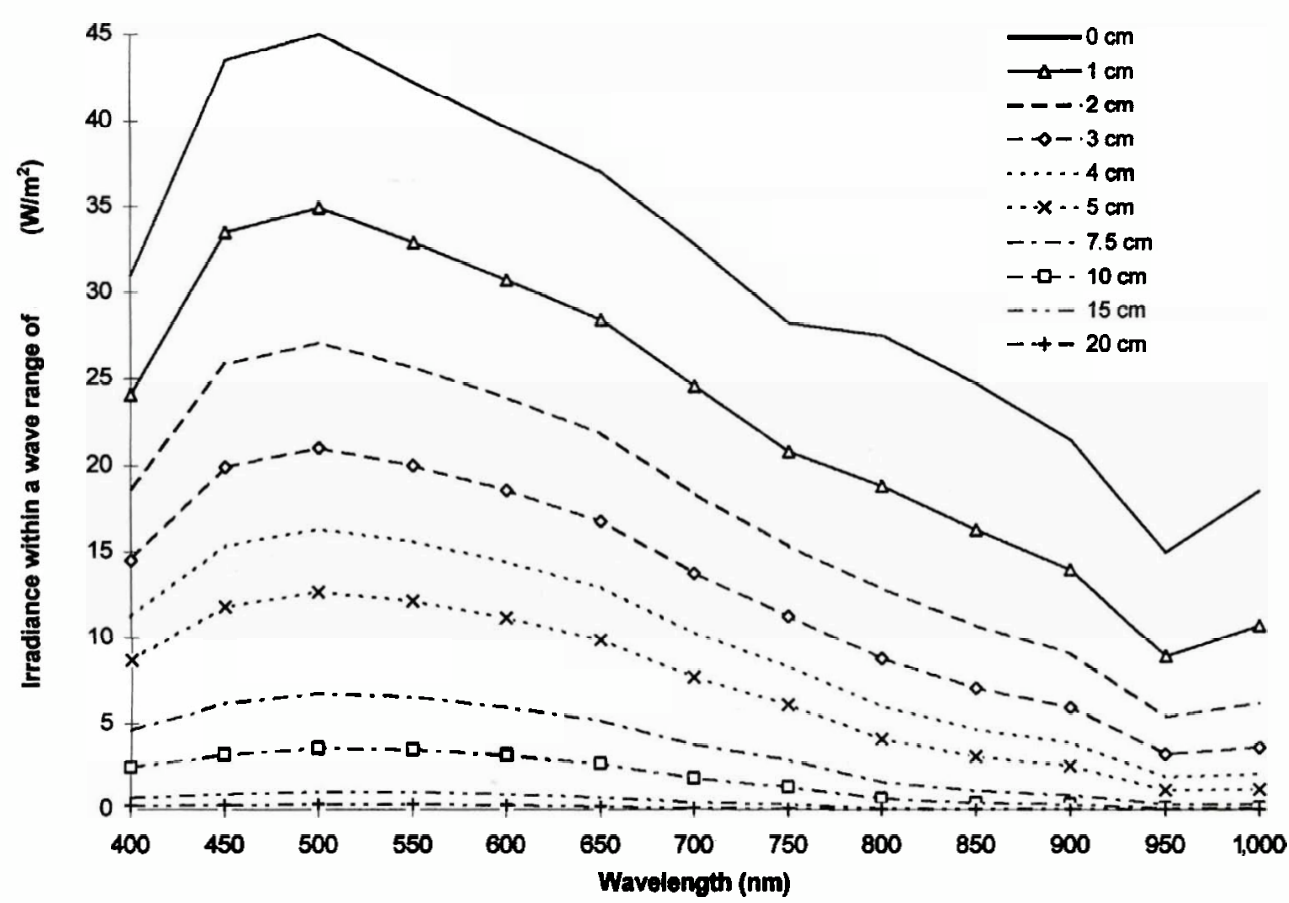

Figure 2.23. Solar irradiance within the snowpack as a function of wavelength for various depths in a clean snowpack composed of uniform spherical snow grains of $200 \mu \mathrm{m}$ diameter and a density of $200 \mathrm{~kg} \mathrm{~m}^{-3}$.

Within the wavelength range of $400-1000 \mathrm{~nm}$, significant radiation penetrates to almost $20 \mathrm{~cm}$ below the surface. The maximum irradiance at depth occurs for a wavelength of about $500 \mathrm{~nm}$ because of the combined effect of the distribution of the solar spectrum and the spectral absorption characteristics of ice. Figure 2.24 shows the differing effects of heavy, wet and loose, dry snow on irradiance for two different wavelength bands. The larger grain size associated with wet snow (500- $\mu \mathrm{m}$ radius) permits deeper penetration in the visible light wavelengths; however, the additional energy is relatively small at less than $3 \mathrm{~W} \mathrm{~m}^{-2}$ for most depths and an insignificant difference near the surface and near $20 \mathrm{~cm}$ below the surface. The coarser grains found in preferential meltwater flow paths promote greater irradiance at depth in these paths; this irradiance is the basis of a technique to map macro flow paths in snowpacks (McGurk and Marsh, 1995).

Dry snow undergoes thermal conduction, thermal convection (where temperature gradients are extreme), and windpumping (in windswept areas), which govern the heat flux between the bottom and top of the snow cover (Sturm, 1991; Colbeck, 1989). 


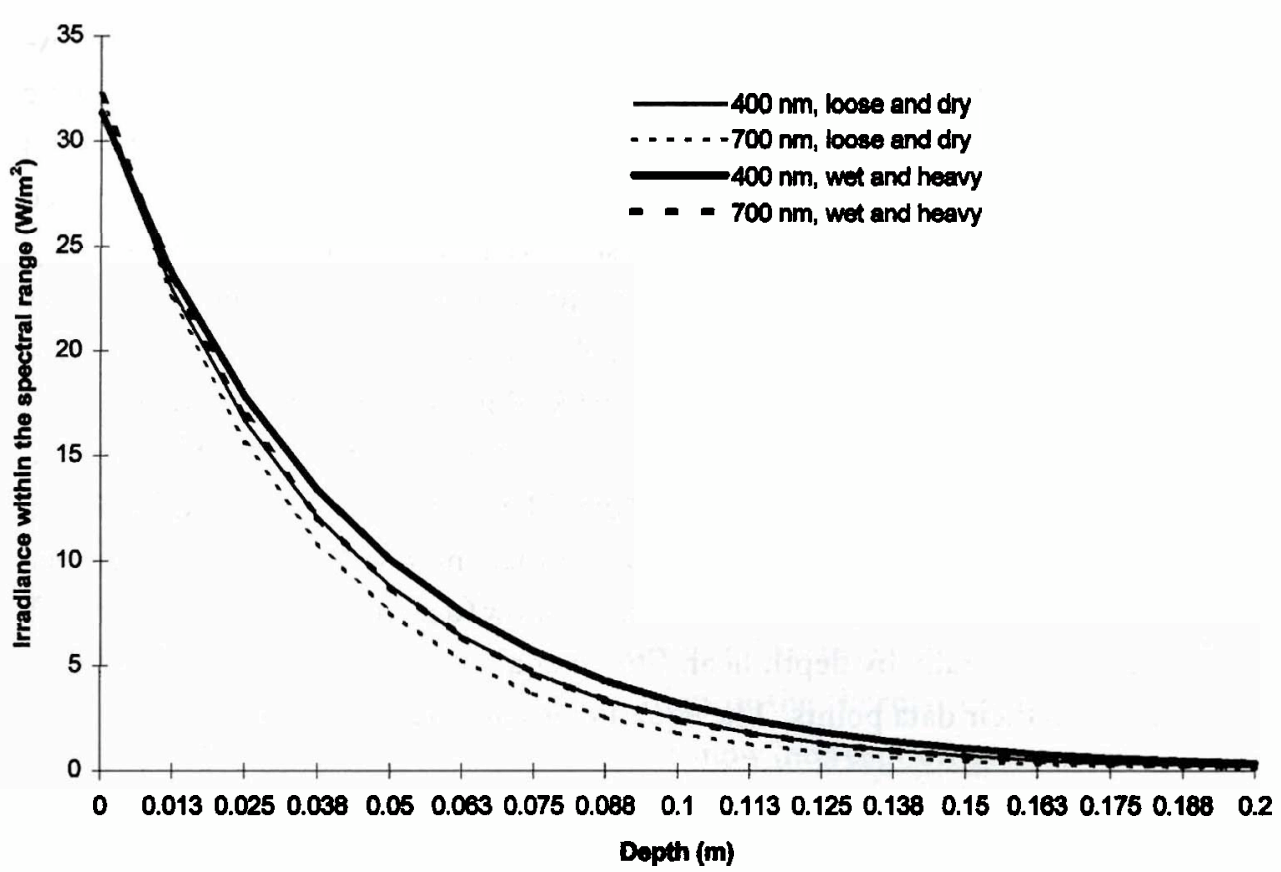

Figure 2.24. Solar irradiance within the snowpack as a function of snow structure. Two structure types are shown: heavy and wet (density $=400 \mathrm{~kg} \mathrm{~m}^{-3}$, grain size $=500-\mu \mathrm{m}$ radius), and loose and dry (density $=200 \mathrm{~kg} \mathrm{~m}^{-3}$, grain size $=1-\mathrm{mm}$ radius) for two wavelengths of 50 -nm bandwidth.

Temperature gradients in dry snow covers induce water vapour gradients and consequently diffusion of water vapour from warmer parts to colder parts. When temperature gradients exceed $10^{\circ} \mathrm{C} \mathrm{m}^{-1}$, complete "destructive" ice crystal sublimation and recrystallisation occur as water vapour moves along the gradient (Colbeck, 1987). The corresponding sublimation or condensation necessary to maintain a thermodynamic equilibrium involves fluxes of latent heat, which account for between 10 and 40 percent of heat transport in snow (Yosida et al., 1955). These fluxes are generally taken into account as an "effective" thermal conductivity that combines all heat transfer mechanisms.

The low thermal conductivity of snow, compared with other types of materials, is of primary importance in the protection of intranivean and subnivean life from severe winter conditions (Aitchison, Chapter 5). The thermal conductivities of air and ice at $-15^{\circ} \mathrm{C}$ are about 0.023 and $2.2 \mathrm{~W} \mathrm{~m}^{-1} \mathrm{~K}^{-1}$, respectively; that of snow must lie between these value. Thermal insulation by the snow cover depends strongly on its depth but also on the crystal structure and density of the surface layers. The dependence on 
density is due to the effective thermal conductivity of snow, which increases approximately with the square of density except for low-density snow reformed by kinetic temperature gradient metamorphism. The nonlinear relationship between thermal conductivity and density causes the thermal insulation of an inhomogeneous, layered snowpack to be higher than that of a uniform snowpack of the same depth and density. Sturm et al. (1997) have reviewed thermal conductivity studies over the last century and supplemented these with a new large set of observations for a variety of snow types. They found that effective thermal conductivity $\left(K_{\text {eff }}\right)$ increased from $0.05 \mathrm{~W} \mathrm{~m}^{-1} \mathrm{~K}^{-1}$ for low-density fresh snow (density $\approx 100 \mathrm{~kg} \mathrm{~m}^{-3}$ ) to $0.6 \mathrm{~W} \mathrm{~m}^{-1} \mathrm{~K}^{-1}$ for dense drifted snow (density $\approx 500 \mathrm{~kg} \mathrm{~m}^{-3}$ ). The data and confidence intervals indicated by Sturm et al. are shown in Figure 2.25 and substantiate that there is little relation between thermal conductivity and density for low-density snow (density $<200 \mathrm{~kg} \mathrm{~m}^{-3}$ ), which is dominated structurally by depth hoar. Sturm et al. also fitted an empirical regression equation to their data points. The equation is consistent with the earlier work of

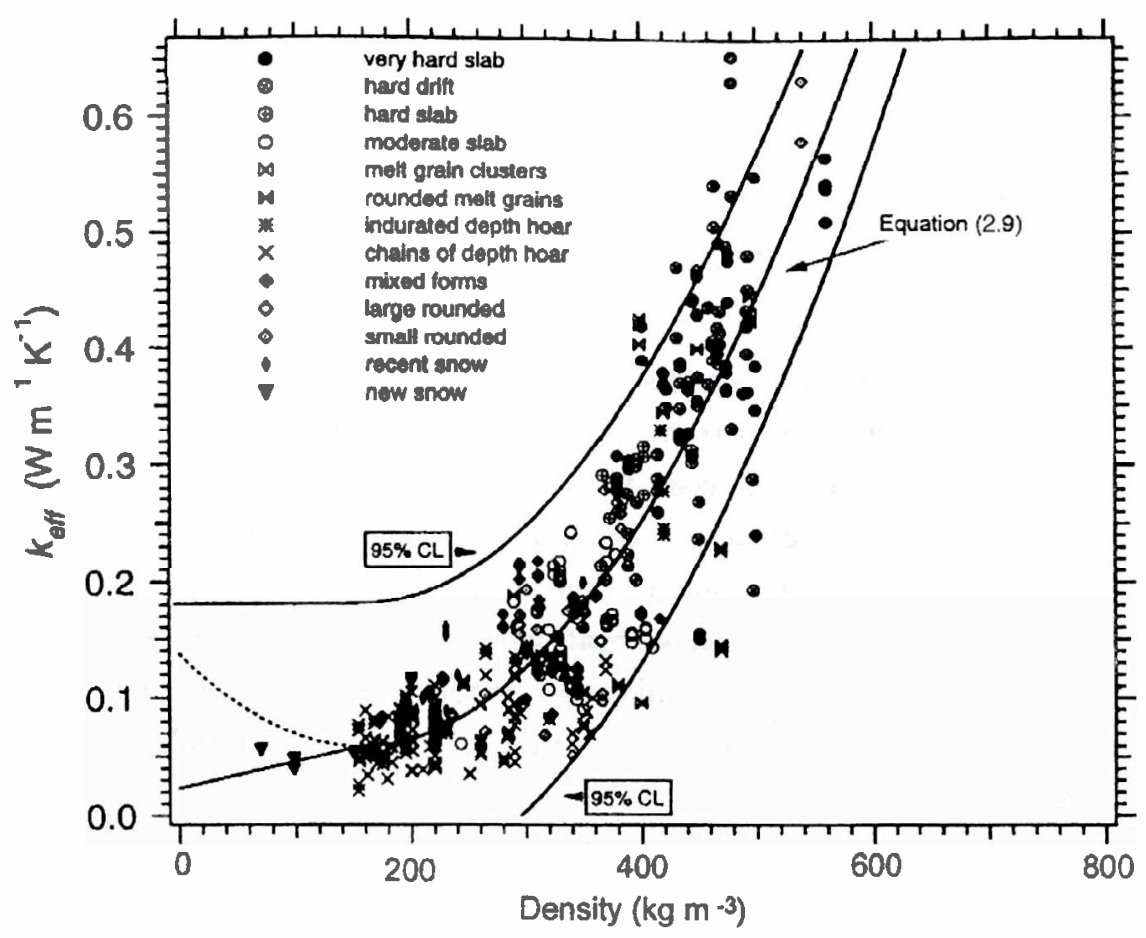

Figure 2.25. Effective thermal conductivity of snow as a function of snow crystal type and snow density, along with Equation 2.9 plotted with its confidence intervals (CI). For a discussion of snow crystal classification, see Section 2.4 in this chapter (after Sturm et al., 1997). 
Yosida et al. (1955) and is

$$
\begin{aligned}
& k_{\text {eff }}=0.138-\frac{\rho}{990}+\frac{\rho^{2}}{309} \quad \text { for } 156 \leq \rho \leq 60 \\
& k_{\text {eff }}=0.023+\frac{\rho}{4273} \quad \text { for } \rho<156 \mathrm{~kg}
\end{aligned}
$$

Temperature regimes in dry snowpacks are exceedingly complex and are controlled by a balance of the energy regimes at the top and bottom of the snowpack, radiation penetration, effective thermal conductivity of snow layers, water vapour transfer, and latent heat exchange during metamorphism. Finite difference, energy, and mass balance models (e.g., Anderson, 1976) have been used to simulate many of the important energy transfers. SNTHERM (Jordan, 1991) contains a relatively complete and accurate physical description and is increasingly popular. Beyond the scope of regimes predicted by point models, horizontal and vertical inhomogeneities in natural snow cover cause substantial spatial variation in the thermal regime of snowpacks. For instance, lower accumulation because of snow interception occurs under isolated conifers, resulting in shallow, cold snowpacks near these trees (Sturm, 1992). Temperature stratification within dry snowpacks is usually unstable (warm temperatures lying below cold temperatures) from formation until late winter and spring, as energy inputs from the soil boundary exceed those from the atmosphere and upper layers. As a result temperatures become warmer with depth, with gradients as high as about $50^{\circ} \mathrm{C} \mathrm{m}^{-1}$ in shallow subarctic and arctic snowpacks during early midwinter. In cold climates with frozen soils, an inversion can develop in late winter where the upper snowpack warms to higher temperatures than the lower layers; this reflects higher energy inputs from the atmosphere (often due to long sunlit periods in the northern spring) than from the frozen soil.

For a given climate, the thermal regime in the snowpack strongly depends on the amount of snowfall early in the winter season. This is illustrated in Figure 2.26 with the evolution of the temperature throughout a snowpack over a winter period in an alpine environment. The temperature is simulated by the snow model CROCUS from meteorological conditions observed in the French Alps during 1995-1996 at an altitude of $2,400 \mathrm{~m}$ above sea level. Figure $2.26 \mathrm{~b}$ shows the simulation with recorded snowfall, and Figure 2.26a and 2.26c correspond to simulations with 50 percent less and 50 percent more snowfall, respectively. In the period from mid-November to midDecember, the 50-cm-deep snowpack efficaciously keeps the bottom snow layer near the melting point (Figure 2.26c), whilst a 30-cm snowpack (Figure 2.26b) does not prevent the temperature from dropping as low as $-5^{\circ} \mathrm{C}$ in the bottom layer. For the 20-cm-deep snowpack the bottom layer reaches $-8^{\circ} \mathrm{C}$ (Figure 2.26a). Other factors 


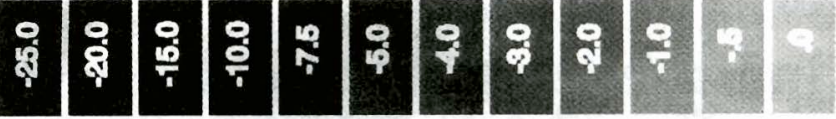
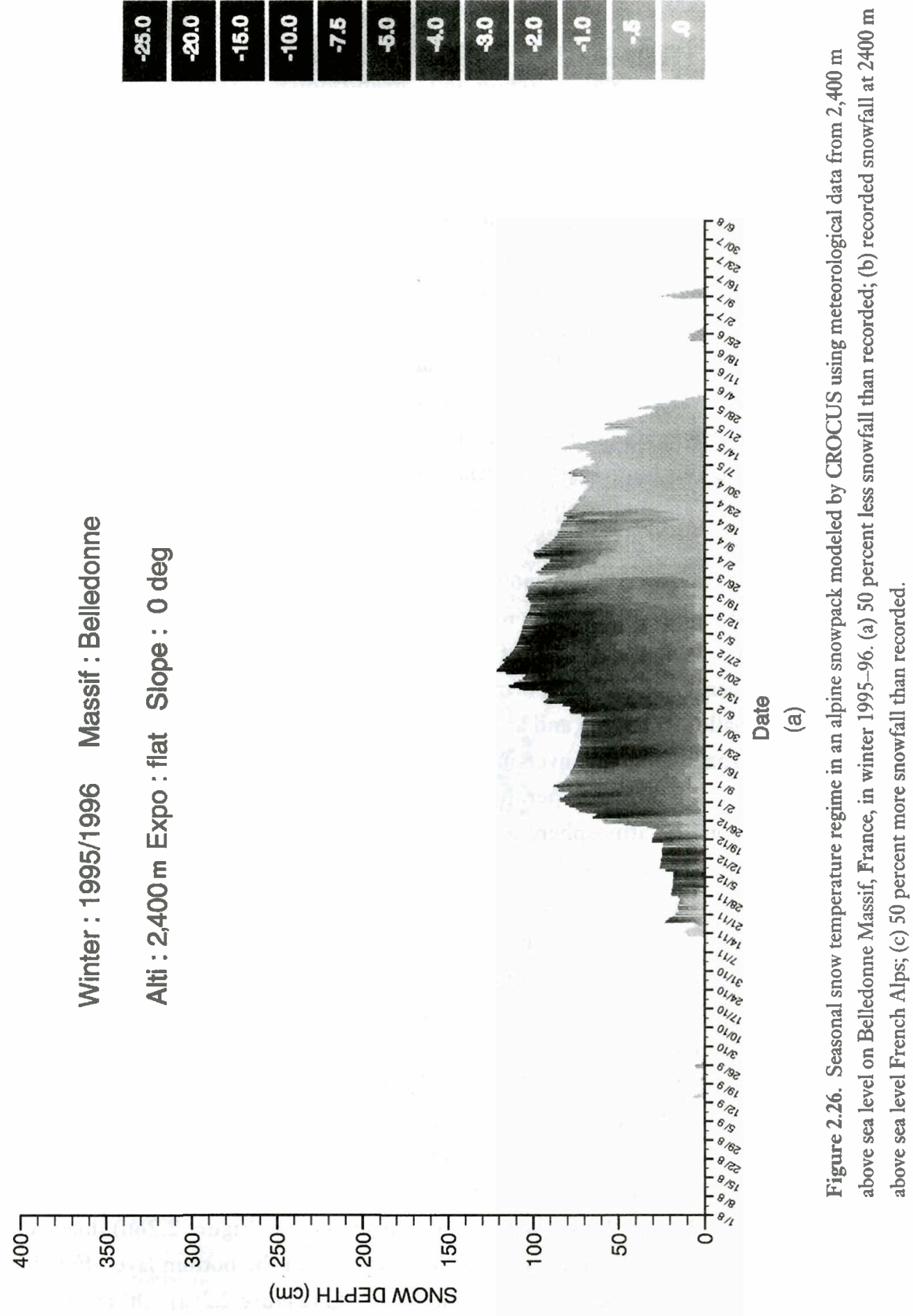


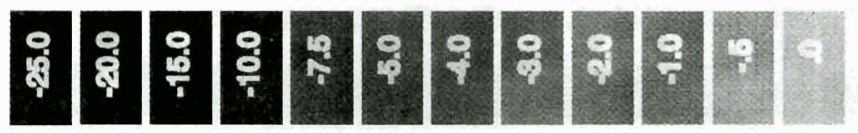

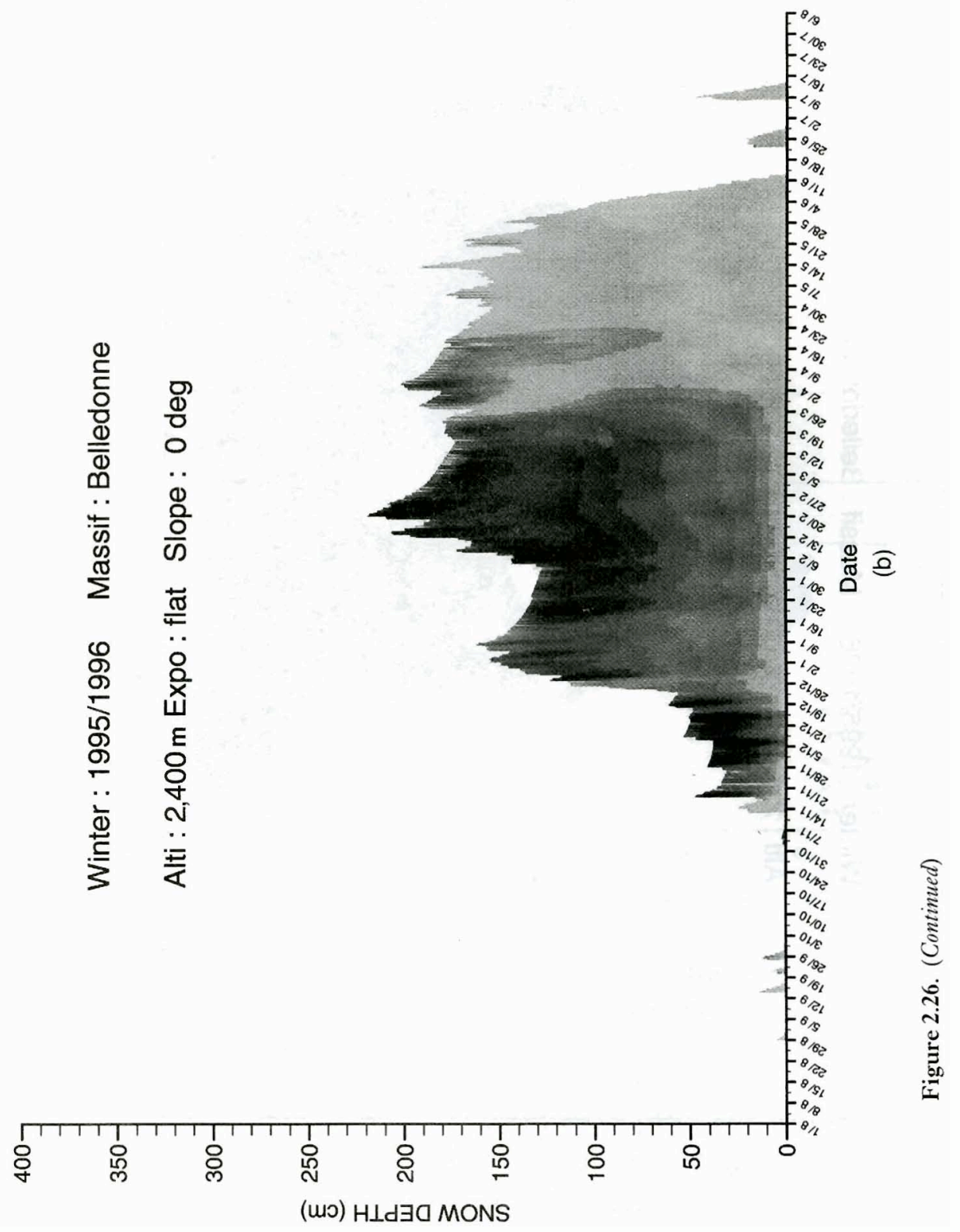




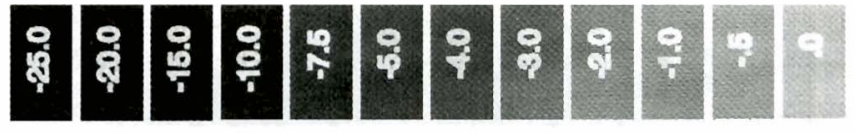

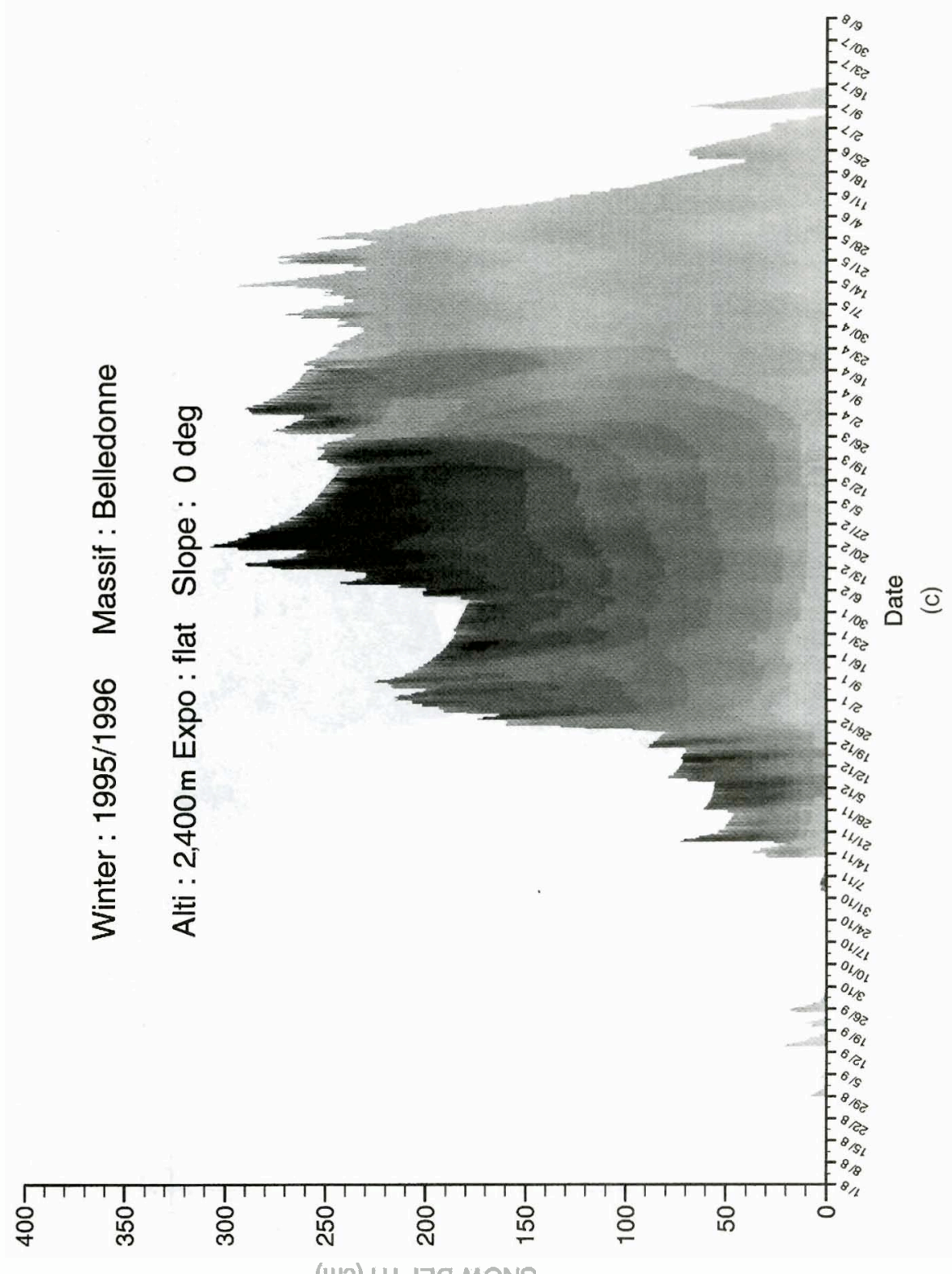

(uv) HLd $\exists G$ MONS 
can strongly influence the thermal regime in this environment. For a deep snowpack a midwinter rainfall would increase density and decrease depth. A doubling of density in such circumstances would reduce the thermal resistivity of the snowpack by a factor of eight!

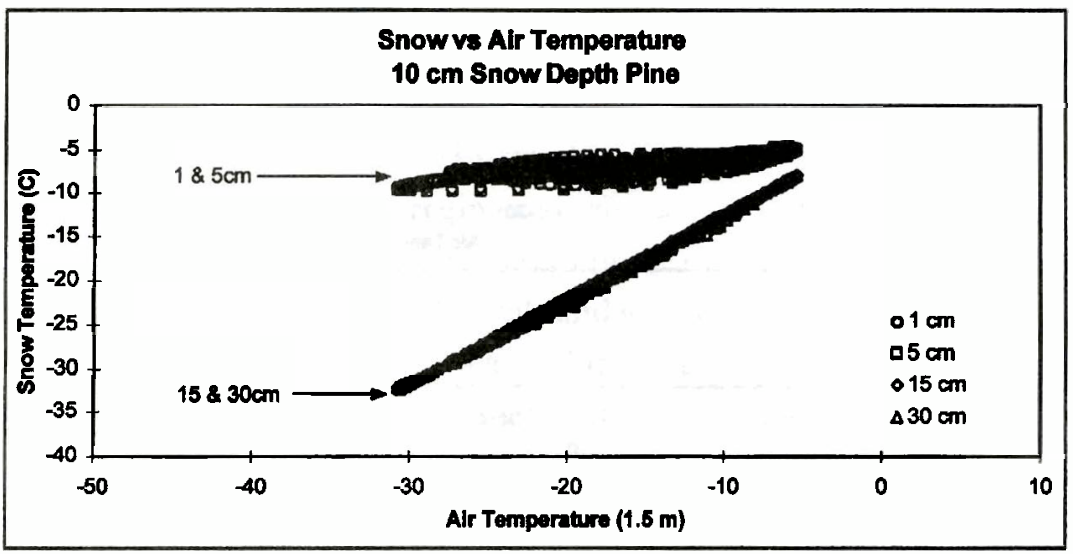

(a)

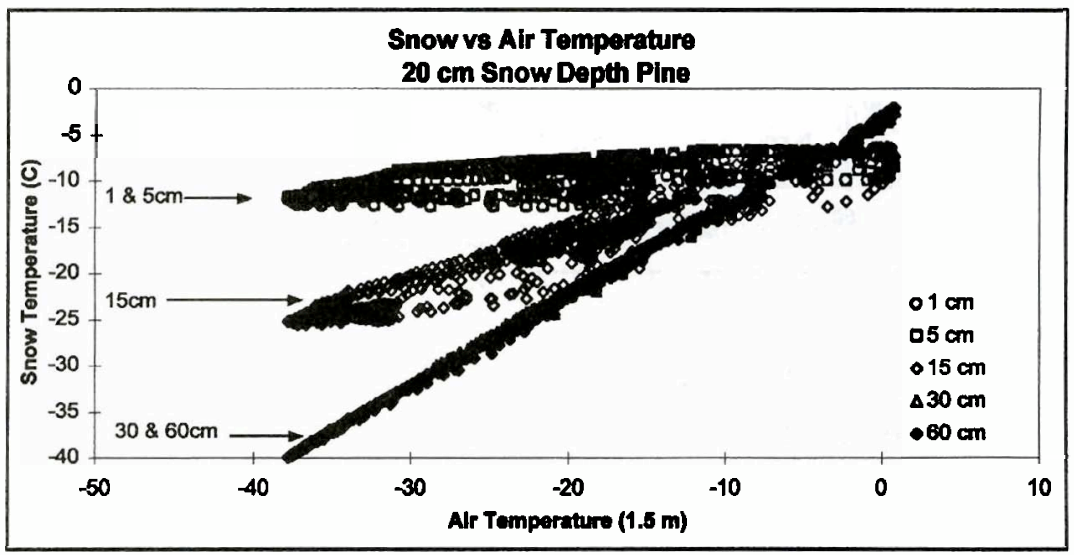

(b)

Figure 2.27. Thermal regime of a boreal forest snowpack. Temperatures measured half-hourly at various heights above the ground in Prince Albert National Park, Saskatchewan, Canada. Note that temperatures measured at heights greater than the snow depth listed for that period are air temperatures slightly above the snow surface rather than snow temperatures. (a) Early winter, $10 \mathrm{~cm}$ depth, $100 \mathrm{~kg} \mathrm{~m}^{-3}$ density; (b) early midwinter, $20 \mathrm{~cm}$ depth, $150 \mathrm{~kg} \mathrm{~m}^{-3}$ density; (c) midwinter, $30 \mathrm{~cm}$ depth, $180 \mathrm{~kg} \mathrm{~m}^{-3}$ density; (d) late winter, $30 \mathrm{~cm}$ depth, $200 \mathrm{~kg} \mathrm{~m}^{-3}$ density. Depths and densities varied over the period and values stated are approximate. 


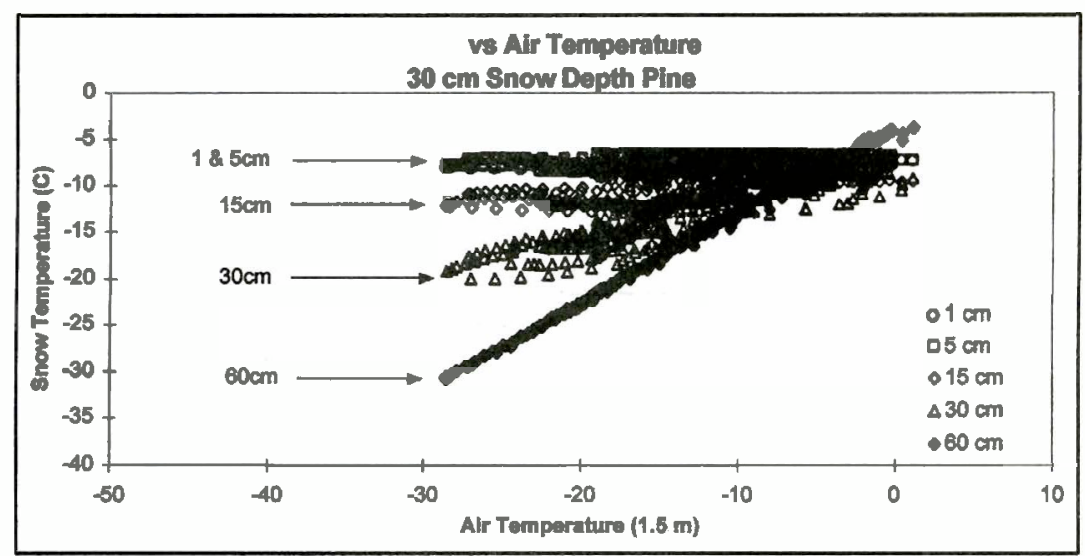

(c)

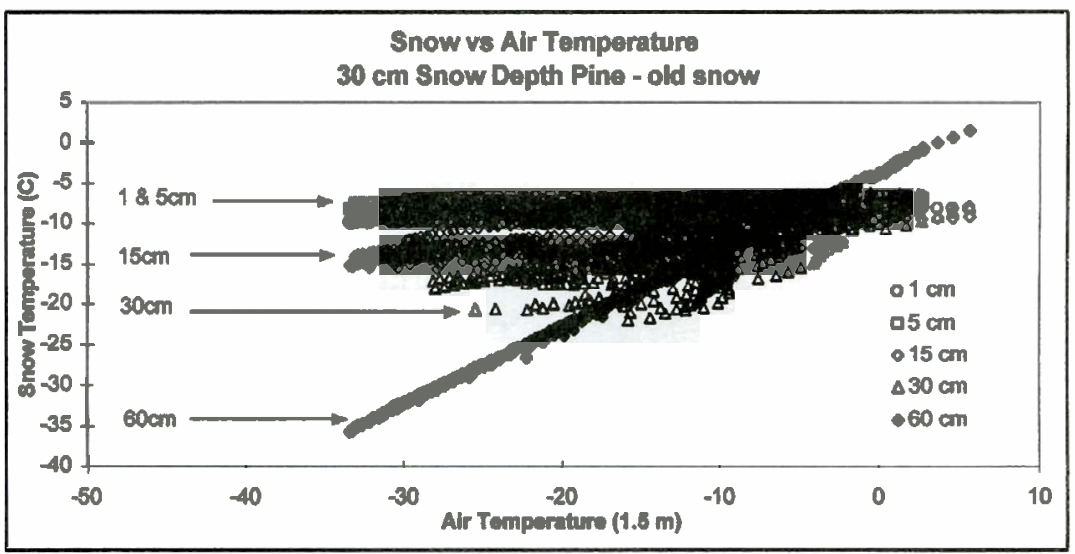

(d)

Figure 2.27. (Continued)

The progression of the thermal regime in a continental boreal forest snowpack is shown in Figure 2.27. Air temperatures, snow temperatures, and snow depth were measured half-hourly over a winter under a pine canopy in central Saskatchewan, Canada (Pomeroy et al., 1997b). The strong diurnal variation in air temperature permits an assessment of the thermal regime of natural snowpacks in severe environments. In early winter an extended period occurred where the snowpack depth and density were approximately $10 \mathrm{~cm}$ and $100 \mathrm{~kg} \mathrm{~m}^{-3}$, respectively; snow temperatures and air temperatures for this period are shown in Figure 2.27a. The temperatures at 1 and $5 \mathrm{~cm}$ above the ground varied from $-5^{\circ} \mathrm{C}$ to $-10^{\circ} \mathrm{C}$, whilst air temperatures just above the snow surface varied from $-8^{\circ} \mathrm{C}$ to $-33^{\circ} \mathrm{C}$, a substantial moderation and an 
indication that thermal moderation can develop under very shallow snowpacks. Later in winter, a 20 -cm-deep $150 \mathrm{~kg} \mathrm{~m}^{-3}$ snow cover developed. Snow temperatures in the bottom $5 \mathrm{~cm}$ varied in a similar manner to the earlier snow $\left(-7^{\circ} \mathrm{C}\right.$ to $\left.-13^{\circ} \mathrm{C}\right)$ and in the layer $15 \mathrm{~cm}$ above the ground from $-6^{\circ} \mathrm{C}$ to $-26^{\circ} \mathrm{C}$, whilst air temperatures varied from $-1^{\circ} \mathrm{C}$ to $-40^{\circ} \mathrm{C}$ (Figure $2.27 \mathrm{~b}$ ). Clearly the thermal moderation increases with depth from the snow surface and decreases with distance from the ground. When a 30-cm-deep snowpack develops, the degree of thermal moderation at the lowest layers increases, with snow temperatures at 1 and $5 \mathrm{~cm}$ of $-7^{\circ} \mathrm{C}$ to $-9^{\circ} \mathrm{C}$ for an air temperature range from $-4^{\circ} \mathrm{C}$ to $-30^{\circ} \mathrm{C}$ (Figure 2.27c). However, at air temperatures greater than $-15^{\circ} \mathrm{C}$, the temperature regimes at various depths become difficult to distinguish and snow temperatures can be exceeded by air temperatures. This reduced thermal stratification is indicative of colder soils and a smaller soil heat flux as winter progresses. The thermal stability that develops due to cold soils in later winter can promote snow temperatures consistently below that of air temperatures as shown in Figure $2.27 \mathrm{~d}$ for a $30-\mathrm{cm}$-deep snowpack with a density of $200 \mathrm{~kg} \mathrm{~m}^{-3}$. Points to the right of a 1:1 line between air and snow temperature indicate conditions when the snowpack is colder than the air. Until melt occurs, the thermal insulation of the snowpack will cause the intranivean and subnivean environments to be sometimes colder than the supranivean environment.

The alpine snow temperature simulation shown in Figure 2.26 showed intranivean temperatures near the melting point from March until the end of melt in June. In this situation the energy inputs to the snowpack have raised its temperature to the melting point and further energy inputs are used to satisfy the latent heat associated with phase change. However, unsteady weather conditions, diurnal variations in the energy status of a snowpack, and stratification of a snowpack cause the internal energetics during melt to be quite complex. Subarctic and arctic snowpacks can undergo melt in upper layers whilst sustaining snow temperatures significantly below freezing in the lower layers. Internal heat fluxes in wet snow, or in partially wet snow, are principally controlled by conduction and by latent heat release due to refreezing of liquid water. In most snow covers, flow initiates along preferential flow paths, in which "flow fingers" may penetrate dry snow several days before the more general "matrix flow" reaches a layer (Marsh and Woo, 1984a). When percolating meltwater reaches cold internal snow layers, a part of this water refreezes and the latent heat produced warms the layer very quickly toward the melting point. When the surface of a wet snow cover cools, it induces an internal heat flux by conduction, which is balanced by refreezing of the liquid water present in the underlying wet layers. At night, this refreezing is usually confined to a depth of less than $20 \mathrm{~cm}$ below the surface. Matrix flow in completely 
wet snow can transmit liquid water produced at the surface by rain or melting through the internal layers without any related energy exchange.

\subsubsection{Snowmelt}

The rate of snowmelt is primarily controlled by the energy balance near the upper surface, where melt normally occurs. Shallow snowpacks may be considered as a "box" to which energy is transferred by radiation, convection, and conduction and across whose boundaries mass fluxes of solid, liquid, and vaporous water occur. Male (1980) indicates that, for deep or cold snows, the energetics of layers within the pack must be considered discretely.

In temperate climates, snowpacks tend to be uniformly close to the melting temperature (isothermal) when melt commences at the surface. However, in cold climates, the change in internal energy of the snowpack $d U / d t$ can be a significant term in the energy balance during melt of shallow snow packs. Meltwater is released from the pack in a diurnal cycle in response to cycling of energy inputs; the nighttime energy deficit must be compensated for the next day before the pack can return to $0^{\circ} \mathrm{C}$ and release water.

The melting point for snow may differ slightly from $0^{\circ} \mathrm{C}$ because of impurities in ice, but typically once the snow layer reaches $0^{\circ} \mathrm{C}$ any further energy inputs are directed toward snowmelt and $d U / d t=0$. The energy balance for melting snow is expressed in terms of $Q_{\mathrm{m}}$, the energy available for melting a unit volume of snow,

$$
Q_{\mathrm{m}}=K^{*}+L^{*}+Q_{\mathrm{H}}+Q_{\mathrm{E}}+Q_{\mathrm{G}}+Q_{\mathrm{R}}-\frac{d U}{d t}
$$

where $K^{*}$ is the net shortwave radiation flux, $L^{*}$ is the net long-wave radiation flux, $Q_{\mathrm{H}}$ is the sensible heat flux, $Q_{\mathrm{E}}$ is the latent heat flux, $Q_{\mathrm{G}}$ is the ground heat flux, and $Q_{\mathrm{R}}$ is the energy flux derived from precipitation.

The amount of meltwater can be calculated from Equation 2.10 by the expression

$$
S W E_{\mathrm{m}}=\frac{Q_{\mathrm{m}}}{\left(\rho_{\mathrm{w}} L_{\mathrm{f}} B\right)}
$$

where $S W E_{\mathrm{m}}$ is the snow meltwater (in mm), $\rho_{\mathrm{w}}$ is the density of water, $L_{\mathrm{f}}$ is the latent heat of fusion, and $B$ is the fraction of ice in a unit mass of wet snow. $B$ is usually 0.95 to 0.97 .

Net radiation and sensible heat largely govern the melt of shallow snowpacks in open environments (Male and Gray, 1981). At the beginning of melt, radiation is the dominant flux with sensible heat growing in contribution through the melt. The relative importance of some of the energy balance terms during melt of a High Arctic 


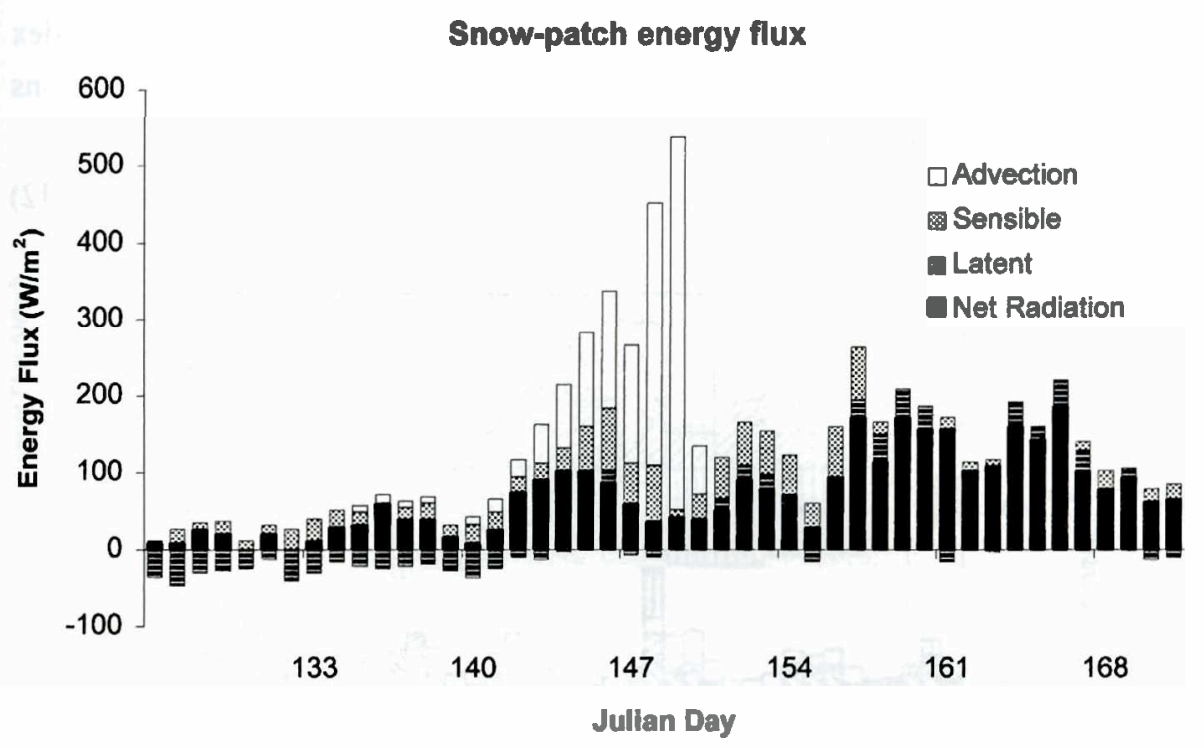

Figure 2.28. Energy fluxes for an isolated melting snowpatch in the Arctic (after Marsh and Pomeroy, 1996).

snowpack is shown in Figure 2.28, which presents daily fluxes to an individual snowpatch measured by Marsh and Pomeroy (1996) near Inuvik, Northwest Territories. In an alpine, midlatitude region, these terms have very different relative importance (Brun et al., 1989) as shown in Figure 2.29. Various mathematical models are available to calculate the energy fluxes for melting snow from standard meteorological variables. Over a patchy snow cover, the classic formulae to calculate $Q_{H}$ and $Q_{E}$ underestimate the turbulent heat fluxes because advection of energy from bare areas to snowpatches plays an important role that cannot be neglected. Over nonisothermal snow covers, the calculation of the different fluxes is quite difficult and requires the use of sophisticated snow models (Anderson, 1976; Brun et al., 1989, 1992; Jordan, 1991; Bader, 1992; Yamazaki and Kondo, 1992).

If a complete set of meteorological measurements is not available, then temperature index models may be used to predict snowmelt (Rango and Martinec, 1987; Braun, 1991). Despite their poor performance for open, continuous snow covers, considerable success has been achieved in using index models to relate melt to air temperature in mountainous areas, forested areas, and for patchy snow cover where advection becomes a dominant term. Shook, Gray, and Pomeroy (1993) have shown that the potential for advection of sensible heat increases dramatically as basin snow cover decreases from 70 to 60 percent and remains relatively high as basin snow cover further 
decreases. Where sensible heat is a dominant term, application of temperature index models may be expected to be relatively successful. Temperature index calculations employing melt factor $M_{\mathrm{f}}$ have the form

$$
S W E_{\mathrm{m}}=M_{\mathrm{f}}\left(T_{\mathrm{A}}-T_{\mathrm{B}}\right)
$$
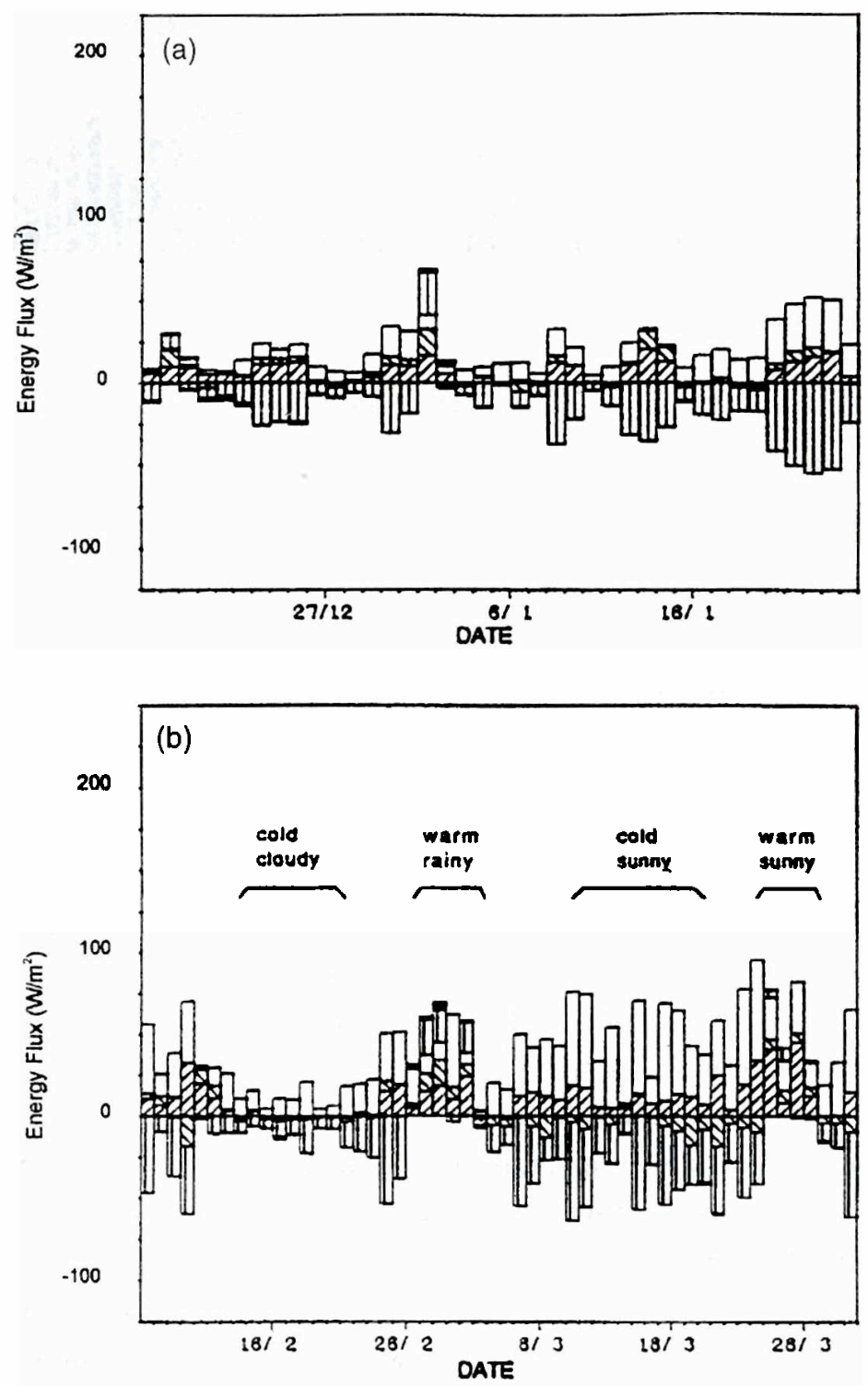

Figure 2.29. Daily variation of energy balance components of an alpine snow cover in the French Alps during three periods: (a) midwinter, (b) late winter, and (c) spring. 


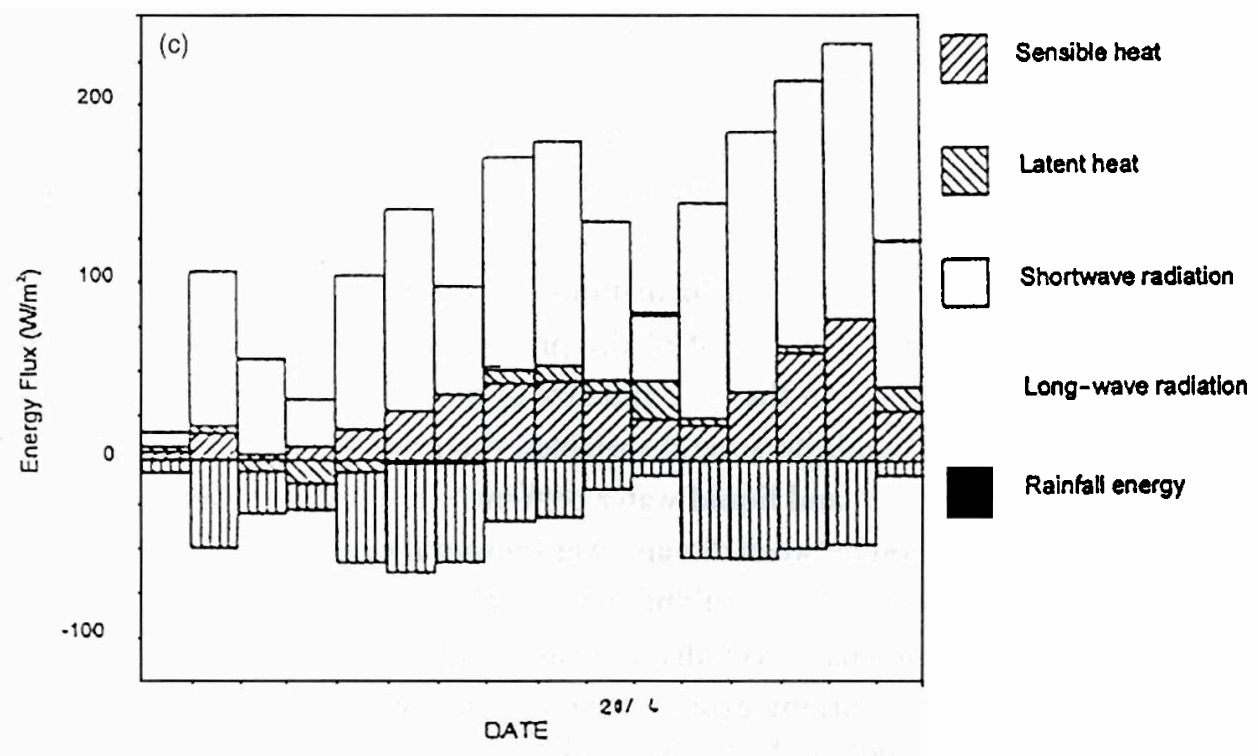

Figure 2.29. (Continued)

where $T_{\mathrm{A}}$ is the mean air temperature over a given time period and $T_{\mathrm{B}}$ is a base temperature below which melt does not occur (usually taken as $0^{\circ} \mathrm{C}$ ). Granger and Male (1978) found the melt factor to vary from 6 to $28 \mathrm{~mm}^{\circ} \mathrm{C}^{-1}$ day ${ }^{-1}$ for snowmelt on the prairies. Exceptionally high values of $M_{\mathrm{f}}\left(50 \mathrm{~mm}^{\circ} \mathrm{C}^{-1}\right.$ day $\left.{ }^{-1}\right)$ were occasionally measured in April and associated with high radiation fluxes. The use of melt factors in calculating snowmelt should be done with caution because of the considerable variation in their value from year to year and with location.

\section{$2.4 \quad$ Snow Cover Structure}

An important characteristic of snow covers is the stratification of their physical structure. In analogy to geological strata, snow stratification results from successive snowfalls over the winter and processes that transform the snow cover between snowfalls. A new snowfall creates a new surface layer that will undergo various transformations before being buried by the next snowfall. Snow crystals undergo the most important transformation by changing their original shapes (stars, needles, dendrites, etc.) under the effect of thermodynamics; this phenomenon is called metamorphism. Crystal transformations due to metamorphism and other transformations of the snow cover result in snow properties that are distinctive enough to permit easy identification of stratigraphic layers over most of the snow season. 
Transformations of snow cover are controlled by two interacting processes: snow settling and snow metamorphism. They cannot be completely separated; settling of a snow layer is principally due to the weight of upper layers and often is represented as a Newtonian viscosity. Snow metamorphism also contributes to settling, especially for fresh snow layers. Furthermore, the type of crystal strongly influences snow viscosity and so affects the settling rate. Transformations by settling and metamorphism are fundamental phenomena because most of the physical properties of snow strongly depend on snow density and on the type and size of grains comprising a snow layer. Snow metamorphism depends on several variables, the principal ones being temperature, temperature gradient, and liquid water content. Liquid water content is quite influential and a distinction between dry and wet snow is always necessary to describe the behaviour of snow layers. As a result of metamorphism, snow grains present various shapes and sizes, which have been distinguished and classified in an international classification created by a working group of the International Commission on Snow and Ice (Colbeck et al., 1990). This classification describes the different types of snow crystals, their size, and their formation. The classification is process oriented in that it remarks on the physical processes involved in creating snow crystal forms and therefore is useful in snow ecological studies where the snow processes also affect ecological processes. The dry and wet snow processes that lead to these crystal forms are discussed in the following sections. A brief summary of the International Classification is shown in Table 2.2, the main classes being precipitation (1), dry snow $(2,3,4,5$, 7 ), wet snow (6), ice (7), and surface-generated features (9). Some examples of snow crystal forms, as investigated by microphotography, are shown in Figure 2.30.

\subsubsection{Dry Snow}

Dry snow is characterised by the relative absence of liquid water. This absence is not complete, because snow crystals may be surrounded by a liquid-like layer that is thin enough to neglect when considering metamorphic processes, but is important to snow chemistry and possibly to microbiology. Snow is necessarily dry when its temperature is below the melting point, but dry snow also may exist in melting snow covers as, for instance, in a dry layer persisting between wet snow layers.

\subsubsection{Dry Snom Metamorphism}

Dry snow metamorphism is principally controlled by the vertical temperature gradient across the snow layer. This gradient develops because of radiative cooling from the snow surface, warm and/or wet soils, and the low thermal conductivity of 
Table 2.2. International classification of snow crystals (adapted from

Colbeck et al., 1990).

\begin{tabular}{lll}
\hline Basic classification & Shape & Process classification \\
\hline $\begin{array}{l}\text { 1. Precipitation } \\
\text { particles }\end{array}$ & a) Columns & $\begin{array}{c}\text { a-g) Cloud-derived falling } \\
\text { snow }\end{array}$ \\
& $\begin{array}{l}\text { b) Needles } \\
\text { c) Plates }\end{array}$ & \\
& d) Stellar dendrites & \\
e) Irregular crystals & \\
& f) Graupel & \\
g) Hail & \\
h) Ice pellets &
\end{tabular}

\section{Decomposing and} fragmented precipitation particles

3. Rounded grains

4. Faceted crystals

5. Cup-shaped crystals and depth hoar

6. Wet grains
a) Partly rounded particles
b) Packed shard fragments

a) Freshly deposited snow

b) Wind-packed snow
a) Small rounded particles
b) Large rounded particles
c) Mixed forms

a-c) Dry equilibrium forms
a) Solid hexagonal
b) Small faceted
c) Mixed forms

a) Solid kinetic growth form

b) Early kinetic growth form

c) Transitional form
a) Cup crystal
b) Columns of depth hoar
c) Columnar crystals

a) Hollow kinetic crystal

b) Columns of a)

c) Final growth stage
a) Clustered rounded grains
b) Rounded polycrystals
c) Slush
a) No melt-freeze cycles
b) Melt-freeze cycles
c) Poorly bonded single crystals

7. Feathery crystals
a) Surface hoar crystals
b) Cavity hoar

a) Kinetic growth in air

b) Kinetic growth in cavities

8. Ice masses
a) Ice layer
b) Ice column
c) Basal ice
a) Refrozen water above less-permeable layer
b) Frozen flow finger
c) Frozen ponded water

9. Surface deposits
a) Rime
b) Rain crust
c) Sun crust, firn-spiegel
d) Wind crust
e) Melt-freeze crust

a) Surface accretion

b) Freezing rain on snow

c) Refrozen sun-melted snow

d) Wind-packed snow

e) Crust of melt-freeze grains 


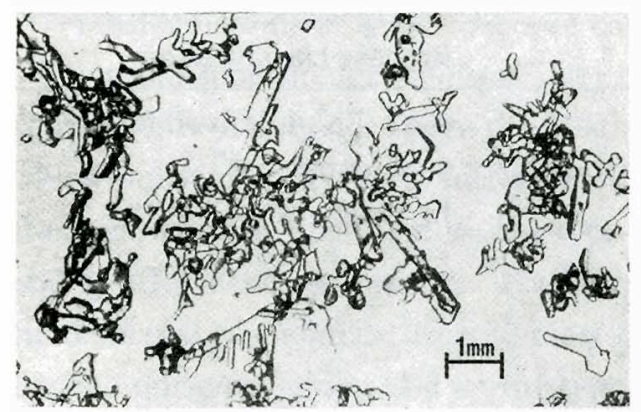

(a)

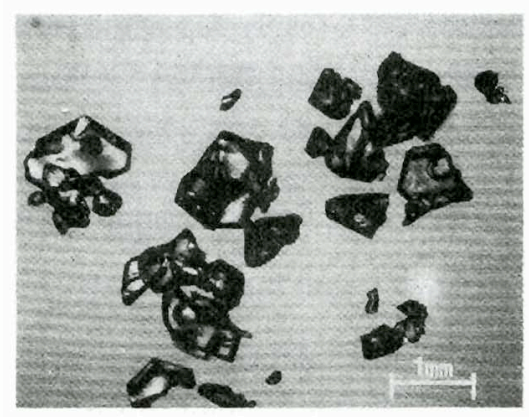

(c)

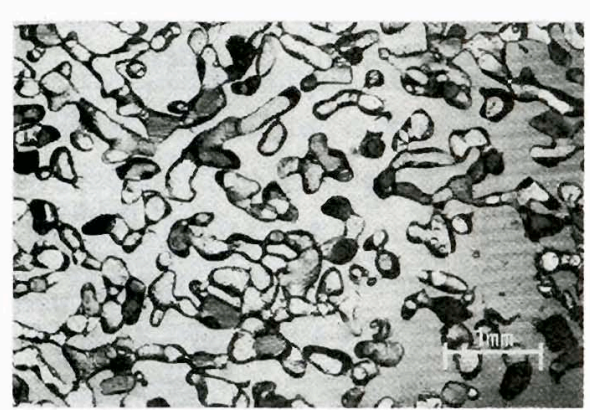

(b)

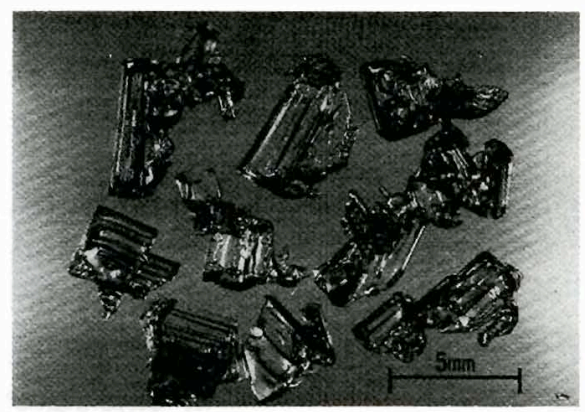

(d)

Figure 2.30. Examples of snow crystals as classified in Table 2.2 (from Colbeck et al., 1990): (a) partially decomposed fresh snow, 2a (by E. Akitaya); (b) large rounded dry grains, 3b (by E. Akitaya); (c) solid hexagonal faceted crystals, 4a (by E. Akitaya); (d) cup-shaped depth hoar crystal, 5a (by K. Izumi).

the snow cover. Low thermal conductivity permits the soil to stay relatively warm, even when the snow surface temperature is very cold. The temperature gradient in the snow cover induces high local temperature gradients between adjacent crystals. Because the saturation water vapour pressure over a flat ice surface is an exponential function of temperature, the temperature gradients induce water vapour pressure gradients and consequently vapour diffusion from the warmest crystals toward the coldest ones. Warm crystals are destroyed and re-formed on the cold side, resulting in a change of crystal shape and size. The rate of diffusion is balanced by sublimation and solid condensation processes.

Water vapour pressure is also a function of the radius of curvature of the ice face, so that the sharpest parts of snow crystals tend to sublimate most rapidly, consequently becoming rounded and diminished. Concave parts of crystals and the largest crystals tend to grow because of this effect. There is a competition between the temperature 
gradient and curvature effects because condensation on the coldest crystals tends to produce the sharp edges typical of ice crystallisation. Consequently, there are some threshold conditions that separate the dry metamorphism producing faceted and angular crystals and that producing rounded crystals. These thresholds are not absolute but can be described as follows:

1. Low temperature gradient metamorphism. When the temperature gradient is lower than $5^{\circ} \mathrm{C} \mathrm{m}^{-1}$, it produces small, rounded grains (class 3 of the International Classification) characterised by an efficient settling rate and good cohesion due to the growth of ice bonds between the grains by sintering. They are typically encountered in temperate regions with heavy snowfalls or strong redistribution due to the wind.

2. Medium temperature gradient metamorphism. When the temperature gradient is between $5^{\circ} \mathrm{C} \mathrm{m}^{-1}$ and $15^{\circ} \mathrm{C} \mathrm{m}^{-1}$, it drives the formation of faceted crystals (class 4). The increase in grain size is slow because gradient effects are partially balanced by curvature effects.

3. High temperature gradient metamorphism. When the temperature gradient is higher than $15^{\circ} \mathrm{C} \mathrm{m}^{-1}$, it drives the formation of depth hoar crystals (class 5). These large, plate-like crystals grow quickly. Such snow layers generally are characterised by a very low settling rate and weak cohesion. They are typically encountered in cold and dry climate regions.

Quantitative empirical laws to describe snow metamorphism have been determined by Marbouty (1980) and Brun et al. (1992). In natural snow, the temperature gradient is not constant and often passes through several thresholds amongst metamorphism types over a season. A dry snow layer therefore may undergo successive types of metamorphism that are partially reversible. The results are often intermediate or mixed snow types.

\subsubsection{Grains and Pores}

The size, type, and bonding of snow crystals are responsible for the pore size and permeability of the snowpack. Depth hoar layers are characterised by very large grains $(2-10 \mathrm{~mm})$. They also include large pores with sizes similar to that of the crystals. These pores partially survive the spring wetting due to rain or snowmelt. Because of their kinetic growth, depth hoar crystals are not principally linked by ice bonds but exist as piles linked by a few strands of brittle chains. Sometimes large voids of several centimetres diameter form because of a previous collapse of grains, especially under ice crusts or close to rocks or tree branches. 
Faceted crystals are formed by medium temperature gradient metamorphism or as a first stage of high temperature gradient metamorphism. Their grain size is between 0.3 and $1 \mathrm{~mm}$. In most cases, the structure is a combination of ice bonds and piled crystals, so that most of the properties of faceted snow layers are intermediate between those of depth hoar and of rounded crystals.

Rounded grains are very small $(0.1-0.4 \mathrm{~mm})$ and are principally formed from fresh snow drifted by strong winds. Their small radius of curvature leads to very efficient sintering between such crystals. The result is strong bonding, with the ice bonds relatively large compared with grain size. Pore size is accordingly very small with no large voids because the structure is not subject to collapse.

An example of pores in snow is shown in Figure 2.31; the photograph is taken from a thin section of a specially treated snowpack sample from a former National Hydrology Research Institute laboratory in the Canadian Rockies (Dozier, Davis, and Perla, 1987). Dozier et al. note from analysis of such photographs that the ratio of ice-pore interface surface area to mass is initially high for fresh snow $\left(100 \mathrm{~m}^{2} \mathrm{~kg}^{-1}\right)$,

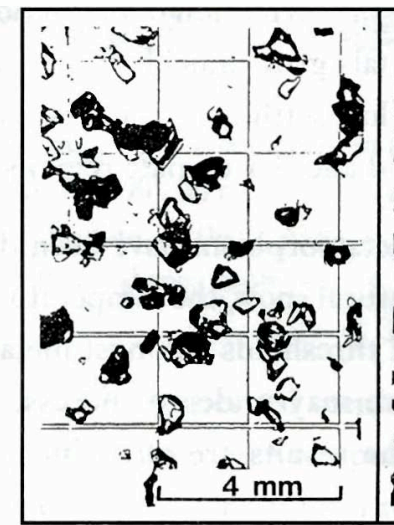

(a)

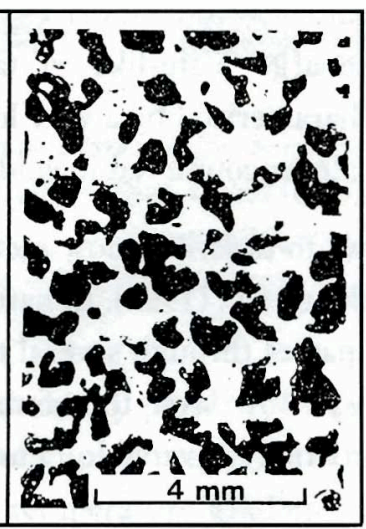

(b)

Figure 2.31. Snow structure collected at middepth from a subalpine snowpit near Banff, Alberta, by Ron Perla and photographed at a former National Hydrology Research Institute snow laboratory. Sample density is $375 \mathrm{~kg} \mathrm{~m}^{-3}$. (a) Photograph of disaggregated grains from the snow sample, displaying both faceted and rounded structure; (b) photograph of a thin-section plane prepared from the sample and showing the cross-sectional snow structure. Dark areas represent snow/ice and white areas represent pores in the snowpack (Perla, 1978) 
declining by a factor of 10 for old seasonal snow. These surface areas presumably form a habitat for microorganisms that require ice, water, and air to survive (see Chapter 4).

\subsubsection{Density and Hardness}

In low wind speed environments, fresh snowfall has very low hardness (ram hardness $<10 \mathrm{~N}$; surface hardness $<1 \mathrm{kN} \mathrm{m}^{-2}$ ) and a density range from 50 to $120 \mathrm{~kg} \mathrm{~m}^{-3}$. High, medium, and low temperature gradient metamorphism modify this snow, resulting in various snow sintering and densification rates. Goodison et al. (1981) measured rates of snow density increase of $7 \mathrm{~kg} \mathrm{~m}^{-3}$ hour ${ }^{-1}$ for the first 6 hours after snowfall. The ranges of density and bonding induce a large range of hardness. The cohesion and hardness of depth hoar or faceted grain layers are normally very low. If these layers are formed from light, fresh snow, they reach a maximum density varying from 150 to $325 \mathrm{~kg} \mathrm{~m}^{-3}$. The corresponding ram hardness is often lower than $10 \mathrm{~N} \mathrm{~m}^{-2}$ (Brun and Rey, 1987). Thick depth hoar layers can be an impediment to the movement of large animals (and humans) on snow cover that do not have special walking features to decrease the pressure applied by their feet or hooves. The low shear strength (less than $5 \mathrm{kN} \mathrm{m}^{-2}$ ) permits relatively easy movement of large animals inside or through depth hoar layers. These mechanical properties may be partially conserved during a rapid melt in spring.

In contrast, small rounded grain layers formed from wind redistribution or low temperature gradient metamorphism present a high density (250 to $500 \mathrm{~kg} \mathrm{~m}^{-3}$ ), high hardness (ram hardness larger than $50 \mathrm{~N}$ ), and strong cohesion (larger than $10 \mathrm{kN} \mathrm{m}^{-2}$ ). Movement over these snow covers is facilitated but movement inside is impeded. The density of dry rounded grain layers is sufficiently high for these grains to retain their high hardness and strong cohesion during the melting period.

Exposure to wind hardens and densifies snow; for example, the surface hardness of freshly fallen snow varied from 2.5 to $1,000 \mathrm{kN} \mathrm{m}^{-2}$ in one winter (1986-1987) near Saskatoon, on the Canadian Prairies (Pomeroy, 1988). The higher hardness values are associated with conditions of high wind speeds, greater age, and concurrent blowing snow during deposition. Hardness increases with the wind speed required to sustain blowing snow. Li and Pomeroy (1997) have shown for prairie environments that these wind speeds increase with the logarithm of time since fresh snowfall. This suggests an initial rapid increase in hardness after snowfall with an asymptotic increase as elapsed time becomes large. Snow deposited within exposed vegetation cover has much lower hardness and density. When snow is transported by wind, the crystals undergo changes to their shape, size, and other physical properties, and upon redeposition form drifts 


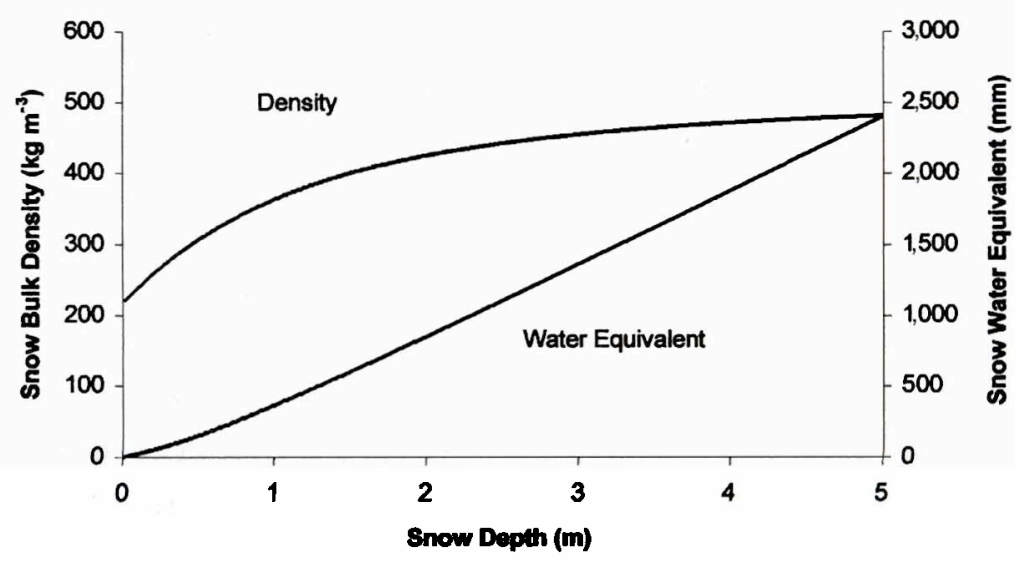

Figure 2.32. Increase in mean density of snowdrifts with increasing depth; trend from extensive measurements in Wyoming, USA, by Tabler et al. (1990b).

and banks of higher density than the parent material. Gray, Norum, and Dyck (1971) measured a sixfold increase in 24 hours, from $45 \mathrm{~kg} \mathrm{~m}^{-3}$ to $250 \mathrm{~kg} \mathrm{~m}^{-3}$, in the density of freshly fallen snow during blowing snow on the Canadian Prairies. When drifted snow becomes very deep, compression further controls the snow density. As shown in Figure 2.32, Tabler et al. (1990b) report that the mean density of deep snow drifts $\rho_{\mathrm{s}}\left(\mathrm{kg} \mathrm{m}^{-3}\right)$ increases with depth $d_{\mathrm{s}}(\mathrm{cm})$ as

$$
\rho_{\mathrm{s}}=522-\frac{20470}{d_{\mathrm{s}}}\left(1-\exp \left[-\frac{d_{\mathrm{s}}}{67.3}\right]\right)
$$

This relationship should be applied only to snowdrifts deeper than $60 \mathrm{~cm}$, as there is no strong relationship between depth and density for shallow windblown snow covers. Figure 2.33 (Pomeroy and Gray, 1995) shows the seasonal increase in snow density determined for various snow environments from data sources around the world.

\subsubsection{Wet Snow}

\subsubsection{Irreducible Water Content and Water Flow}

Wet snow is characterised by a significant amount of liquid water in snow. Significant, in this instance, means an amount larger than that in the liquid-like layer that still exists at subfreezing temperatures on the edges of ice crystals (Hobbs, 1974). Consequently, wet snow is usually encountered only at mean snow temperatures equal to the melting point. An exception is where zones of preferential meltwater flow into the normally dry and cold internal pack layers (Marsh and Woo, 1984a). Wet snow can also exist in small areas of the snowpack at below $0^{\circ} \mathrm{C}$ due to freezing point depression 


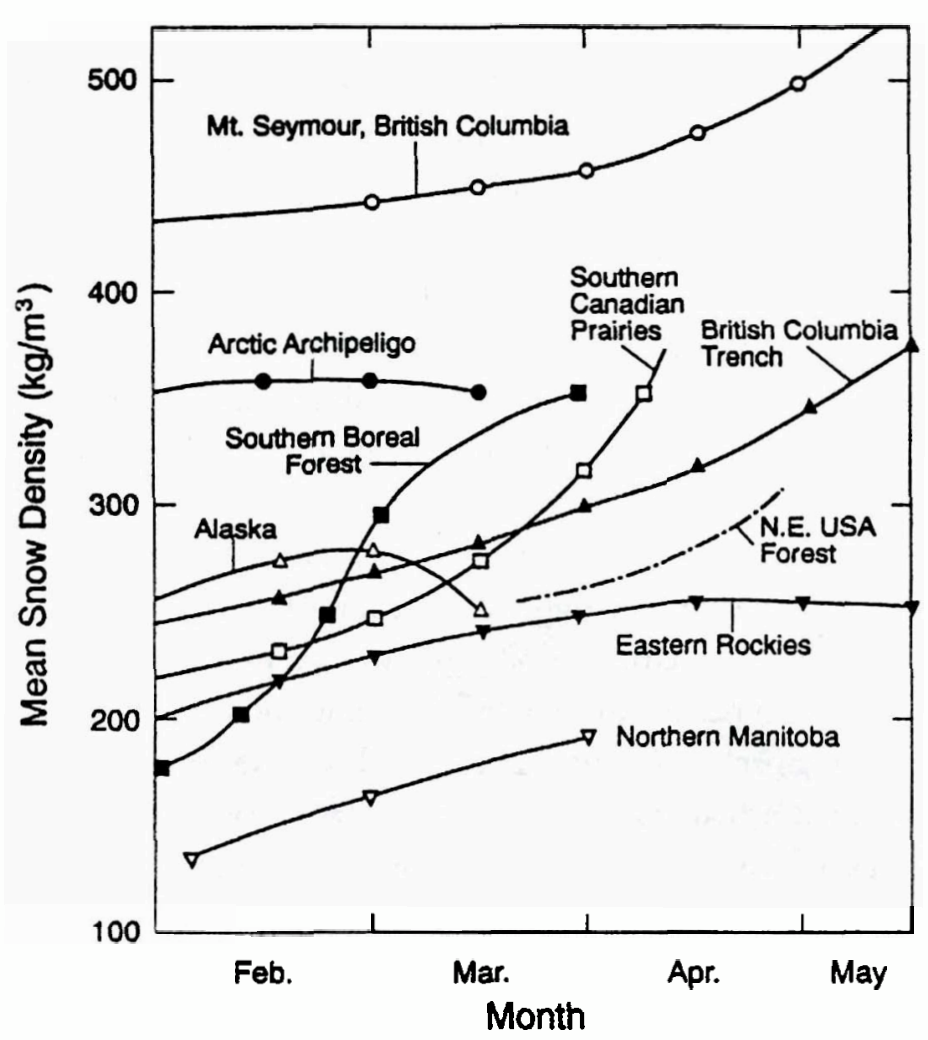

Figure 2.33. Seasonal variation in average snow cover density, drawn from many sources (Pomeroy and Gray, 1995)

by chemical impurities and pressure exerted by overlying snow layers. Freezing point depression is not normally more than a few tenths of a degree Celsius. Dry snow also may exist at the melting point. A deep, isothermal snow cover typically retains dry snow in internal layers when the surface begins to melt. Consequently, it is necessary to measure the liquid water content of a snow layer to determine whether it is wet or dry snow.

Liquid water content may be measured with reference to the snow mass, snow volume, or the volume of pores. The typical range of liquid water content in welldrained snow layers is from 0.1 to 8 percent of the snow mass. Liquid water percolates downward when its content exceeds the irreducible water content, which is that held within a snow layer by capillary forces (Colbeck, 1973; Denoth et al., 1979). When the water flux is high, or when a snow layer lies upon an impermeable layer of snow, ice, or soil, the snow may become saturated. Saturated layers may also form when a snow layer lies upon a permeable ground or snow layer with larger grain size than 
the overlying layer. In this last case, snow is saturated over a depth ranging from 3 to $10 \mathrm{~cm}$; the depth depends on grain size. Smaller grains result in a deeper saturated layer. Field measurements of snow liquid water content are accurately and easily done with dielectric sensors and a density kit (Denoth et al., 1984).

Water flow through snow is not stable and is strongly affected by flow instabilities such as relatively impermeable layers, zones of preferential flow called flow fingers, and large meltwater drains. Flow fingers and wet snow above less-permeable layers in cold snow are shown in Figure 2.34. Meltwater drains are large and often extend directly to the bottom of the pack (Wakahama, 1968), whilst flow fingers usually initiate and terminate at snow layer boundaries (U.S. Army Corps of Engineers, 1956). A conceptual cross-sectional representation of water movement around impermeable layers and in flow fingers is shown in Figure 2.35 (adapted from Marsh and Woo, 1984a). Water dammed at these boundaries moves rapidly down to the next one via the flow fingers until it refreezes or reaches the soil. In this manner, flow instabilities concentrate water within a melting pack, resulting in a greater flux of water at the leading edge of the wetting front than if that front were from uniform flow. Liquid water therefore can quickly reach snow layers far below the surface whilst the dry zones in the upper pack remain so for some time. Marsh and Woo (1984a) report a mean flow finger diameter of $3.6 \mathrm{~cm}$ and spacing of $13.1 \mathrm{~cm}$, with fingers occupying 22 percent of the horizontal area of the pack in the Canadian High Arctic. In the subarctic/boreal forest transition Marsh (1988) noted finger diameters of $5 \mathrm{~cm}$ and similar spacing resulting in a horizontal area of 27 percent. For a warm, isothermal snowpack with a 1.2-m depth, the meltwater model of Marsh and Woo (1984b) suggests that the flow finger wetting front can reach the ground 4 days before the background wetting front, whilst for a cold snow pack $\left(-12^{\circ} \mathrm{C}\right.$ at bottom) the wetting fronts reach the bottom at approximately the same time, because the flow finger water is refrozen as it penetrates the cold layers of the pack. On slopes, meltwater may be diverted downslope by ice layers so that it reaches the snowpack base well downhill of its origin (English et al., 1987). In general, peak discharges from a snowpack with flow instabilities are much higher and faster than if the pack were homogeneous. The inhomogeneities of flow paths, water content, and water flux during melt have important implications for the chemistry and microbiology of snow covers as discussed in Chapters 3 and 4 .

\subsubsection{Grain Growth}

Liquid water in snow drastically affects the evolution and physical properties of snow crystals and layers, primarily by wet snow metamorphism. The melting point at an ice-water interface depends on radius of curvature of the interface. Hence, 


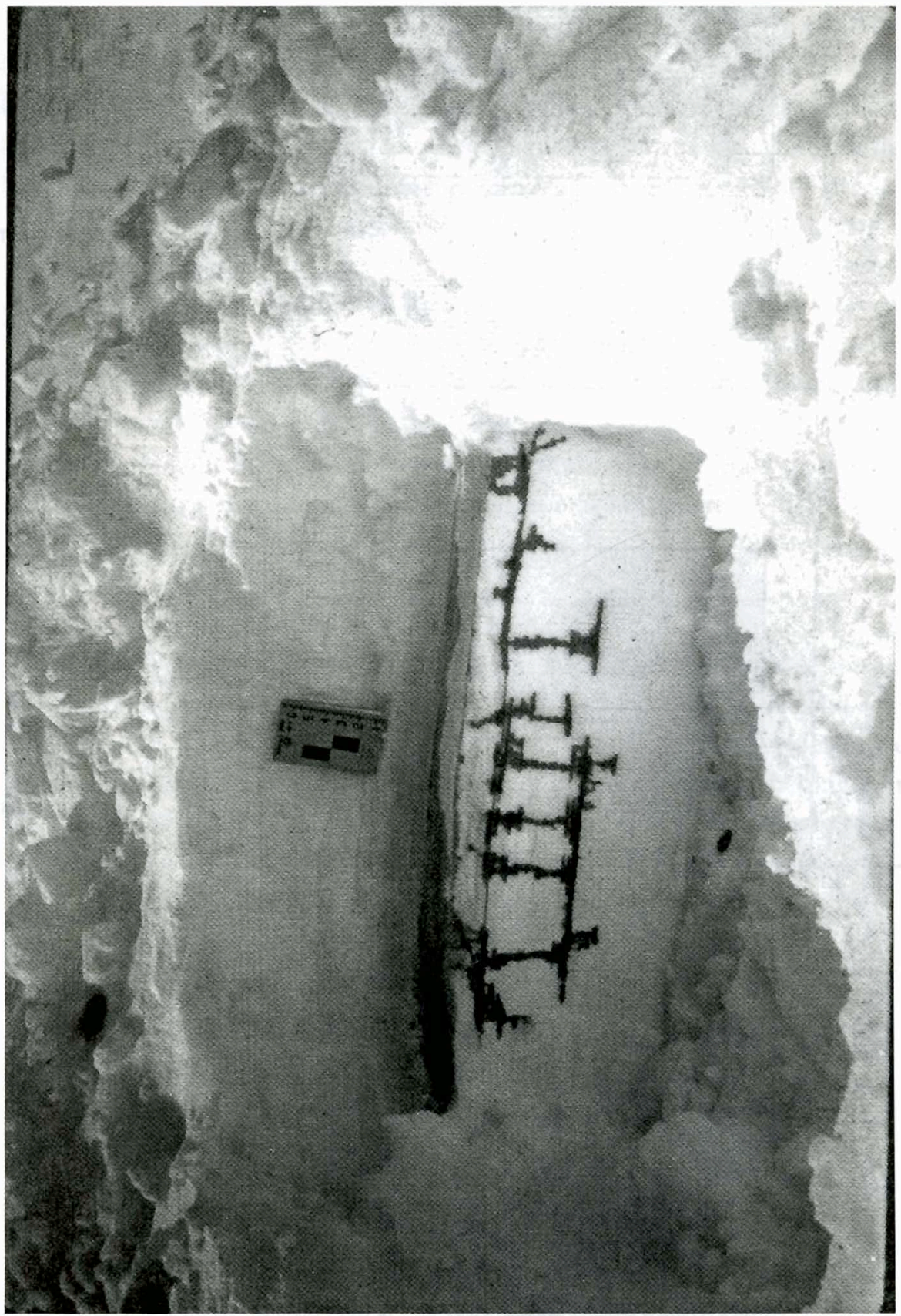

Figure 2.34. Photograph showing dye injection into developing flow fingers and wet layers in cold arctic snow (by Phil Marsh, NHRI). 
(a)

TEMPERATURE

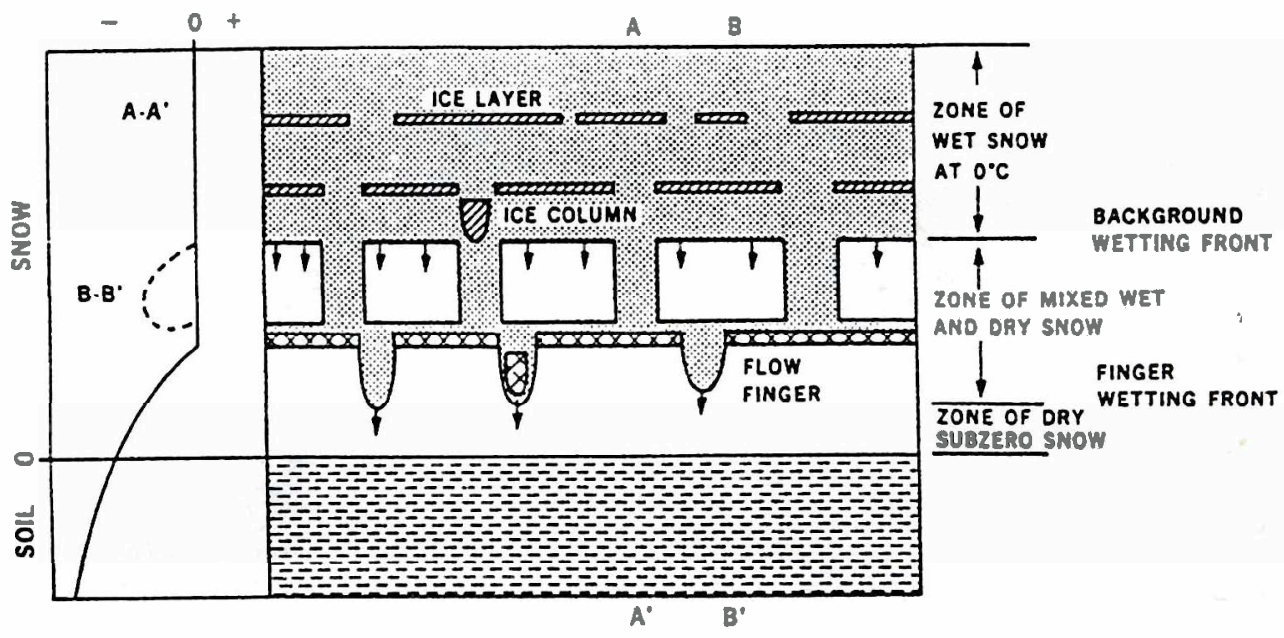

(b)

TEMPERATURE

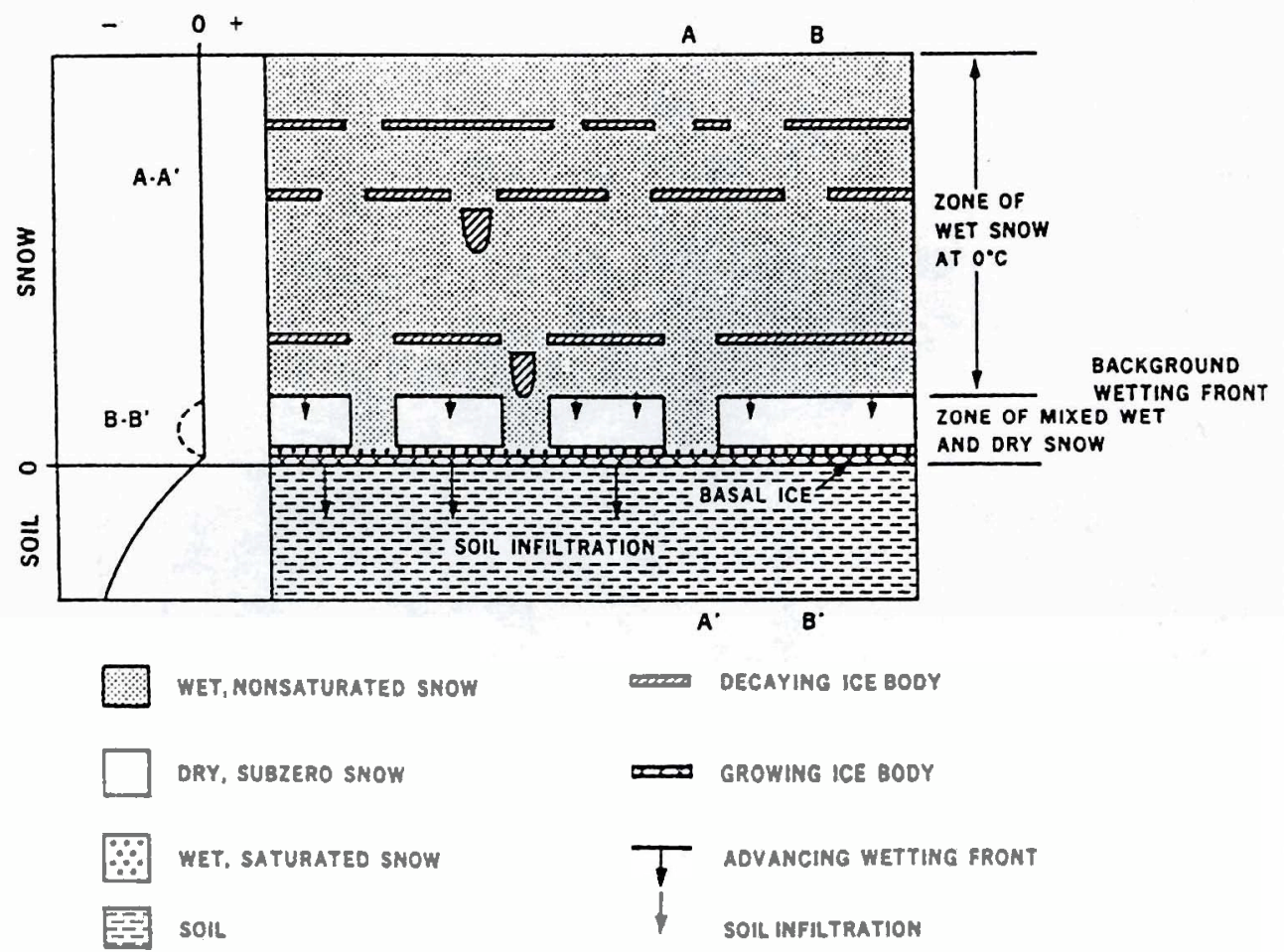

Figure 2.35. Conceptual representation of water flow, flow finger development, temperature change, and ice layer growth during meltwater percolation into an initially cold snowpack (after Marsh and Woo, 1984b). (a) Nonisothermal, before meltwater reaches the base; (b) Isothermal, after meltwater reaches the base but before the pack is fully wetted. 
the sharpest parts of the snow crystals can be melting when the concave or flattest parts are refreezing. This induces a microflow of water from sharp points to flat or concave points on a snow crystal, rounding the crystals into a classic wet grain shape. Furthermore, larger grains are growing at the expense of the rapidly melting smaller ones to form a snow layer of large, rounded grains. Wet snow metamorphism is very efficient when the liquid water content is larger than 5 percent of mass, because the presence of liquid veins among the grains facilitates the heat and mass transfer necessary for the phase changes (Brun, 1989). In wet snow under constant conditions, the growth rate of the grain diameter varies with the cubic root of time (Raymond and Tusima, 1979; Brun, 1989). However, for natural snow under liquid water contents that vary with diurnal and daily energy input changes, the grain growth rate is more linear with time (Marsh, 1987). Wet snow grains rapidly round and grow up to a diameter of about $0.5 \mathrm{~mm}$ in a few hours. However, in natural conditions it takes several days to reach a diameter of $1 \mathrm{~mm}$ and several weeks to reach $2 \mathrm{~mm}$. An example of wet snow grain structure is shown in Figure 2.36.

\subsubsection{Density and Hardness}

Wet snow metamorphism at first induces a decrease in cohesion and hardness as liquid bonds form between the crystals at the expense of solid ones. This phenomenon is most likely due to higher concentrations of impurities in ice bonds than in surrounding crystals with subsequent depression of the melting point. The decrease of cohesion in wet snow is well known through its inducement of avalanche

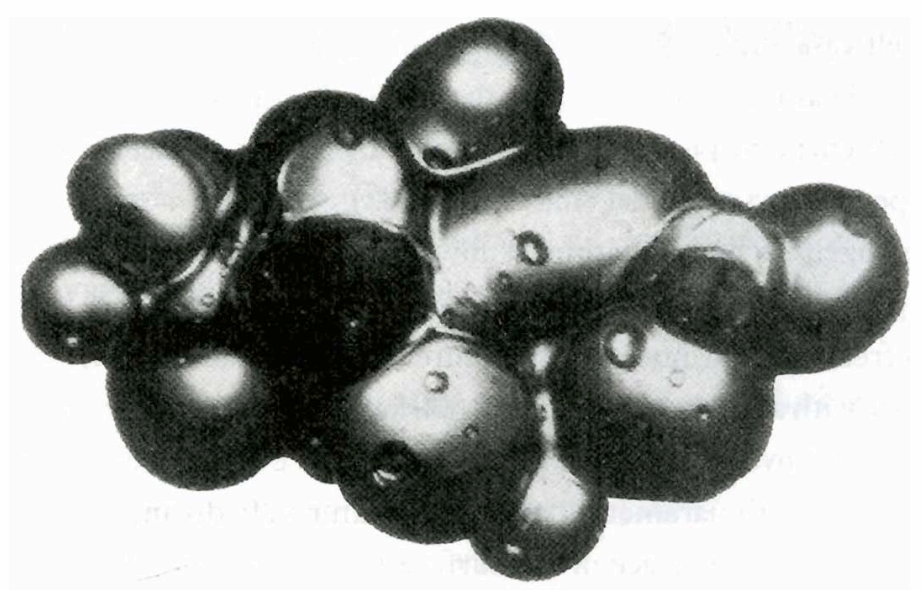

Figure 2.36. Microphotograph of wet, clustered, rounded snow grains, showing the snow grain, wet snow bonds, and surrounding liquid water layer, 6a (from Colbeck et al., 1990). 
activity and plays an important role in snow ecology by changing the ability of animals to move upon the snow surface or inside the pack.

The presence of liquid water increases the compaction rate because of the decrease in viscosity of wet snow and because the metamorphism directly transforms faceted or plate-like crystals into spherical ones. Denser, more cohesive, and harder snow covers form in a few days even when wetting affects fresh, low-density snow. If wet conditions prevail for from one to several weeks, the density can reach $350-550 \mathrm{~kg} \mathrm{~m}^{-3}$, with strong diurnal variations as the liquid water content of the snow changes with meltwater production. It is possible during active snowmelt to measure a density in the morning of $350 \mathrm{~kg} \mathrm{~m}^{-3}$ and a density in late afternoon (when the snowpack is primed with meltwater) of $550 \mathrm{~kg} \mathrm{~m}^{-3}$.

\subsubsection{Refreezing, Ice Layers, Basal Ice Gromth}

When a wetting front is stationary, the heat flux from wet to dry snow may be sufficient to refreeze water and form ice bodies within the snowpack. As this happens, flow fingers form ice columns, snow layer boundaries form ice layers, and the snow-soil boundary forms basal ice (Marsh, 1991). An example of a large ice column capped by an ice layer is shown in Figure 2.37. When refreezing, ice columns develop very large, rounded, clustered crystals (Kattelmann, 1990). Horizontal ice layers often develop where a flow finger spreads the flowing water over a cold internal layer made from small rounded grains and overlying a layer made up of larger crystals (for instance, at the wind-packed to depth hoar layer transition). Ice layers are typically 0.1 to $20 \mathrm{~cm}$ thick and extend horizontally from 0.2 to more than $3 \mathrm{~m}$ (Langham, 1974). Basal ice forms where the meltwater flux exceeds the infiltration rate of frozen soils and there is a strong negative heat flux from the snow to the soil. Basal ice layers may become quite thick (up to $70 \mathrm{~cm}$ ) and persist after the snow cover has melted, but they are most prevalent in permafrost regions (Woo et al., 1982).

Initially refrozen ice bodies within a snow cover are formed of large polycrystalline melt-freeze particles up to $5 \mathrm{~mm}$ in diameter, which are bonded in a honeycomb structure. As freezing continues this structure becomes a hard, rigid, relatively impermeable ice body with a density greater than $800 \mathrm{~kg} \mathrm{~m}^{-3}$ (Marsh and Woo, 1984a). As the temperature rises above $-0.1^{\circ} \mathrm{C}$, the permeability of ice layers increases rapidly, hardness decreases, and both parameters may change diurnally during melt. The hardness of refrozen meltwater in surface or subsurface layers is remarkably high and usually sufficient to support a human or large animal. However, it is subject to strong diurnal fluctuations during melt, along with temperature and net radiation. Basal ice prevents 


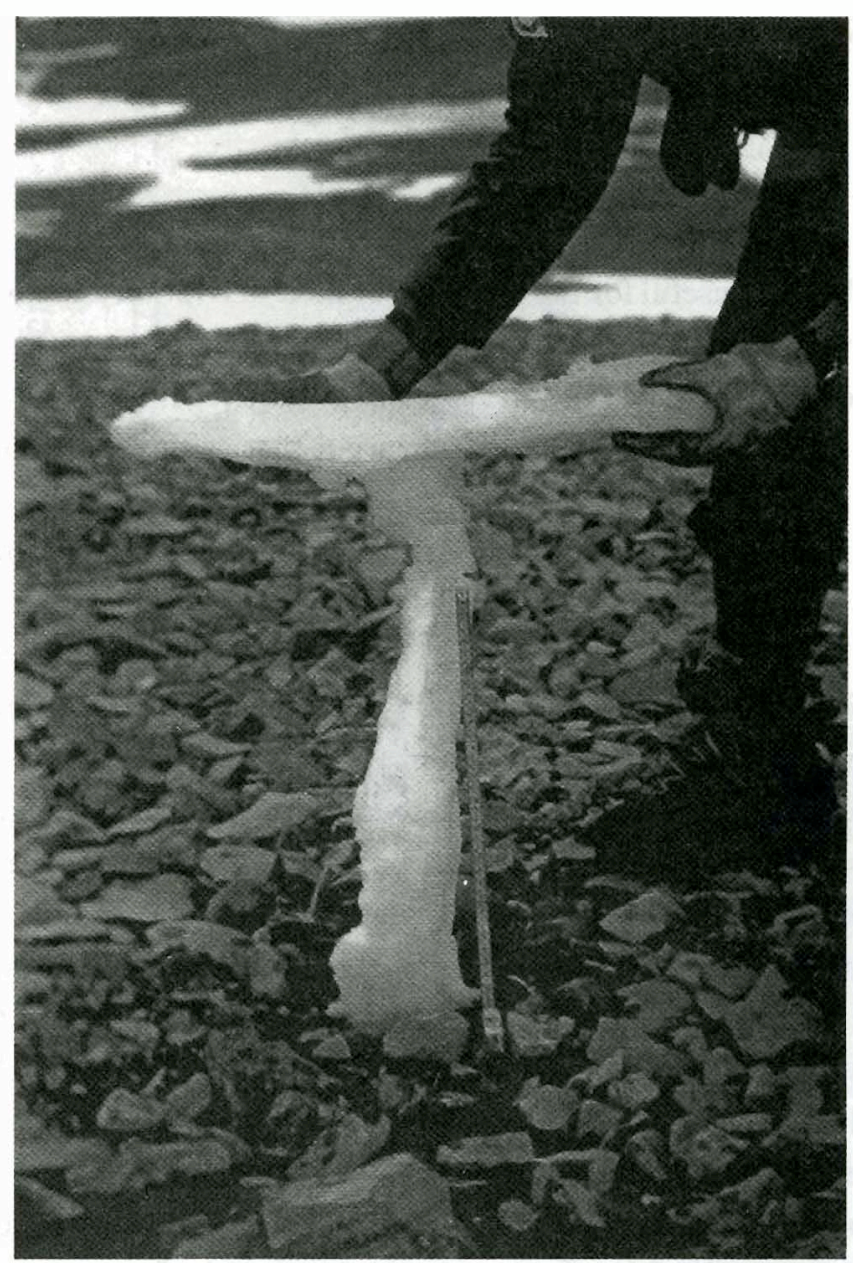

m

Figure 2.37. Photograph of a large ice column, capped by an ice layer that had been removed from a cold snow cover in the Arctic (Phil Marsh, NHRI). The column was formed by meltwater refreezing where ponded along a horizontal structural divide in the snowpack and in a vertical preferential flow path.

access to ground-hugging vegetation by grazing herbivores during snowmelt in the High Arctic.

Rain-on-snow events play a major role in wetting the snow surface and in forming ice crusts, especially during midwinter when the energy balance is generally unable to generate sufficient snow melt to wet deep snow layers. In regions where such events are very rare under the present climate, a climate change could increase their 
frequency and consequently change drastically the structure of the snow cover and the ecology.

\subsubsection{Snow Cover Classification}

Snow classification is an extremely complex subject because classification schemes tend to be most useful for the purposes of their derivation and no scheme has received widespread use in the study of snow. Snow covers evolve over time and vary at both small and meso spatial scales in association with vegetation and topography and at very large scales with climate. One might argue that, with a good understanding of the physical characteristics of a snow cover, static classification of such a dynamic phenomenon is somewhat misleading and probably unnecessary to gain an understanding of snow ecology.

Pruitt (1984) and McKay and Gray (1981) have presented schemes that classify snow by vegetation zone, presuming a strong association between natural vegetation cover and regional climate. Although these schemes correspond with broad ecozone categories and hence are easy to apply, they have not been rigorously defined in terms of snow properties, are not sensitive to land use or climate change, and offer incomplete physical descriptions of snow covers.

A scheme that has attempted to classify global snow cover using physically based measures is that by Sturm, Holmgren, and Liston (1995); elements of this scheme and global snow maps have been presented in Chapter 1. Sturm et al.'s climatic scheme is based on three major variables (temperature, wind speed, and snowfall) and discriminates snow cover into seven classes (tundra, taiga, alpine, prairie, maritime, mountain, and ephemeral). Climatic rather than land cover indicators are used despite the naming of classes by associated ecoregion and biome; hence, a tundra snow can develop in a prairie environment if the climate falls within the tundra snow class and alpine snow can develop in a transitional forest/prairie (parkland) region. The strict use of climatic indicators can result in confusing classifications when applied outside the region of development, as the microclimate that influences snow cover formation is strongly associated with both climate and vegetation cover (biome) as described earlier in this chapter. Despite the difficulties that can arise in using a climatic classification for ecological purposes, the scheme of Sturm et al. provides rigorous quantitative descriptions of snow characteristics in various climates. If used with discretion it provides the most objective physical classification currently available.

In Figure 2.38 snow stratigraphy using the crystal classification in Table 2.2 is demonstrated for class averages in mid to late winter. Tundra and prairie snow is shallow and dominated by wind slab and either depth hoar (tundra) or fresh to 


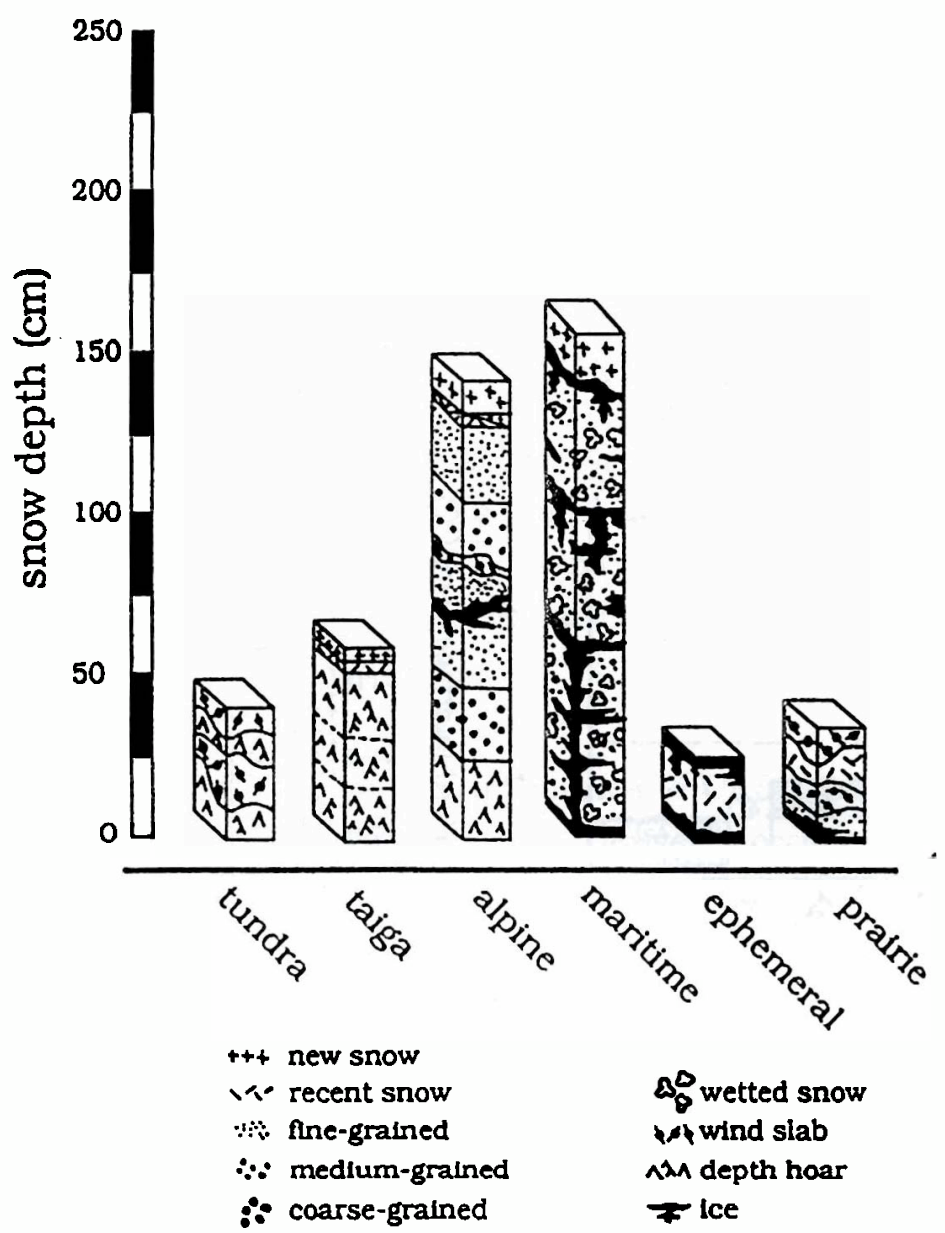

Figure 2.38. Basic stratigraphy and texture for each snow class in Sturm et al.'s climatic classification, as found in mid-to-late winter (after Sturm et al., 1995).

fine-grained snow (prairie); taiga snow is deeper and dominated by depth hoar; alpine and maritime snow are the deepest and structurally the most complex, with layers of varying grain size, wetness, and ice bodies. Boundaries between tundra, taiga, alpine, and maritime classes along with measured data from Alaska are shown in Figure 2.39 for average winter air temperature, soil heat flux, snow depth, snow-soil interface temperature, and vertical temperature gradient. These values provide representative ranges for these snow properties. The vertical temperature gradient shows that only tundra and taiga snow develop gradients sufficient for kinetic metamorphism; the gradients are controlled by cold air temperatures and shallow snow depth and result 


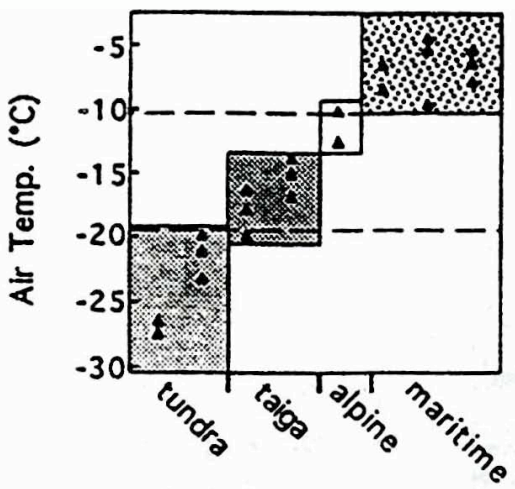

KEY

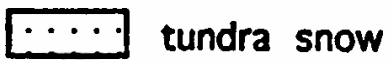

taiga snow

$\prod$ alpine snow

maritime snow
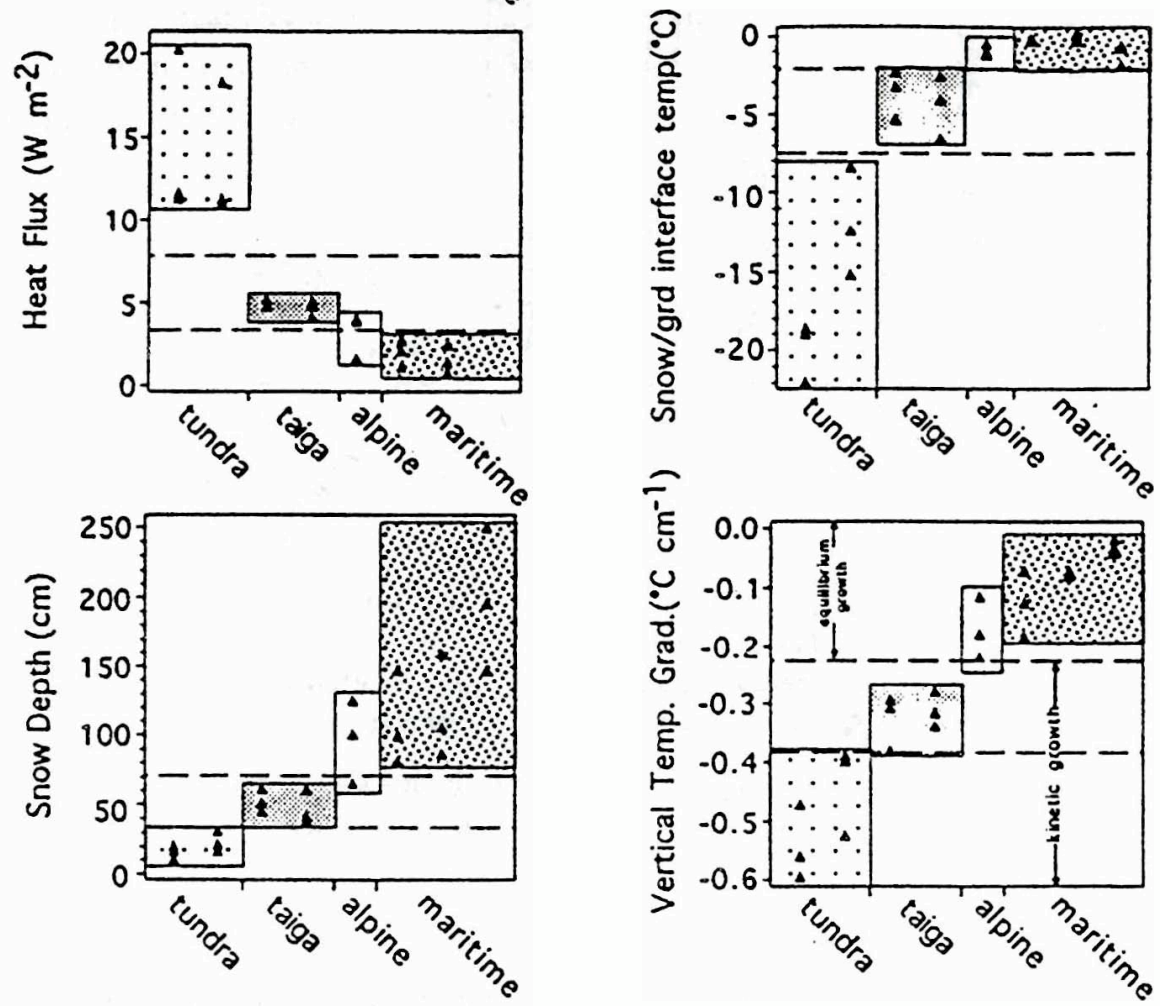

Figure 2.39. Snow classes and measured values of air temperature, ground heat flux, snow-soil interface temperature, snow depth, and vertical temperature gradient for tundra, taiga, maritime, and alpine snow (after Sturm et al., 1995).

in large soil heat fluxes and cold snow-soil interface temperatures. The snow properties shown in Figures 2.38 and 2.39 can be used to anticipate conditions in the appropriate environments where measurements are lacking. A map of average snow cover classes for much of the globe is shown in Chapter 1. 


\subsection{Impact of Snow on Soil and Aquatic Ecosystems}

Snow cover provides an insulating blanket over soil and lake ice for the winter period and provides an important episodic flux of latent heat, water, and chemicals into soils and water bodies during the spring melt. The important role of snow covers on lakes in controlling lake ice thickness and strength is reviewed by Adams (1981). The insulation of soils by snow cover is discussed in the preceding sections with typical snow-soil interface temperatures shown in Figure 2.39. In northern prairie environments, snow accumulation is managed to provide a deep insulating snow cover for winter wheat crops (Steppuhn, 1981). In many high latitude and altitude environments, snowfall accounts for over 40 percent of annual precipitation, and the release as meltwater over the course of a few days can be the single most important hydrological event in these environments (Woo, 1990).

\subsubsection{Infiltration of Meltwater into Frozen and Unfrozen Soils}

Meltwater infiltration into unfrozen soils usually occurs in environments. with deep snowpacks or maritime climates. Soils frozen to depths less than $150 \mathrm{~mm}$ behave as unfrozen soils with respect to infiltration. The proportion of snowmelt water that infiltrates to unfrozen soils depends on the application rate of meltwater from the snowpack, the hydraulic conductivity of soil layers, and the water-retention characteristics of the soil. Snowmelt discharge rates less than the saturated hydraulic conductivity of the soil will completely infiltrate. Discharge rates in excess of the saturated hydraulic conductivity will infiltrate until the soil becomes saturated and ponding of water at the base of the snowpack occurs. When water is ponded on the soil surface, procedures such as the Philip infiltration equation (Philip, 1957) are used to calculate the infiltration rate. Infiltration in this case depends on the hydraulic conductivity of the soil, suction at the wetting front in the soil, soil porosity, and initial soil water content. A complete discussion of techniques for calculating infiltration into unfrozen soils is provided by Rawls, Brakensiek, and Miller (1993).

Frozen soils develop where snow cover is thin or extremely cold winter temperatures prevail. Frozen soil indices can be used to estimate the occurrence of soils with frozen infiltration characteristics; these indices are exponential functions of the mean daily air temperature and depth of snow on the ground (Molnau and Bissell, 1983). One index developed for the northwestern United States is

$$
F S I_{i}=A\left(F S I_{i-1}\right)-T_{\mathrm{m}} e^{\left(-0.4 K d_{\mathrm{s}}\right)}
$$


where $F S I$ is the frozen soil index, $i$ is the day of the snow year, $T_{\mathrm{m}}$ is mean daily air temperature, $d_{\mathrm{s}}$ is the depth of snow on the ground $(\mathrm{cm}), A$ is a daily decay coefficient (0.97), and $K$ is a snow depth reduction coefficient $\left(0.57 \mathrm{~cm}^{-1}\right)$. FSI values between $56^{\circ} \mathrm{C}$ and $83^{\circ} \mathrm{C}$ days correspond to the transition between frozen and unfrozen infiltration characteristics in soils of the northwestern United States.

Frozen soils normally have lower infiltration capacities than do unfrozen soils of similar saturation levels because the presence of ice from initial water or refreezing reduces the effective porosity of the soils. Saturated frozen soils lacking macropores have a negligible infiltration capacity and are considered impermeable. Unsaturated frozen soils have snowmelt infiltration amounts that vary with the SWE of the snow cover and the frozen water content of the upper $300 \mathrm{~mm}$ of soil. Granger, Gray, and Dyck (1984) provide the following equation to calculate snowmelt infiltration into frozen prairie soils:

$$
I N F=5\left(1-\theta_{\mathrm{p}}\right) S W E^{0.584}
$$

where $I N F$ is infiltration (mm of water) and $\theta_{\mathrm{p}}$ is the degree of soil pore saturation $\left(\mathrm{mm}^{3} \mathrm{~mm}^{-3}\right)$ that can be measured in the autumn. Pomeroy et al. (1997b) provide a somewhat different equation for southern boreal forest snowmelt infiltration, where

$$
I N F=\left(1-1.36 \theta_{\mathrm{p}}\right) \frac{S W E^{2.41}}{364}
$$

Equation 2.16 normally should be applied only to snowpacks of less than $100 \mathrm{~mm}$ SWE. The higher exponent for the forest compared with the prairie reflects the role of deep snowpacks in insulating soil, so that soils are not always completely frozen at the time of melt. Where snow was deep (normally clear-cuts or burns), Pomeroy et al. found the soils to be incompletely frozen; hence infiltration was high. Frozen soils that contain large cracks or macropores normally will be able to accommodate infiltration of all snowmelt water.

\subsubsection{Runoff and Streamflow Generation}

Streamflow is generated by snowmelt water that directly runs off rather than infiltrating or from water that infiltrates and then moves downslope through a shallow subsurface soil of high permeability. During snowmelt, frozen or saturated soils restrict infiltration and evaporation is relatively low; this promotes a water excess over a basin and permits relatively large runoff generation for the amount of water applied to the ground. As a result, peak annual streamflows often occur directly after 
snowmelt. The constituent waters of this freshet comprise both snowmelt water and water expelled from soils by infiltrating snowmelt water, with important implications for stream chemistry (see Tranter and Jones, Chapter 3). For point scales, the influence of SWE on infiltration and runoff generation is shown, presuming negligible evaporation, for a variety of soil types in prairie, arctic, and boreal forest environments in Figure 2.40. The effect of deep forest environment snowpacks in promoting warm soils causes forest runoff to drop with increasing SWE for deep snow and dry soils.

In northern forests (boreal, northern hardwoods), from 40 to 60 percent of annual streamflow is derived from snowmelt, with increases in snowmelt runoff of from 24 to 75 percent when the forest is removed by harvesting or fire (Hetherington, 1987). In cold, semiarid environments (arctic, northern prairies, steppes) greater than 80 percent of annual streamflow is derived from snowmelt, even though snowfall accounts for less than 50 percent of annual precipitation (Gray, 1970). Snowmelt in the western cordillera of North America and mountain systems of central Asia is the major source of water when carried as streamflow to semiarid regions downstream. Snowmelt water sustains arctic, alpine, prairie, and boreal forest lakes and wetlands, which are primary aquatic habitats in their respective ecosystems. Prairie pothole ponds are part of an interesting symbiotic relationship between snow, pond/wetland, and trees. The poplar trees surrounding these ponds induce large snowdrifts, which upon melt replenish the pond water supply. The high water table surrounding the pond in turn sustains the poplar trees.

Attempts to modify streamflow generation through snow management in the United States have involved streamflow enhancement in the upper Colorado River basin by selective clear-cutting of coniferous forests at high elevations and in the upper Missouri River basin by placement of arrays of tall snow fences in high-elevation steppe basins. In the Canadian Prairies, snow management is practised by leaving tall wheat stubble strips (one per swath) perpendicular to the primary wind direction to trap small snowdrifts. Snowpack can more than double that of adjacent fallow fields but, when infiltration capacity is low, results in increased runoff from the field. Snow management can increase water supplies deriving from snowmelt on the prairies. Estimates by de Jong and Kachanoski (1987) suggest that if snow management were universally adopted across the Canadian Prairies, water supply in the region would increase by $2-4 \times 10^{9} \mathrm{~m}^{3}$ of water per year, more than the amount of water currently used for irrigation. Inadvertent modification of the snow environment by clear-cutting forests or agricultural practises can cause unanticipated changes in downstream runoff, increased flooding, and damage to the aquatic ecosystem, but it 


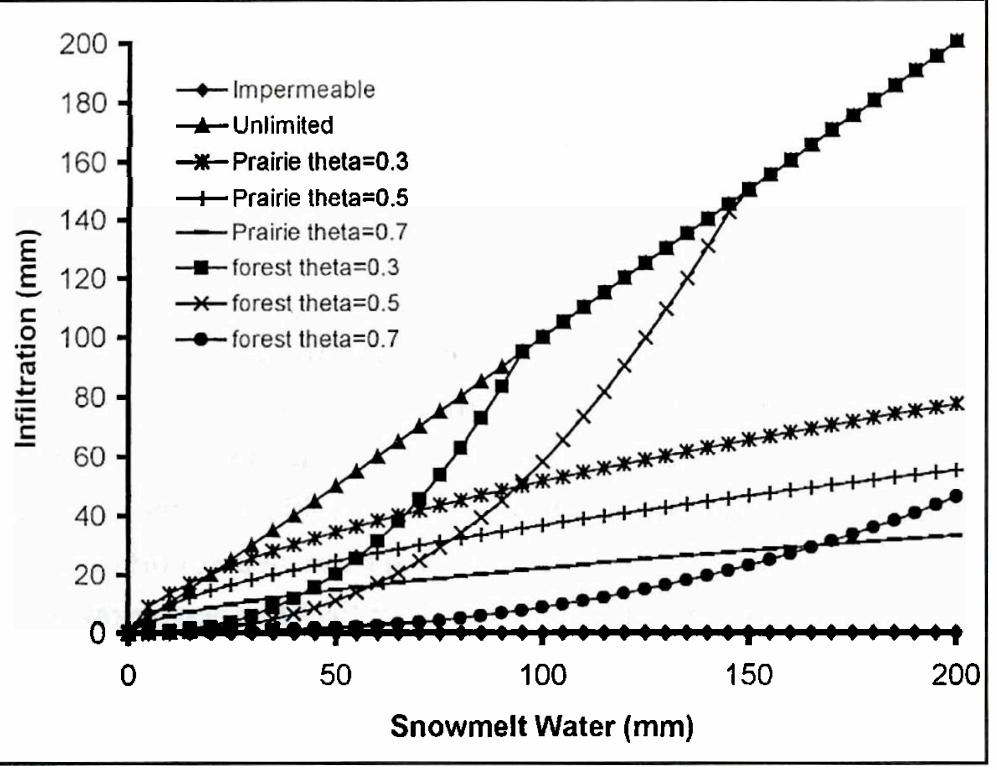

(a)

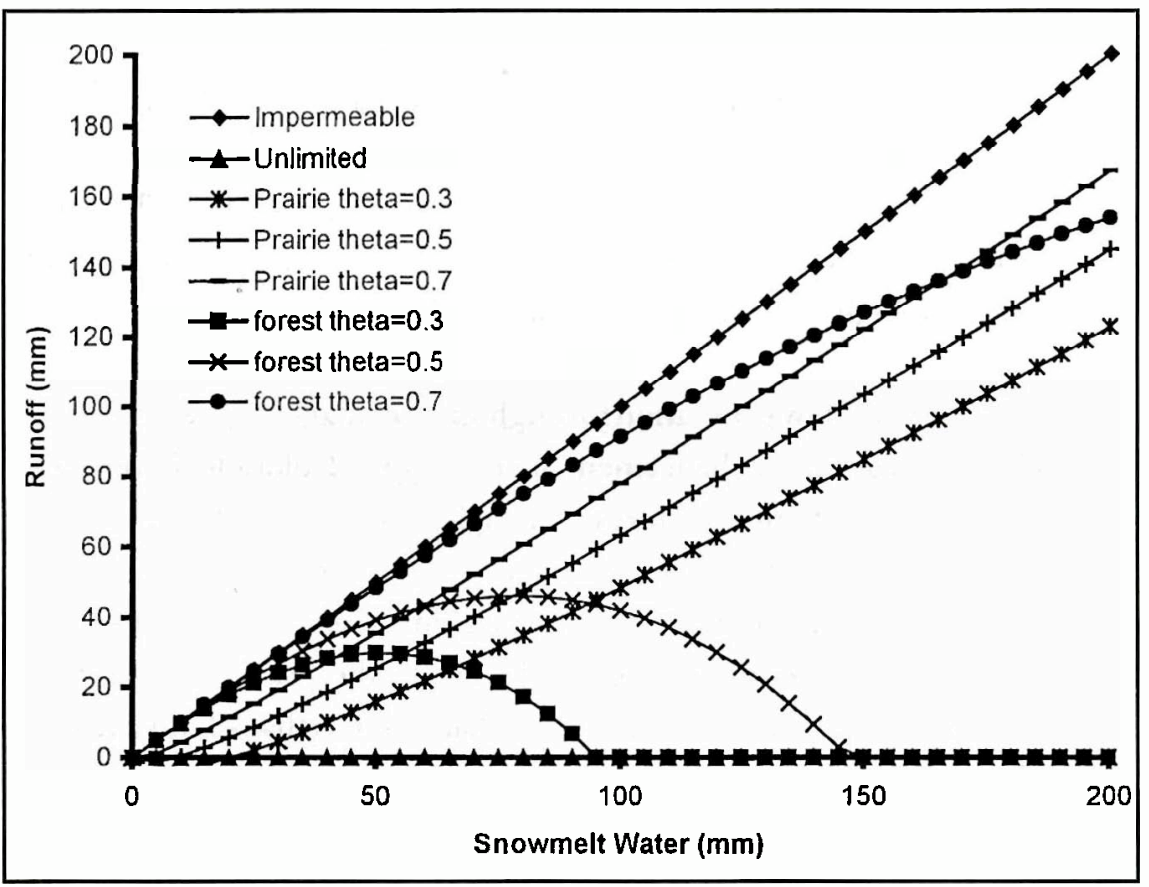

(b)

Figure 2.40. Disposition of snowmelt in various environments with frozen soils (prairie, arctic, southern boreal forest), presuming negligible evaporation during melt. Soils coated with a basal ice layer will be impermeable (typical of High Arctic); those with extensive soil macropores will be unlimited (typical of organic terrain and some heavy clays). Theta refers to $\theta_{\mathbf{p}}$, the degree of pore saturation. (a) Infiltration to frozen soils; (b) local runoff generation. 
may also provide a means to ameliorate the impacts of drought associated with climate warming.

\subsection{Conclusions}

Snow is one of the most complex physical materials on Earth and therefore provides a challenging habitat for life. Its presence is often ephemeral, governed by weather, climate, topography, and vegetation cover. As a substance, it is crystalline at small scales and porous at larger scales. It is highly reflective and uniquely undergoes phase change to both liquid and vapour forms of water at temperatures that are normally encountered in the winter and under conditions that may be manipulated by life forms. Snow is also one of the lightest natural materials, such that it is relocated by wind and vegetation and can be burrowed in or stepped through by mammals. The porous feature of snow means that it is an excellent insulator and is capable of remaining wet and percolating meltwater over periods of several days. The crystalline nature of snow sometimes results in poor strength, so that it cannot support heavy animals or remain in the branches of trees when bond strength weakens upon warming. Snowmelt water - whether retained within the snowpack or delivered to soils and streams - is a critical supporter of life and medium for nutrients. The following chapters will detail the chemical properties of snow and how various plant and animal communities live in, on, and beneath this fascinating material.

\subsubsection{Future Research}

Research into snow physical processes will continue to provide information of benefit to snow ecologists. Often physical research has been conducted to solve applied problems (e.g., avalanche control, remote sensing) but has then been found useful in biological fields (e.g., snow microbiology). Scientists conducting research on snow properties in relation to ecology should note that because of the complex multi-phase physical nature of snow, relationships developed must be consistent with conservation of mass and energy. The inter-relationships between snow properties and vegetation have been addressed in this chapter, by Walker, Billings and de Mollenaar (Chapter 6) and by Bégin and Boivin (Chapter 7) and involve a fascinating series of feedbacks between vegetation structure and snow structure. In this sense, the snowpack not only affects ecology but also can be controlled by the resulting vegetation. No other feedback between physical and biological systems is so strong, evident, and persistent around the world. The relationships between snow and 
vegetation are complex and vary with biome and climate; they will require a specialized research effort focusing on process-based interactions in both open and forested environments.

\section{$2.7 \quad$ References}

Adams, P. 1981. Snow and ice on lakes. In Handbook of Snow, Principles, Processes, Management and Use, D.M. Gray and D.H. Male (Eds.). Pergamon Press, Toronto, pp. 437474.

Anderson, E. 1976. A point energy and mass balance model of snow cover. NOAA Technical Report NWS 19, U.S. National Weather Service, Dept. of Commerce, Washington, DC.

Auld, H. 1995. Dependence of ground snow loads on elevation in western Canada. Proc. Western Snow Conf., 63, 143-146.

Bader, H.-P. 1992. Modelling temperature distribution, energy and mass flow in a phasechanging snowpack. I. Model and case studies. Cold Regions Sci. Technol, 20, 157-181.

Braun, L. 1991. Modelling the snow water equivalent in the mountain environment. In Snow, Hydrology and Forests in High Alpine Areas, H. Bergmann, H. Lang, W. Frey, D. Issler, and B. Salm (Eds.). IAHS Publication No. 205, IAHS Press, Wallingford, UK, pp. 3-17.

Brun, E. 1989. Investigation on wet snow metamorphism in respect of liquid water content. Ann. Glaciol., 13, 22-26.

Brun, E., and Rey, L. 1987. Field studies on snow mechanical properties. In Avalanche, Formation, Movement and Effects, B. Salm and H. Gubler (Eds.). IAHS Publication No. 162, IAHS Press, Wallingford, UK, pp. 183-193.

Brun, E., Martin, E., Simon, V., Gendre, C., and Col, ou C. 1989. An energy and mass model of snow cover suitable for operational avalanche forecasting. 7 . Glaciol, 35(121), 333-342.

Brun, E., David, P., Sudal, M., and Brunot, G. 1992. A numerical model to simulate snowcover stratigraphy for operational avalanche forecasting. 7. Glaciol., 38(128), 13-22.

Budd, W.F., Dingle, W.R.J., and Radok, U. 1966. The Byrd snow drift project: outline and basic results. Studies Antarctic Meteorol. Am. Geophys. Union Antartic Res. Ser., 9, 71-134.

Calder, I.R. 1990. Evaporation in the Uplands. Wiley, Chichester, p. 144.

Colbeck, S.C. 1973. Theory of Metamorphism of Wet Snow. CRREL Research Report 313, U.S. Army Cold Regions Research and Engineering Laboratory, Hanover, NH.

Colbeck, S.C. 1983. Theory of metamorphism of dry snow. 7. Geophys. Res., 88(C9), 54755482.

Colbeck, S.C. 1987. Snow metamorphism and classification. In NATO ASI Series C: Mathemat. Physic. Sci., Vol. 21I, Seasonal Snowcovers: Physics, Chemistry, Hydrology, H.G. Jones and W.J. Orville-Thomas (Eds.). Reidel, Dordrecht, The Netherlands, pp. 1-35. 
Colbeck, S.C. 1989. Air movement in snow due to windpumping. 7. Glaciol, 35(120), 209-213.

Colbeck, S.C., Akitaya, E., Armstrong, R., Gubler, H., Lafeuille, J., Lied, K., McClung, D., and Morris, E. 1990. The International Classification for Seasonal Snom on the Ground. International Association of Hydrological Sciences, International Commission on Snow and Ice, Wallingford, Oxfordshire.

Conway, H., Gades, A., and Raymond, C.F. 1996. Albedo of dirty snow during conditions of melt. Water Resources Res., 32(6), 1713-1718.

de Jong, E., and Kachanoski, R.G. 1987. The role of grasslands in hydrology. Can. Bull. Fish. and Aquatic Sci, 215, 213-241.

Denoth, A., Seidenbusch, W., Blumthaler, M., Kirchlechner, P., Ambach, W., and Colbeck, S.C. 1979. Study of Water Drainage from Columns of Snow. CRREL Report 79-1, U.S. Army Cold Regions Research and Engineering Laboratory, Hanover, NH.

Denoth, A., Foglar, A., Weiland, P., Matzler, C., Aebischer, H., Tiuri, M., and Sihvola, A. 1984. A comparative study of instruments for measuring the liquid water content of snow. 7. Appl. Phys., 56, 2154-2159.

Dozier, J., Davis, R.E., and Perla, R.I. 1987. Snow microstructure measurements using stereology. In Snom Property Measurement Workshop. Technical Memorandum No. 130, National Research Council of Canada, Ottawa, pp. 60-70.

Dyunin, A.K., Kvon, Ya.D., Zhilin, A.M., and Komarov, A.A. 1991. Effect of snow drifting on large-scale aridization. In Glaciers-Ocean-Atmosphere Interactions, V.M. Kotlyakov, A. Ushakov, and A. Glazovsky (Eds.). IAHS Publication No. 208, IAHS Press, Wallingford, UK, pp. 489-494.

English, M.C., Semkin, R.G., Jeffries, D.S., Hazlett, P.W., and Foster, N.W. 1987. Methodology for investigation of snowmelt hydrology and chemistry within an undisturbed Canadian shield watershed. In NATO ASI Series C: Mathemat. Physic. Sci., Vol. 211, Seasonal Snowcovers: Physics, Chemistry, Hydrology, H.G. Jones and W.J. Orville-Thomas (Eds.). Reidel, Dordrecht, The Netherlands, pp. 467-500.

Föhn, P.M.B., and Meister, R. 1983. Distribution of snow drifts on ridge slopes: measurements and theoretical approximations. Ann. Glaciol., 4, 52-57.

Gold, L.W. 1957. The Influence of Snowcover on Heat Flow from the Ground. In Snow and Ice, IAHS Publication No. 46, IAHS Press, Wallingford, UK, pp. 13-21.

Gold, L.W., and Williams, G.P. 1961. Energy balance during the snowmelt period at an Ottawa site. In Snow and Ice, IAHS Publication No. 54, IAHS Press, Wallingford, UK, pp. 288-294.

Golding, D.L., and Swanson, R.H. 1986. Snow distribution patterns in clearings and adjacent forest. Water Resources Res., 22(13), 1931-1940.

Goodison, B.E., Ferguson, H.L., and McKay, G.A. 1981. Measurement and data analysis. In Handbook of Snow, Principles, Processes, Management and Use, D.M. Gray and D.H. Male (Eds.). Pergamon Press, Toronto, pp. 191-274.

Granger, R.J., and Gray, D.M. 1990. A net radiation model for calculating daily snowmelt in open environments. Nordic Hydrol., 21, 217-234. 
Granger, R.J., and Male, D.H. 1978. Melting of a prairie snowpack. 7. Appl. Meteorol, 17(12), 1833-1842.

Granger, R.J., Gray, D.M., and Dyck, G.E. 1984. Snowmelt infiltration into frozen Prairie soils. Can. 7. Earth Sci, 21, 669-687.

Gray, D.M. (Ed). 1970. Handbook on the Principles of Hydrology. Canadian National Committee for the International Hydrological Decade, Ottawa.

Gray, D.M., and O'Neill, A.D.J. 1974. Application of the energy budget for predicting snowmelt runoff. In Advanced Concepts in the Study of Snow and Ice Resources, H.S. Santeford and J.L. Smith (Eds.). National Academy Press, Washington, DC, pp. 108-118.

Gray, D.M., Norum, D.I., and Dyck, G.E. 1971. Densities of prairie snowpacks. Proc. Western Snow Conf., 39, 24-30.

Gray, D.M., and others. 1979. Snow accumulation and redistribution. In Proceedings, Modeling of Snow Cover Runoff, S.C. Colbeck and M. Ray (Eds.). U.S. Army Cold Regions Research and Engineering Laboratory, Hanover, NH, pp. 3-33.

Gubler, H. 1985. Model of dry snow metamorphism by interparticle vapor flux. 7. Geophys. Res., 90(C8), 8081-8092.

Gubler, H., and Rychetnik, J. 1991. Effects of forests near the timberline on avalanche formation. In Snow, Hydrology and Forests in High Alpine Areas, H. Bergman, H. Lang, W. Frey, D. Issler, and B. Salm (Eds.). IAHS Publication No. 205, IAHS Press, Wallingford, UK, pp. 19-38.

Harding, R.J., and Pomeroy, J.W. 1996. The energy balance of the winter boreal landscape. 7. Climate, 9, 2778-2787.

Harestead, A.S., and Bunnell, F.L. 1981. Prediction of snow-water equivalents in coniferous forests. Can. 7. Forest Res., 11, 854-857.

Hedstrom, N.R., and Pomeroy, J.W. 1998. Accumulation of intercepted snow in the boreal forest: measurements and modelling. Hydrol. Processes, 12, 1611-1623.

Hetherington, E.D. 1987. The importance of forests in the hydrological regime. Can. Bull. Fish. and Aquatic Sci., 215, 179-211.

Hobbs, P.V. 1974. Ice Physics. Clarendon Press, Oxford.

Jordan, R. 1991. A One-Dimensional Temperature Model for a Snow Cover. Cold Regions Research and Engineering Laboratory Special Report 91-16, U.S. Army Research and Engineering Laboratory, Hanover, NH.

Kattelmann, R. 1990. Liquid water at the snowpack surface [Abstract]. Eos, 71(43), 1328.

Kind, R.J. 1981. Snow drifting. In Handbook of Snow, Principles, Processes, Management and Use, D.M. Gray and D.H. Male (Eds.). Pergamon Press, Toronto, pp. 338-359.

Kobayashi, D. 1972. Studies of snow transport in low-level drifting snow. Contrib. Inst. Low Temp. Sci. Ser. A, 24, 1-58.

Kohshima, S., Yoshimura, Y., Seko, K., and Ohata, T. 1994. Albedo reduction by biotic impurities on a perennial snowpatch in the Japan Alps. In Snow and Ice Covers: Interactions with the Atmosphere and Ecosystems, H.G. Jones, T.D. Davies, A. Ohmura, and E. Morris (Eds.). IAHS Publication No. 223, IAHS Press, Wallingford, UK, pp. 323330. 
Komarov, A.A. 1957. Some rules on the migration and deposition of snow in western Siberia and their application to control measures. Trudy Transportno-Energetichesko-go Instituta, 4, 89-97 (National Research Council of Canada Technical Translation 1094, 1963).

Kotlyakov, V.M. 1961. Results of study of the ice sheet in Eastern Antarctica. In Antarctic Glaciology. IAHS Publication No. 55, IAHS Press, Wallingford, UK, pp. 88-99.

Kuz'min, P.P. 1960. Snowcover and snow reserves. Gidrometeorologicheskoe, Izdatelsko, Leningrad. (Translated by US National Science Foundation, Washington, DC, 1963).

Langham, E.J. 1974. Phase equilibria of veins in polycrystalline ice. Can. 7. Earth Sci., 11, 1280-1287.

Langham, E.J. 1981. Physics and properties of snowcover. In Handbook of Snow, Principles, Processes, Management and Use, D.M. Gray and D.H. Male (Eds.). Pergamon Press, Toronto, pp. 275-337.

Li, L., and Pomeroy, J.W. 1997. Estimates of threshold wind speeds for snow transport using meteorological data. 7. Appl. Meteorol., 36, 205-213.

Liljequest, G.H. 1956. Energy exchange of an Antarctic snow field: short wave radiation (Maudheim $71^{\circ} 03^{\prime} \mathrm{S} 10^{\circ} 56^{\prime} \mathrm{W}$ ). In Normegian-British-Swedish Antartic Expedition, 1949-52, Scientific Results. Vol. 2, Part 1A. Norsk Polarinstitutt, Oslo.

Liston, G.E. 1995. Local advection of momentum, heat and moisture during the melt of patchy snow covers. 7. Appl. Meteorol., 34(7), 1705-1715.

Male, D.H. 1980. The seasonal snowcover. In Dynamics of Snow and Ice Masses, S. Colbeck (Ed.). Academic Press, Toronto, pp. 305-395.

Male, D.H., and Granger, R.J. 1979. Energy and mass fluxes at the snow surface in a prairie environment. In Proceedings of the Modelling of Snow Cover Runoff, S. Colbeck and M. Ray (Eds.). U.S. Army Cold Regions Research and Engineering Laboratory, Hanover, NH, pp. 101-124.

Male, D.H., and Gray, D.M. 1981. Snowcover ablation and runoff. In Handbook of Snow, Principles, Processes, Management and Use, D.M. Gray and D.H. Male (Eds.). Pergamon Press, Toronto, pp. 360-436.

Marbouty, D. 1980. An experimental study of temperature-gradient metamorphism. 7. Glaciol., 26(94), 303-312.

Marsh, P. 1987. Grain growth in a wet Arctic snow cover. Cold Regions Sci. Technol., 14, 23-31.

Marsh, P. 1988. Flow fingers and ice columns in a cold snowcover. Proc. Western Snow Conf., 56, 105-112.

Marsh, P. 1991. Water flux in melting snow covers. In Advances in Porous Media, Vol. 1, M.Y. Corapcioglu (Ed.). Elsevier Science, Amsterdam, pp. 61-124.

Marsh, P., and Pomeroy, J.W. 1996. Meltwater fluxes at an arctic forest-tundra site. Hydrol. Processes, 10, 1383-1400.

Marsh, P., and Woo, M-K. 1984a. Wetting front advance and freezing of meltwater within a snowcover 1. Observations in the Canadian Arctic. Water Resources Res., 20(12), $1853-1864$. 
Marsh, P., and Woo, M-K. 1984b. Wetting front advance and freezing of meltwater within a snowcover 2. A simulation model. Water Resources Res., 20(12), 1865-1874.

Marsh, P., and Woo, M-K. 1987. Soil heat flux, wetting front advance and ice layer growth in cold, dry snow covers. In Snow Property Measurement Workshop. Technical Memorandum No. 140, Snow and Ice Subcommittee, Associate Committee on Geotechnical Research, National Research Council of Canada, Ottawa, pp. 497-524.

McGurk, B.J., and Marsh, P. 1995. Flow-finger continuity in serial thick-sections in a melting Sierra snowpack. In Biogeochemistry of Seasonally Snow-Covered Catchments, K.A. Tonnessen, M.W. Williams, and M. Tranter (Eds.). IAHS Publication No. 228, IAHS Press, Wallingford, UK, pp. 81-88.

McKay, G.A., and Gray, D.M. 1981. The distribution of snowcover. In Handbook of Snow, Principles, Processes, Management and Use, D.M. Gray and D.H. Male (Eds.). Pergamon Press, Toronto, pp. 153-190.

Meiman, J.R. 1970. Snow accumulation related to elevation, aspect and forest canopy. Proc. Workshop Seminar on Snow Hydrology. Queen's Printer for Canada, Ottawa, pp. 3547.

Molnau, M., and Bissell, V.C. 1983. A continuous frozen ground index for flood forecasting. Proc. Western Snow Conf., 51, pp. 109-119.

Norton, D.C. 1991. Digital investigation of Great Lakes regional snowfall, 1951-1980. Proc. Eastern Snow Conf., 48, 67-80.

O'Neill, A.D.J., and Gray, D.M. 1973. Spatial and temporal variations of the albedo of a prairie snowpack. In The Role of Snow and Ice in Hydrology: Proceedings of the Banff Symposium, Vol. 1, Sept. 1972, UNESCO-WMO-IAHS, Geneva-Budapest-Paris, pp. 176-186.

Palm, E., and Tveitereid, M. 1979. On heat and mass flow through dry snow. 7. Geophys. Res., 84(C2), 745-749.

Perla, R.I. 1978. Snow Crystals. NHRI Paper No. 1, National Hydrology Research Institute, Environment Canada, Ottawa.

Philip, J.R. 1957. The theory of infiltration: 1 . The infiltration equation and solution. Soil Sci., 83(5), 345-357.

Pomeroy, J.W. 1988. Wind Transport of Snow. Thesis in partial fulfilment of the requirements for the Degree of Doctor of Philosophy in the College of Graduate Studies and Research, University of Saskatchewan, Saskatoon.

Pomeroy, J.W. 1989. A process-based model of snow drifting. Ann. Glaciol., 13, 237-240.

Pomeroy, J.W., and Dion, K. 1996. Winter radiation extinction and reflection in a boreal pine canopy: measurements and modelling. Hydrol. Processes, 10, 1591-1608.

Pomeroy, J.W., and Goodison, B.E. 1997. Winter and snow. In The Surface Climates of Canada, W.G. Bailey, T.R. Oke, and W.R. Rouse (Eds.). McGill-Queen's University Press, Montreal, pp. 68-100.

Pomeroy, J.W., and Granger, R.J. 1997. Sustainability of the western Canadian boreal forest under changing hydrological conditions - I - snow accumulation and ablation. In 
Sustainability of Water Resources under Increasing Uncertainty, D. Rosjberg, N. Boutayeb, A. Gustard, Z. Kundzewicz, and P. Rasmussen (Eds.). IAHS Publication No. 240, IAHS Press, Wallingford, UK, pp. 237-242.

Pomeroy, J.W., and Gray, D.M. 1990. Saltation of snow. Water Resources Res., 26(7), 1583-1594.

Pomeroy, J.W., and Gray, D.M. 1994. Sensitivity of snow relocation and sublimation to climate and surface vegetation. In Snow and Ice Covers: Interactions with Atmosphere and Ecosystems, H.G. Jones, T.D. Davies, A. Ohmura, and E.M. Morris (Eds.). IAHS Publication No. 223, IAHS Press, Wallingford, UK, pp. 213-226.

Pomeroy, J.W., and Gray, D.M. 1995. Snow Accumulation, Relocation and Management. NHRI Science Report No. 7. National Hydrology Research Institute, Saskatoon.

Pomeroy, J.W., and Male, D.H. 1992. Steady-state suspension of snow: a model. 7. Hydrol., 136, 275-301.

Pomeroy, J.W., and Marsh, P. 1997. The application of remote sensing and a blowing snow model to determine snow water equivalent over northern basins. In Applications of Remote Sensing in Hydrology, G.W. Kite, A. Pietroniro, and T.J. Pultz (Eds.). NHRI Symposium No. 17, National Hydrology Research Institute, Saskatoon, pp. 253270.

Pomeroy, J.W., and Schmidt, R.A. 1993. The use of fractal geometry in modelling intercepted snow accumulation and sublimation. Proc. Eastern Snow Conf., 50, 1-10.

Pomeroy, J.W., Gray, D.M., and Landine, P.G. 1991. Modelling the transport and sublimation of blowing snow on the prairies. Proc. Eastern Snow Conf., 48 175188.

Pomeroy, J.W., Gray, D.M., and Landine, P.G. 1993. The Prairie Blowing Snow Model: characteristics, validation, operation. 7. Hydrol., 144, 165-192.

Pomeroy, J.W., Marsh, P., and Gray, D.M. 1997a. Application of a distributed blowing snow model to the Arctic. Hydrol. Processes, 11, 1451-1464.

Pomeroy, J.W., Granger, R.J., Pietroniro, A., Elliott, J., Toth, B., and Hedstrom, N. 1997b. Hydrological Pathways in the Prince Albert Model Forest: Final Report, NHRI Contribution Series No. CS-97007, National Hydrology Research Institute, Saskatoon, Environment Canada.

Pruitt, W.O. 1984. Snow and living things. In Northern Ecology and Resource Management, University of Alberta Press, Edmonton, pp. 51-77.

Pruitt, W.O. 1990. Clarification of some Api characteristics in relation to Caribou (Rangifer tarandus). Rangifer, Special Issue No. 3, 133-137.

Rango, A., and Martinec, J. 1987. Large-scale effects of seasonal snow cover and temperature increase on runoff. In Large Scale Effects of Seasonal Snow Cover, B.E. Goodison, R.G. Barry, and J. Dozier (Eds.). IAHS Publication No. 166, IAHS Press, Wallingford, UK, pp 121-127.

Rawls, W.J., Brakensiek, D.L., and Miller, N. 1983. Green-Ampt infiltration parameters from soils data. 7. Hydraulics Div. Ame. Soc. Civil Eng., 109, 62-70. 
Raymond, C.F., and Tusima, K. 1979. Grain coarsening of water-saturated snow. 7 . Glaciol, 22(86), 83-105.

Rhea, J.O., and Grant, L.O. 1974. Topographic influences on snowfall patterns in mountainous terrain. In Advanced Concepts and Techniques in the Study of Snow and Ice Resources, National Academy Press, Washington, DC, pp. 182-192.

Rouse, W.R. 1990. The regional energy balance. In Northern Hydrology, Canadian Perspectives, T. Prowse and S. Ommanney (Eds.). Supply and Services Canada, Saskatoon, pp. 187-206.

Santeford, H.S. 1979. Snow-soil interactions in interior Alaska. In Proceedings, Modelling of Snow Cover Runoff, S. Colbeck and M. Ray (Eds.). U.S. Army Cold Regions Research and Engineering Laboratory, Hanover, NH, pp. 311-318.

Satterlund, D.R., and Haupt, H.F. 1970. The disposition of snow caught by conifer crowns. Water Resources Res., 6, 649-652.

Schemenauer, R.S., Berry, M.O., and Maxwell, J.B. 1981. Snowfall formation. In Handbook of Snow, Principles, Processes, Management and Use, D.M. Gray and D.H. Male (Eds.). Pergamon Press, Toronto, pp. 129-152.

Schmidt, R.A. 1972. Sublimation of Wind-Transported Snow: A Model. USDA Forest Service Research Paper RM-90, Rocky Mountain Forest and Range Experiment Station, Fort Collins, CO.

Schmidt, R.A. 1980. Threshold windspeeds and elastic impact in snow transport, 7 . Glaciol., 26(94), 453-467.

Schmidt, R.A. 1991. Sublimation of snow intercepted by an artificial conifer. Agric. Forest Meteorol., 54, 1-27.

Schmidt, R.A., and Gluns, D.R. 1991. Snowfall interception on branches of three conifer species. Can. 7. Forest Res., 21, 1262-1269.

Schmidt, R.A., and Pomeroy, J.W. 1990. Bending of a conifer branch at subfreezing temperatures: implications for snow interception. Can. F. Forest Res., 20, 1250-1253.

Schmidt, R.A., and Troendle, C.A. 1992. Sublimation of intercepted snow as a global source of water vapour. Proc. Western Snow Conf., 60, 1-9.

Sergent, C., Chevrand, P., Lafeuille, J., and Marbouty, D. 1987. Caractérisation optique de différents types de neige, Extinction de la lumière dans la neige. 7. Phys., 48(C1, suppl. no. 3), 361-367.

Shook, K., and Gray, D.M. 1996. Small-scale spatial structure of shallow snowcovers. Hydrol. Processes, 10, 1283-1292.

Shook, K., and Gray, D.M. 1997. Snowmelt resulting from advection. Hydrol. Processes, 11, 1725-1736.

Shook, K., Gray, D.M., and Pomeroy, J.W. 1993. Temporal variations in snowcover area during melt in Prairie and Alpine environments. Nordic Hydrol., 24, 183-198.

Sommerfeld, R.A., and LaChapelle, E. 1970. The classification of snow metamorphism. 7. Glaciol., 9(55), 3-17.

Steppuhn, H. 1981. Snow and agriculture. In Handbook of Snow, Principles, Processes, Management and $U$ se, D.M. Gray and D.H. Male (Eds.). Pergamon Press, Toronto, pp. 60-125. 
Strobel, T. 1978. Schneeinterzeption in Fichten-Bestaenden in den Voralapen des Kantons Schwyz. In Proc. IUFRO Seminar on Mountain, Forests and Avalanches. Davos, Switzerland, pp. 63-79.

Sturm, M. 1991. The Role of Thermal Convection in Heat and Mass Transport in the Subarctic Snow Cover, CRREL Report 91-19, U.S. Army Cold Regions Research and Engineering Laboratory, Hanover, NH.

Sturm, M. 1992. Snow distribution and heat flow in the taiga. Arctic Alpine Res., 24(2), 145-152.

Sturm, M., Holmgren, J., and Liston, G.E. 1995. A seasonal snow cover classification system for local to global applications. 7. Climate, 8, 1261-1283.

Sturm, M., Holmgren, J., Konig, M., and Morris, K. 1997. The thermal conductivity of seasonal snow. 7. Glaciol., 43(143), 26-41.

Tabler, R.D. 1975. Estimating the transport and evaporation of blowing snow. In Snow Management on the Great Plains. Great Plains Agricultural Council Publication No. 73. University of Nebraska, Lincoln, pp. 85-105.

Tabler, R.D., and Schmidt, R.A. 1986. Snow erosion, transport and deposition. In Proc. Symposium on Snow Management for Agriculture, H. Steppuhn and W. Nicholaichuk (Eds.). Great Plains Agricultural Council Publication No. 120. University of Nebraska, Lincoln, pp. 12-58.

Tabler, R.D., Benson, C.S., Santana, B.W., and Ganguly, P. 1990a. Estimating snow transport from wind speed records: estimates versus measurements at Prudhoe Bay, Alaska. Proc. Western Snow Conf., 58, 61-78.

Tabler, R.D., Pomeroy, J.W., and Santana, B.W. 1990b. Drifting snow. In Cold Regions Hydrology and Hydraulics, W.L. Ryan and R.D. Crissman (Eds.). American Society of Civil Engineers, New York, pp. 95-146.

Toews, D.A., and Gluns, D.R. 1986. Snow accumulation and ablation on adjacent forested and clearcut sites in southeastern British Columbia. Proc. Western Snow Conf., 54, 101-111.

Troendle, C.A., and Leaf, C.F. 1981. Effects of timber harvest in the snow zone on volume and timing of water yield. In Interior West Watershed Management Symposium, D.M. Baumgartner (Ed.). Washington State University, Pullman, pp. 231-243.

U.S. Army Corps of Engineers. 1956. Snow Hydrology. North Pacific Division, Portland, OR.

Wallace, J.M., and Hobbs, P.V. 1977. Atmospheric Science: An Introductory Survey, Academic Press, San Diego.

Wakahama, G. 1968. The Metamorphism of Wet Snow. In Snom and Ice: Reports and Discussions. IAHS Publication No. 79, IAHS Press, Wallingford, pp. 370-379.

Warren, S.G. 1982. Optical properties of snow. Rev. Geophys. Space Phys., 20, 67-89.

Warren, S.G., and Wiscombe, W.J. 1980. A model for the spectral albedo of snow, II, snow containing atmospheric aerosols. 7. Atmos. Sci., 37, 2734-2745.

Woo, M-K. 1990. Permafrost hydrology. In Northern Hydrology: Canadian Perspectives, T.D. Prowse and C.S.L. Ommanney (Eds.). NHRI Science Report No. 1, 
National Hydrology Research Institute, Environment Canada, Saskatoon, pp. 6376.

Woo, M-K., and Steer, P. 1986. Monte Carlo simulation of snow depth in a forest. Water Resources Res., 22(6), 864-868.

Woo, M-K., Heron, R., and Marsh, P. 1982. Basal ice in High Arctic snowpacks. Arctic Alpine Res., 14, 251-260.

Yamazaki, T., and Kondo, J. 1992. The snowmelt and heat balance in snow-covered, forested areas. 7. Appl. Meteorol., 31, 1322-1327.

Yosida, Z., and others. 1955. Physical studies on deposited snow: thermal properties. Contrib. Inst. Low Temperature Sci., Ser. A, 27, 19-74.

Zhao, L., Gray, D.M., and Male, D.H. 1997. Numerical analysis of simultaneous heat and mass transfer during infiltration into frozen ground. 7. Hydrol., 200, 345-363. 